\title{
Educating planners in Europe: A review of 21 st century study programmes
}

\author{
Andrea I. Frank ${ }^{1, *}$ \\ School of Planning and Geography, Cardiff University, King Edward VII Ave, Cardiff CF10 3WA, United Kingdom
}

Izabela Mironowicz ${ }^{2}$

Wroctaw University of Technology, Faculty of Architecture, Department of Planning,

B. Prusa Street 53/55, 50-317 Wroctaw, Poland

Julia Lourenço ${ }^{3}$

Universidade do Minho, Largo do Paço, 4704-553 Braga, Portugal

Teresa Franchini ${ }^{4}$

CEU San Pablo University, Department of Architecture and Building, Polytechnic School, Campus de Monteprincipe, 28668 Boadilla del Monte, Madrid, Spain

Peter Ache ${ }^{5}$

Aalto University Foundation, YTK Land Use Planning and Urban Studies Group, Rakentajanaukio 2, FI-00076 Aalto, Finland

Maroš Finka ${ }^{6}$

Slovak University of Technology, Department of Spatial Planning, Institute of Management of STU, Vazovova 5, 81243 Bratislava, Slovakia

\section{Bernd Scholl $^{7}$, Anita Grams ${ }^{7}$}

Institute of Spatial and Landscape Development, Swiss Federal Institute of Technology (ETH Zürich), Wolfgang-Paul-Str 15, CH-8093 Zürich, Switzerland

\footnotetext{
* Corresponding author. Tel.: +44 2920 876610; fax: +44 2920874845.

E-mail address: FrankA@Cardiff.ac.uk.

${ }^{1}$ Guest editor co-author with Mironowicz, sole author of Section 4.6: United Kingdom; other national case study section authors as identified below.

${ }^{2}$ Guest editor, co-author with Frank, also sole author of Section 4.4: Poland. Tel.: +48 713206354.

3 Author of Section 4.1: Portugal. Tel: +351 253510217.

${ }^{4}$ Author of Section 4.2: Spain. Tel: +34 $913724087 \times 4847$.

5 Author of Section 4.3: Finland. He wrote the contribution while at Aalto University, but is now in post at University of Nijmegen (NL). New contact address: Department of Spatial Planning, School of Management, Radboud University Nijmegen, P.O. Box 9108, 6500 HK Nijmegen, The Netherlands. Tel: +31 243612099 .

${ }^{6}$ Author of Section 4.5: Slovakia. Tel: +421905612465 .

${ }^{7}$ Joint authors of Section 4.7: Switzerland. Tel: +41 446333003.
} 


\begin{abstract}
Education for urban, regional and spatial planning has become a regular subject throughout most European nations; this can be attributed in part to European policies promoting planning and spatially balanced development, but also to the recognition that planning can support sustainability. Nevertheless, there is lingering and justifiable concern about the status, profile and recognition of planning as a profession in its own right with the result that planning and planning education remain contested territories in academia. Conceptions of planning differ between countries and over time. The array of different planning cultures and associated educational models and pedagogies that traditionally have coexisted in Europe mean that education for planning can be either very visible or leading a shadow existence being embedded in programmes of other disciplines. While planning education provision customarily has been shaped by changes in planning practice paradigms and the profession, in 21st century Europe the provision is also influenced by European integration policies, the Bologna process and powerful transformations affecting the higher education sector writ large.

This review seeks to advance our understanding of the complex dynamics at work, which to date have been only partially explored in the literature, by taking stock of the current state-of-play of planning education provision in Europe. Aside from examining the factors influencing planning education in Europe, an inventory of planning education programmes available throughout the member states of the Council of Europe was developed to quantify the provision as a critical first step. Figures indicate a substantial increase in the number of programmes when compared to limited historical data. Data also suggest an underdeveloped provision for education in planning in about ten per cent of European countries. Country case studies with historically differing planning cultures and education provision, i.e., Spain, Portugal, Finland, Poland, Slovakia, the United Kingdom and Switzerland are used to compare and explore trends and developments (e.g., in respect to programme structure, curriculum content and focus, professional conceptions, specialisms) in detail. Findings demonstrate, both, an enduring power of national preferences and traditions but also some emerging commonalities. Overall a picture of increasing pluralism and diversity of education models transpires in the aftermath of Bologna which may contravene efforts to establish cross-national professional recognition and standards. Education for planning seems to embrace trends to provide increasingly international learning experiences and degrees while the provision of flexible recognised (online) degree programmes remains sparse. Recommendations for future actions and strategies to further develop and strengthen the field which is at present complex and little coordinated conclude the contribution.
\end{abstract}

(C) 2014 Elsevier Ltd. All rights reserved.

Keywords: Planning education; Planning cultures; European integration; Bologna reform

\title{
Contents
}

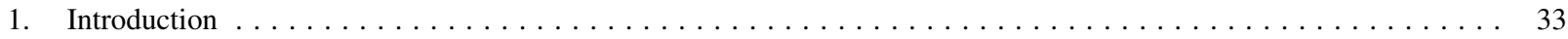

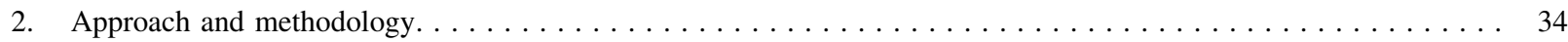

3. History, cultures of planning and planning education in Europe. $\ldots \ldots \ldots \ldots \ldots$

3.1. Inception: planning education as post-professional degree $\ldots \ldots \ldots \ldots \ldots$

3.2. Gaining momentum: autonomous professional degrees $\ldots \ldots \ldots \ldots \ldots \ldots$

3.3. Expanding: new developments 1990 to present $\ldots \ldots \ldots \ldots \ldots \ldots$

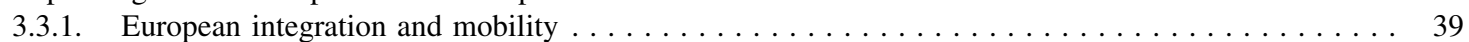

3.3.2. European spatial planning and degree portability . . . . . . . . . . . . . . . . . . . 39

3.3.3. Bologna agreement and higher education reforms $\ldots \ldots \ldots \ldots \ldots \ldots$

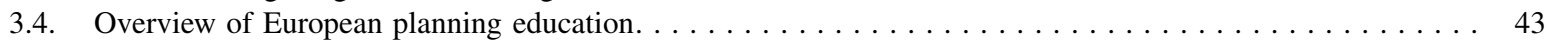

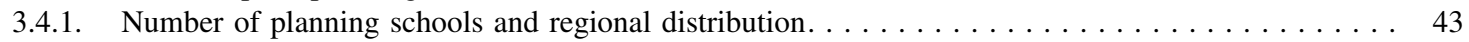

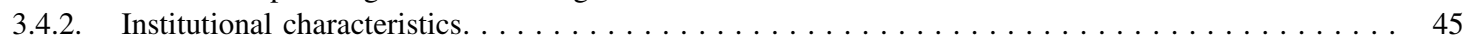

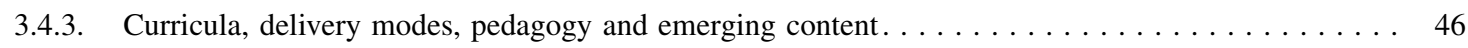

3.4.4. Academic and professional networks $\ldots \ldots \ldots \ldots \ldots \ldots$

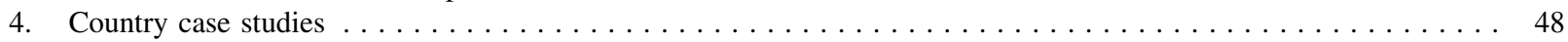

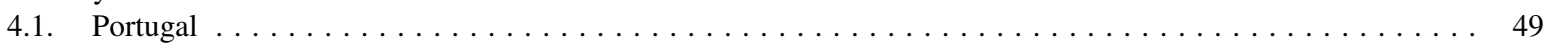

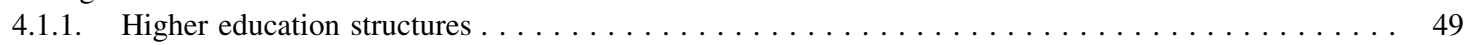

4.1.2. History of planning education $\ldots \ldots \ldots \ldots \ldots \ldots \ldots \ldots$

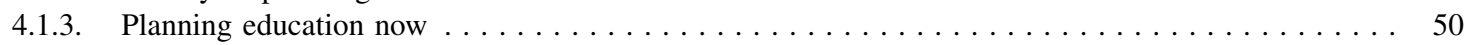

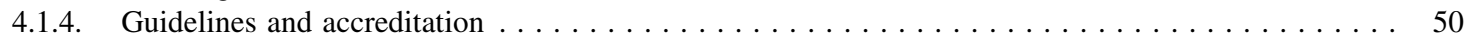

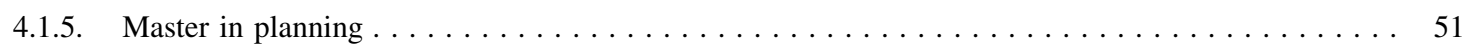

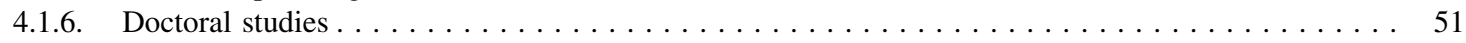




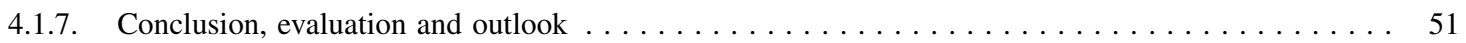

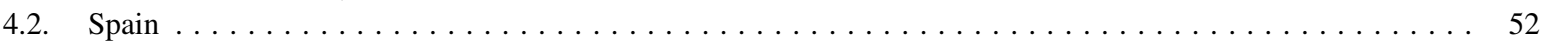

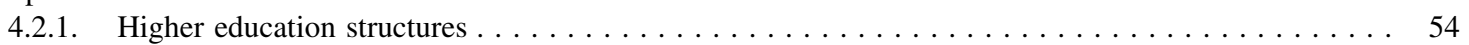

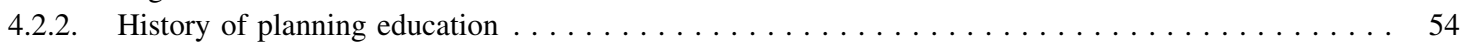

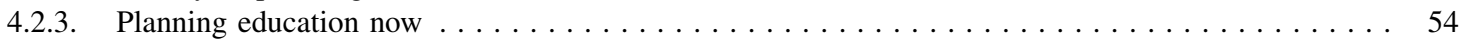

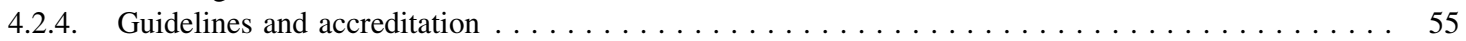

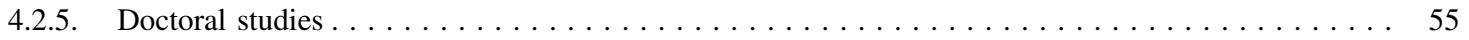

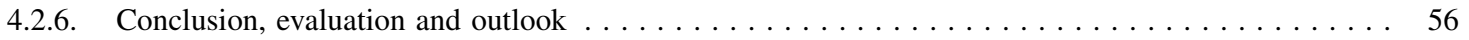

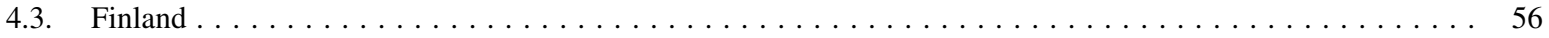

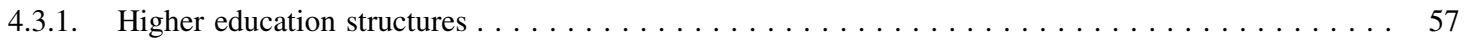

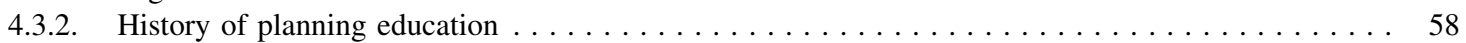

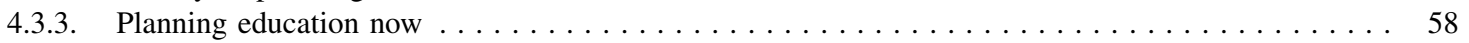

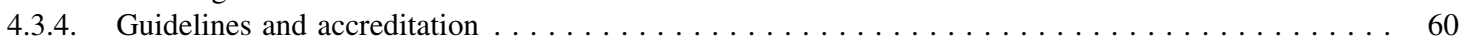

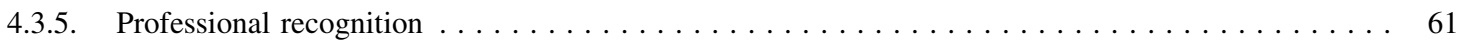

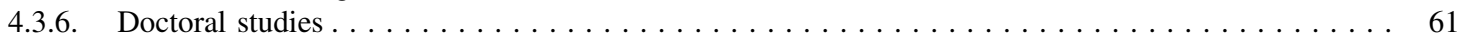

4.3.7. Post-graduate and continued professional education $\ldots \ldots \ldots \ldots \ldots$

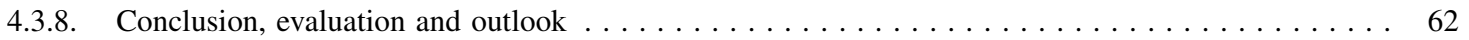

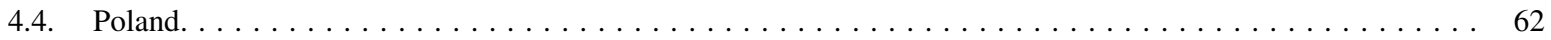

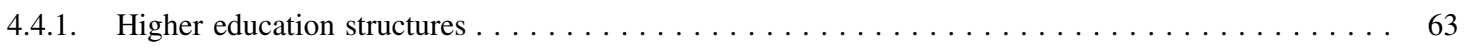

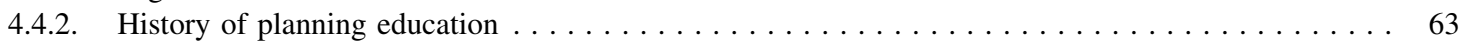

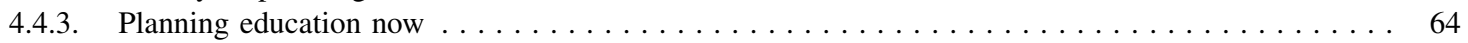

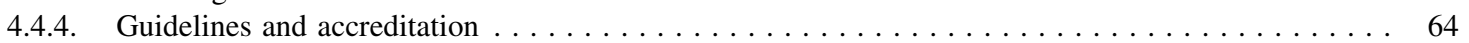

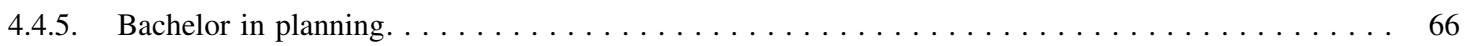

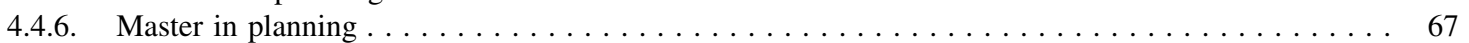

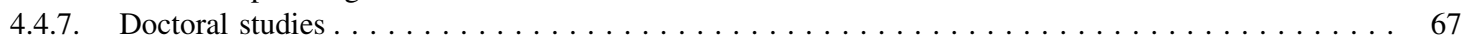

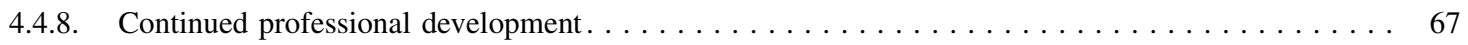

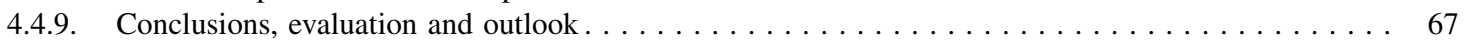

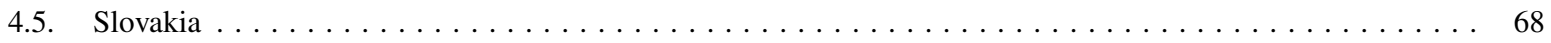

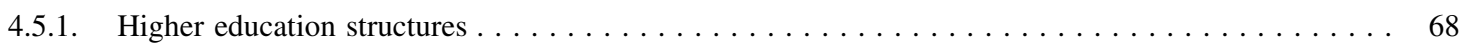

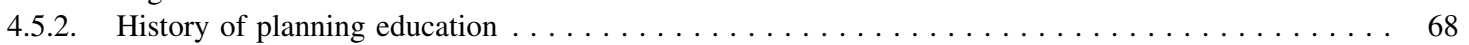

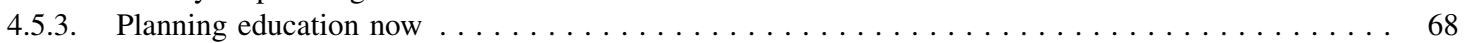

4.5.4. Guidelines for planning education $\ldots \ldots \ldots \ldots \ldots \ldots \ldots$

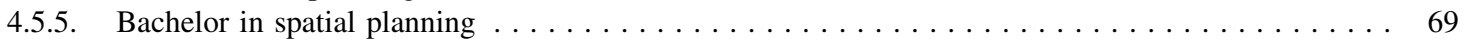

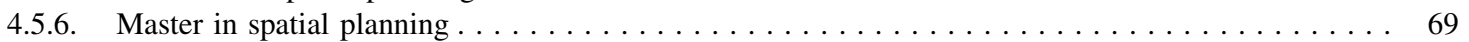

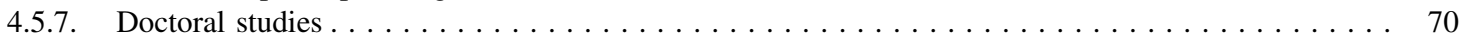

4.5.8. Programme curriculum in spatial planning: case study $\ldots \ldots \ldots \ldots \ldots$

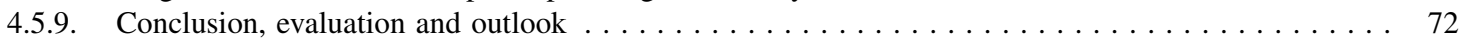

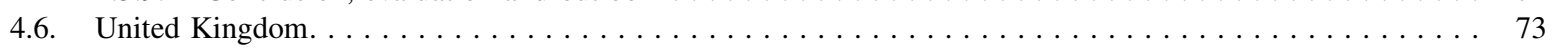

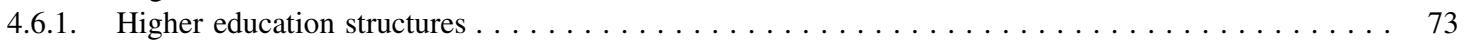

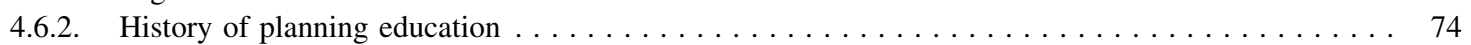

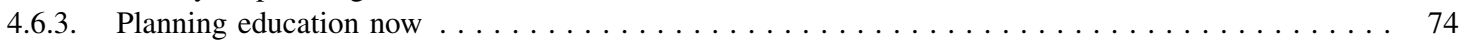

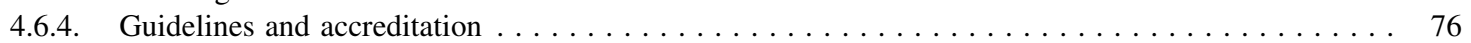

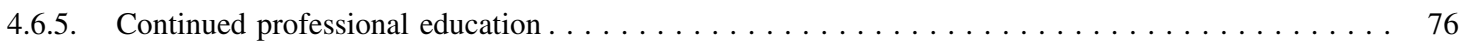

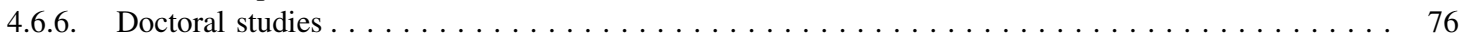

4.6.7. Conclusion, evaluation and outlook $\ldots \ldots \ldots \ldots \ldots \ldots$

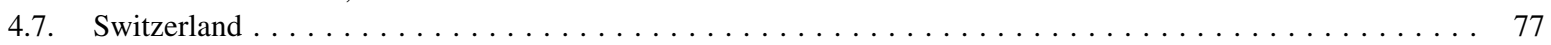

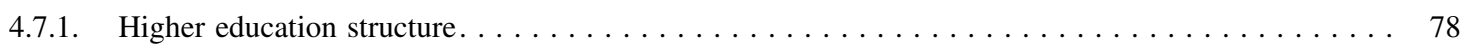

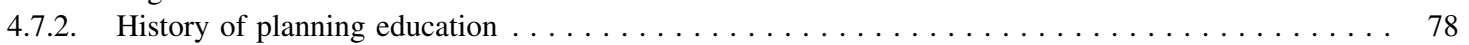

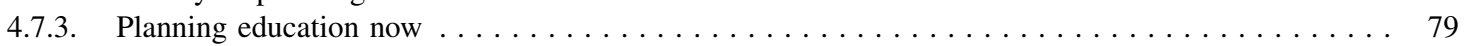

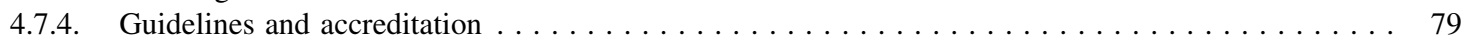

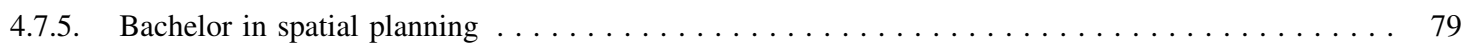

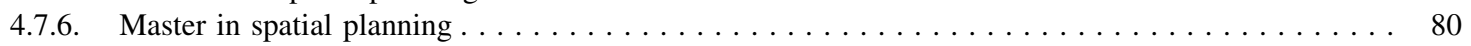

4.7.7. Advanced studies and continued professional education $\ldots \ldots \ldots \ldots$

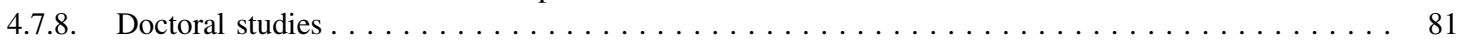

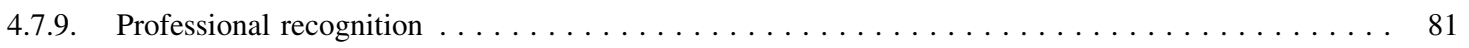

4.7.10. Conclusion, evaluation and outlook $\ldots \ldots \ldots \ldots \ldots$ 
5. Educating planners in Europe: evaluation and recommendations $\ldots \ldots \ldots . \ldots \ldots$

5.1. Level and character of educational provision $\ldots \ldots \ldots \ldots \ldots \ldots$

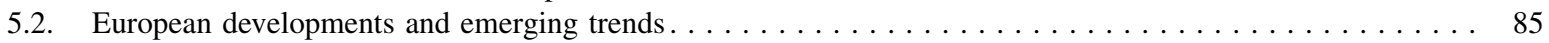

5.3. Recommendations $\ldots \ldots \ldots \ldots \ldots \ldots \ldots \ldots \ldots \ldots$

Acknowledgements $\ldots \ldots \ldots \ldots \ldots \ldots \ldots \ldots$

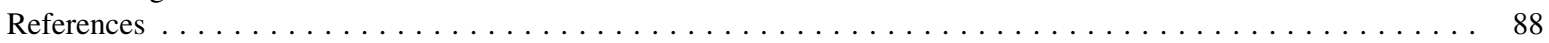

\section{Introduction}

The emergence of planning as a discipline taught at university was a rather piecemeal affair. While the establishment of professional societies and the first university-level education for planning in the early decades of the 20th century are commonly taken as the birth of planning as a distinct professional field - at least in Europe and North America - initially just a few institutions offered planning degrees at postgraduate level. The perceived need for a specialised profession and education for planning has waxed and waned and only gradually gained acceptance. Calls for planners and planning interventions often derive from crisis situations. For example, planning as an independent academic discipline and professional field received a considerable boost resulting in a proliferation of new planning degree programmes as part of the reconstruction and rebuilding efforts post WW II (e.g., Batey, 1985; Keller, Koch, \& Selle, 1996). More recently, the identification of planning as a key activity in building sustainable communities and cities (e.g., Egan, 2004; UN Habitat, 2009) or the recognition of the importance of planning in preparing for and mitigating climate change impact has renewed interest in the subject. In Europe, notions of transnational European spatial planning, cohesion and integration are furthermore creating new demands (e.g., Mangels \& Cotella, 2012), while at the same time the Bologna agreement and associated reforms of the higher education sector have created opportunities to swiftly adjust and diversify the provision to respond to emerging planning aspects (Frank \& Kurth, 2010; La Greca, 2012, p. 170).

Despite the present positive trajectory, many scholars remain concerned about the status and profile of planning as a profession. Academically the discipline is considered a contested territory (Davoudi \& Pendlebury, 2010; McLoughlin, 1994; Wildavsky, 1973). Recognition of planning as an independent field of study differs considerably between countries, as do the interpretations of what planning entails and what planners (should) do in practice. The diversity is reflected in varied professional conceptions and educational models. At one end of the spectrum, planning has become an established, even regulated, profession of "generalists" with a specialism such as urban design, transport or land use planning (Perloff, 1957), supported by comprehensive degrees, agreed professional standards and competencies monitored by professional bodies or governments. At the other end, planners first and foremost are educated as engineers, economist, social scientists, geographers, or architects who specialise in planning at urban or regional scales. The diverse conceptualisation of planning has not only implications for planning curricula, accreditation and recognition but also for planners' skills sets, the portability of degrees and ultimately the mobility of planners in a European or global labour market.

Establishing the core of the discipline as well as clear boundaries to related fields will remain an on-going project - at least for the time being (Geppert \& Cotella, 2010). The causes are manifold. Firstly, planning as an interdisciplinary subject is frequently usurped as a specialist part of an established albeit cognate field, rather than a discipline in its own right. Related professions such as architecture or disciplines such as geography attract far more students than planning-only degrees; this suggests that planning is generally not seen as a viable endeavour in its own right. Secondly, with an applied creative focus, the field's standing in academia has been criticised for a lack of scientific rigour in the classical sense and its contributions disparaged within emerging research excellence frameworks. This is peculiar, as literature addressing trends in higher education more generally detect a push for employability (European University Association - EUA, 2003) and performativity (Barnett, 2000, 2004), criteria on which planning as well as other professional programmes traditionally score highly. It seems that planning scholars have yet to capitalise on this opportunity by better communicating the fields' contributions and educational merits. Thirdly, the field has undergone a sequence of paradigm shifts (Dalton, 2001; Stiftel et al., 2009) as planning practice, approaches and processes adapted to changing external conditions in society (i.e., political ideas or Zeitgeist) to 
secure the field's relevance (Kunzmann, 1985). Changes in planning practice and the required adjustments in curricula are well documented (Brković, 2012; Castells, 1998; Cuthbert, 1994a, 1994b; Dalton, 2001; Friedmann, 1996; Keller et al., 1996; Ozawa \& Seltzer, 1999; Pezzoli \& Howe, 2001; Rodwin \& Sanyal, 2000; Sandercock, 1997); they are testimony to the responsiveness of education providers (Frank, 2006) to ensure graduates have the knowledge and skills to address topical planning issues. In sum, planning has shifted from a rather narrowly focused technical design-based field to include a wide range of other dimensions such as policy and processes of governance. In some national contexts planning has moved almost exclusively into the realm of the social, behavioural, political, economic or environmental sciences although in others a strong design element has been maintained. Further changes in focus are practically pre-programmed in light of the need to develop sustainable cities and to mitigate climate change impacts (Birch \& Silver, 2009; Hurlimann, 2009; RTPI, 2011a; UN Habitat, 2009, pp. 202-205). The continuous evolution and adaptation of planning approaches and divergent perspectives in different countries, regrettably, is seen as weakness by critics of the field. Even from within the field, voices warn of the loss of disciplinary identity, the dangers of diffusion and fragmentation associated with interdisciplinarity and diversity and the risk of planning education degrading to profession-led training (Davoudi \& Pendlebury, 2010; Myers \& Banerjee, 2005). There are no simple answers in how to address or overcome these concerns. A better understanding of current trends and developments in planning education may be a first step to identify a meaningful way forward.

This study, thus aims to review the planning education provision in European countries a decade into the 21 st century and roughly a century after the first planning degrees were established. It represents a stock taking which builds on a tradition of reviews. For instance Amos et al. (1973) provided an in-depth evaluation of the Education for Planning from a UK perspective, while other studies offer more international comparative assessments (e.g., Ache \& Jarenko, 2010; Batey, 1985; Fubini, 2004; Rodriquez-Bachiller, 1988; Scholl, 2012). Reviews typically explored both quantitative and qualitative aspects of the provision. A first global inventory of planning education (UN Habitat, 2009 , p. 189), for example, estimated that as of 2008, accredited planning degrees of one sort or another were offered world-wide by at least 550 universities in 82 countries. Analyses of this data by continents showed that educational opportunities globally are not always reflecting needs. The provision is geographically uneven with $1 / 3$ of all planning schools concentrated in Europe where less than $1 / 7$ of the global population resides. A study by the Commonwealth Association of Planners (CAP) corroborates the inequality of provision, observing a dearth of education programmes and resultant lack of planning capacity in a number of African and Asian Commonwealth countries (Commonwealth Secretariat, 2011). Moreover, curricula and pedagogies can be outdated without providing the skills and knowledge necessary to address planning problems at hand (Lorens, 2012; UN Habitat, 2009; Watson, 2007). Akin to past studies, this appraisal will on one hand quantitatively assess the provision and spatial distribution of the provision throughout Europe. As the number of programmes, indirectly at least, substantiates a market for planning competencies we can make some inferences on the value and status of the field of planning. On the other hand, the study will seek to advance our understanding of the implications of global and, in particular, Europe-specific developments for present and future planning education provision. For example, how do the relative small programmes in planning cope with massification (Trow, 2005) and demands for performativity due to the re-alignment of government, industry and universities? (Barnett, 2004; Etzkowitz, Webster, Gebhardt, \& Terra, 2000); and in what ways are planning educators reconciling professional needs and educational traditions with the harmonisation of educational structures associated with the Bologna process are some of the questions that are addressed.

The remainder of the study is presented in five sections. Assumptions and methods will be elaborated in the following section. Section 3 comprises a brief historical account before specifying results of the inventory. The latest developments in planning education and main drivers of change in Europe such as the Bologna declaration (1999) are discussed. Section 4 explores the character and structure of education for planning and recent developments via selected national case studies to discern differences and similarities across countries. The final section summarises key points, and offers suggestions on how to secure and improve the status and profile of the profession.

\section{Approach and methodology}

As different interpretations and definitions for planning coexist within countries and in particular between countries (e.g., Alterman, 1992; Nadin \& Stead, 2008; Newman \& Thornley, 1996), the study adopts a relatively broad definition of planning. In 
particular, we chose the European Council of Spatial Planners' (ECTP-CEU) description, whereby planning

"embraces all forms of development and land use activities. It operates in all social strata and on several inter-related spatial levels - local, rural, suburban urban, metropolitan, regional, national and international. It is concerned with the promotion, guidance, enhancement and control of development in the constantly changing physical environment in the interest of common good but respecting the rights of the individual. It makes provision for the future; helps reconcile conflicts of interest, projects physical and social change, facilitates the harmonious evolution of communities and initiates action for the optimum use of resources. It is both a management and a creative activity. It is a catalyst in conserving and developing the present and future structure and form of urban and rural areas. It contributes to the creation of the present and future character of social, physical, economic organisation and environmental quality. (ECTP, 2003)"

Planners by extension assume a multitude of roles from technician and scientist to land use managers, advisors and advocates for minorities and disadvantaged, designers and entrepreneurs (ECTP, 2003). Different nations attribute greater weight to certain aspects of planning creating diverse planning cultures (Fubini, 2004; Nadin \& Stead, 2008). As a consequence, planning education provision in Europe follows different educational models (Rodriquez-Bachiller, 1988) and displays a rich diversity in programme foci, degree structures, titles, and curricula.

Mindful of these national differences, the quantitative part of the review is based on an inventory of planning education programmes (undergraduate and/or master level) that offer spatial, urban or regional planning degrees which are recognised or accredited and allow graduates to formally practice the profession of planning within the context of the country where the programme is offered. For countries where there is no official recognition of planning as a profession or study field per se we have included programmes providing a substantial portion of planning content and which generally fulfil the basic requirements of the Association of European Schools of Planning's (AESOP) core curriculum. This approach is likely to result in an undercount as a variety of additional programmes offering planning related skills and knowledge exist that will have inadvertently been excluded.

The data collection drew on multiple information sources. The drawback of a greater variability in interpretations of what constitutes planning derived from this approach is counterbalanced by the benefit of data triangulation. A key source was the membership directory of $\mathrm{AESOP}^{8}$ an association of schools/ departments/faculties offering planning degrees. Any institution that offers a planning education degree that conforms to a basic core curriculum can become a member. As membership is voluntary, the association naturally does not capture all providers. Indeed, only one provider from Russia so far has joint while others do exist (Hirt \& Stanilov, 2009, p. 79). To provide a more complete picture, AESOP membership information was supplemented and cross-checked with data held by other networks and institutions such as the list of accredited planning programmes from the Royal Town Planning Institute (RTPI), a list of planning degree providers compiled by the CAP, membership data of APERAU (Association pour la Promotion de l'Enseignement et de la Recherche en Aménagement et Urbanisme - a network of French language planning schools) and the Turkish Planning Schools Association (TUPOB). Additionally, the authors conducted internet searches and solicited or verified information via planning educators in relevant European countries. Although every care was taken in compiling data (current as of 2012), it is impossible to offer absolute accuracy due to the constantly changing provision and language barriers.

For the qualitative perspective, narrative national case studies provide further information on recent developments in planning education provision. As far as possible each case study follows the same structure exploring (a) the character of the higher education sector, (b) if and how Bologna actions were implemented, (c) what models of planning education exist or prevail and (d) the number and names of institutions where planning is taught. In addition we sought to examine (e) curricula characteristics in respect to national frameworks or prescribed learning outcomes, (f) accreditation practices and routes to professional qualification, as well as ( $\mathrm{g}$ ) any emerging issues and topics in planning education in the case study country. Certain elements may be absent from individual cases as they do not apply equally in all national contexts.

As planning education provision is shaped in large part by the needs of practice, which in turn are influenced by a country's planning system we selected nations which have been identified as having different models and approaches to planning following the typologies for planning systems and professional milieus (Alterman,

${ }^{8}$ http://www.aesop-planning.eu/en_GB/members-directory. 


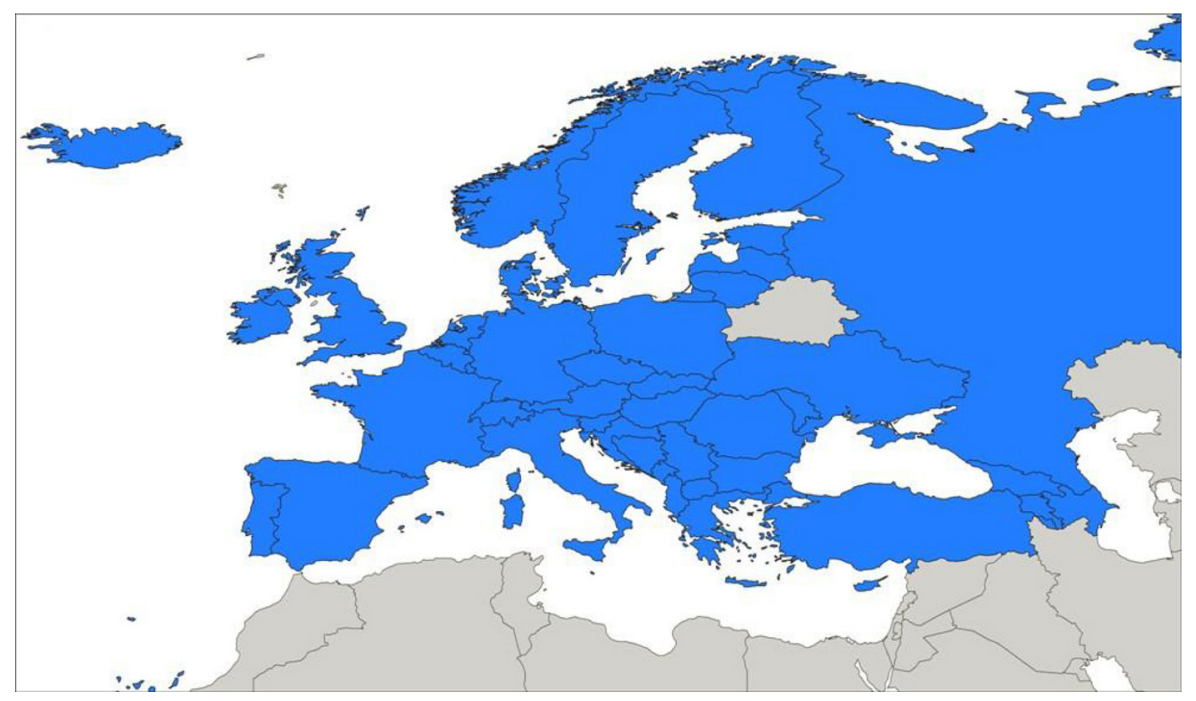

Fig. 1. Geographical coverage of the Council of Europe. List of Council of Europe member states and year of joining; Bologna signatory countries are marked with ${ }^{\dagger}:$ Albania $^{\dagger}$ (1995), Andorra ${ }^{\dagger}$ (1994), Armenia $^{\dagger}$ (2001), Austria ${ }^{\dagger}$ (1956), Azerbaijan ${ }^{\dagger}$ (2001), Belgium ${ }^{\dagger}$ (1949), Bosnia \& Herzegovina $^{\dagger}$ (2002), Bulgaria ${ }^{\dagger}$ (1992), Croatia ${ }^{\dagger}$ (1996), Cyprus ${ }^{\dagger}$ (1961), Czech Republic ${ }^{\dagger}$ (1993), Denmark ${ }^{\dagger}$ (1949), Estonia ${ }^{\dagger}$ (1993), Finland ${ }^{\dagger}$ (1989), France $^{\dagger}$ (1949), Georgia ${ }^{\dagger}$ (1999), Germany ${ }^{\dagger}$ (1950), Greece ${ }^{\dagger}$ (1949), Hungary ${ }^{\dagger}$ (1990), Iceland ${ }^{\dagger}$ (1950), Ireland ${ }^{\dagger}$ (1949), Italy ${ }^{\dagger}(1949)$, Latvia $^{\dagger}$ (1995), Lichtenstein ${ }^{\dagger}$ (1978), Lithuania ${ }^{\dagger}$ (1993), Luxembourg ${ }^{\dagger}$ (1949), Malta ${ }^{\dagger}$ (1965), Moldova ${ }^{\dagger}$ (1995), Monaco (2004), Montenegro ${ }^{\dagger}$ (2007), Netherlands ${ }^{\dagger}$ (1949), Norway ${ }^{\dagger}$ (1949), Poland ${ }^{\dagger}$ (1991), Portugal $^{\dagger}$ (1976), Romania $^{\dagger}$ (1993), Russian Federation ${ }^{\dagger}$ (1996), San Marino (1988), Serbia ${ }^{\dagger}$ (2003), Slovakia ${ }^{\dagger}$ (1993), Slovenia ${ }^{\dagger}$ (1993), Spain $^{\dagger}$ (1977), Sweden ${ }^{\dagger}$ (1949), Switzerland ${ }^{\dagger}$ (1963), The former Yugoslav Republic of Macedonia (1995), Turkey $^{\dagger}$ (1949), Ukraine ${ }^{\dagger}$ (1995), United Kingdom ${ }^{\dagger}$ (1949).

Source: http://www.coe.int/T/e/Com/about_coe/ and http://www.ond.vlaanderen.be/hogeronderwijs/bologna/pcao/).

1992; Nadin \& Stead, 2008; Newman \& Thornley, 1996). In particular we chose two nations with a design based, technical planning tradition, namely Spain and Portugal, one with a comprehensive planning tradition such as Switzerland, one from a Scandinavian country, and two from Central and Eastern Europe to explore the development pathways taken post 1989. The list of case studies is completed by the UK which has not only a long history in planning education but also a unique planning system focused on land management and flexible, discretionary development control. Case studies from a range of other countries would have been useful in this context but would have exceeded the limits of this volume.

The geographical boundaries of the study region comprises the 47 member nations of the 1949 founded Council of Europe (CoE) which is next to the European Commission a major player in European integration (Fig. 1). This geographical extent matches with minor exceptions the list of Bologna signatory countries as of 2012. Exceptions are Kazakhstan and Holy See which have signed Bologna but are not in $\mathrm{CoE}$, and $\mathrm{CoE}$ members Monaco and San Marino, both home to only a single university, who have not (yet) joined the growing Bologna family.

\section{History, cultures of planning and planning education in Europe}

Although texts on the design of cities and town extensions, the management of community life,,$^{9}$ and planning go back centuries, planning as distinct field of study is relatively new to academia. Similar to other modern academic disciplines (e.g., biotechnology), planning is by nature interdisciplinary and focused on problem-solving. Planning education is about critically thinking about space and place making (RTPI, 2004) to inform interventions to manage and shape human environments to be liveable and sustainable. For this, the field draws widely on knowledge and approaches of professions such as (landscape) architecture, surveying, engineering, management and disciplines such as geography, social and natural sciences and economics (Davoudi \& Pendlebury, 2010; Grant, 1999).

\footnotetext{
${ }^{9}$ For example, Aristotle, Politics - Book I; Vitruvius (ca. 33 B.C.) De Architectura libri decem - Books VI and VIII; Sitte, C. (1889) City Planning According to Artistic Principles.
} 
The different planning traditions and educational models (Rodriquez-Bachiller, 1988) along with nations across Europe developing planning education provision within their own temporal framework make it impossible to provide a singular historical account. Some generalisation of the approaches to planning may be possible following categories developed through comparative studies that distinguish between different planning families or cultures (Newman \& Thornley, 1996) although there is no precise match. For this reason, the development of planning education programmes is recounted in a crude manner distinguishing three phases: incipient, gaining momentum, expanding. The first phase represents the beginnings up to circa 1945, while the second marks the development of a tradition of planning education (post WWII to around 1990). The third phase is characterised by an expansion of programmes, thematically and geographically, triggered by the demise of communism and growing European influences, as well as newly emerging planning paradigms. Phases one and two are covered only briefly as they are discussed elsewhere (Batey, 1985; Healey \& Samuels, 1981; Keller et al., 1996). The third phase is given more weight as it provides the context to our review and assessment of the opportunities to study planning in different parts of Europe.

\subsection{Inception: planning education as post- professional degree}

Traditionally, much planning work was conducted by engineers and architects. However, during the 19th century, government interventions pertaining to planning became more common. Laws and legislation such as the 1846 Bohemian building regulation and code in the Austrian-Hungarian Empire (Albers, 1997, p. 84) or the 1885 "Housing of the Working Class Act" (Albers, 1997, p. 59) in the UK represented conscious efforts to control development and land speculation and thereby guaranteeing minimum building standards for dwellings and protecting inhabitants' health. One of the first calls for the establishment of a special profession of "planners" can be found in the essay City Plans by the American Horace Bushell (1864):

"Considering the immense importance of a right location, and a right planning for cities, no step should ever be taken by the parties concerned, without employing some person who is qualified by a special culture, to assist and direct. Our engineers are trained for a very different kind of service, and are partially disqualified for this by the habit of a study more strictly linear, more rigidly scientific, and less artistic. The qualifications of surveyors are commonly more meagre still. . Nothing is more to be regretted, in this view, than that the American nation, having a new world to make, and clean map on which to place it, should be sacrificing their advantage so cheaply, in the extempore planning of towns and cities. The peoples of the old world have their cities built for times gone by, when railroads and gunpowder were unknown. We can have cities for the new age that has come, adopted to its better conditions and ornament. So great an advantage ought not to be thrown away. We want therefore a city-planning profession, as truly as an architectural, house-planning profession. Every new village, town, city, ought to be contrived as a work of art, and prepared for the new age... (pp. 308-336)"

Approximately four decades later, the first planning degree was established at the University of Liverpool in 1909 (Albers, 1997; Batey, 1985; Hall, 1996). This "civic design" degree as well as other similar degrees, which were started at the University of Karlsruhe (ca. 1915), and University College London ${ }^{10}$ (n.d.) in 1914, was a postprofessional qualification. It was aimed at architects, surveyors and engineers seeking an additional specialist qualification. Quite different from today, a planning degree in those early days was an "elitist" qualification, elevating its bearers above the traditional architect or engineer by means of skills and training for large scale work. In the case of Liverpool's civic design degree teaching was especially geared to working professionals with late afternoon and evening classes. The focus of such programmes all the way through the end of WWII was the organisation of land use, urban layout and physical design. Other aspects of planning - such as regional, economic, strategic planning, and transport/ infrastructure planning were being taught within other disciplines such as geography, political science, or engineering (Amos et al., 1973), but to the best of our knowledge no specific degrees were awarded.

\subsection{Gaining momentum: autonomous professional degrees}

Between 1946 and 1990 a substantial number of autonomous planning programmes were established in Western European countries like France, Germany, the Netherlands and the UK (Batey, 1985; Frank \& Kurth, 2010). The first independent planning programme in Turkey was established at Middle Eastern Technical University in Ankara 1961 (Babalik-Sutcliffe, 2012) and in Austria a five-year diploma programme in spatial

\footnotetext{
${ }^{10}$ http://www.bartlett.ucl.ac.uk/general/admissions/history.htm.
} 
planning was established in $1970 .{ }^{11}$ These programmes by and large adopted a comprehensive, interdisciplinary approach to planning education incorporating policy, economic, geographic and social sciences as new components with urban design declining in importance. Especially in the UK, planning degrees adopted a marked social science focus (Chandler, 1985) while in other countries such as the Netherlands programmes assumed different traditions (Needham, 2004, p. 416). The main difference to pre-1945 was that degrees established in this period in the main led directly to professional qualification rather than being post-professional top-up programmes. In the UK, both bachelors and masters degrees were offered while in continental Europe four- and fiveyear degrees leading to an engineering title were the norm.

Post-professional degrees continued to exist as well as the option to specialise in planning as part of a degree in a cognate discipline. In fact, opportunities to study planning as an independent professional degree did not arise everywhere in Europe. Especially in the European South (Greece, Italy, Portugal and Spain), independent degrees in planning were only established from the 1980s. And, as a focus on physical planning with a strong emphasis on design or engineering customarily prevails, most planning education is delivered as specialism route within architecture and engineering programmes until today (Gospodini \& Skayannis, 2005; see Sections 4.1 and 4.2).

Interestingly, in Scandinavia (Denmark, Sweden, Finland and Norway) the situation is not that dissimilar. There is a strong tradition of comprehensive planning practice and yet, planning is frequently still embedded within architecture, engineering and surveying programmes, despite identified shortcomings of this approach (Virtanen, 2004; see Section 4.3).

Especially in those countries where planning education became less design oriented, there was also a shift in the types of educators from practitioners to career researchers holding doctoral degrees - a development leading to the establishment of planning as academic discipline (Davoudi \& Pendlebury, 2010). On the flip side, the professionalisation of HE let to a growing gap between practice and academia often seen as problematic (Baum, 1994; Checkoway, 1998; Ellis, Murtagh, \& Copeland, 2010).

\subsection{Expanding: new developments 1990 to present}

Over the past 20 odd years, changes in planning practice (Frank, 2007; Rodwin \& Sanyal, 2000), and a

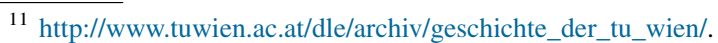

conceptual shift from rational planning to a communicative social learning model (Stiftel et al., 2009) as well as increasing environmental, social and economic problems related to urbanisation, have nurtured an extensive world-wide, albeit regionally contextualised discourse on the renewal of planning education curricula and pedagogy (e.g., Brković, 2012; Frank, 2006; Gurran et al., 2008; RTPI, 2003, 2004). From a European perspective, European Union policies intended to facilitate European integration and a common labour market became important change agents. The European Spatial Development Perspective (ESDP) and its themes of spatial cohesion and coherence (Faludi, 2010) has spurred on transnational, regional and strategic planning and inspired new modules and degree programmes.

Although there has been an increase of the number of planning education programmes in Europe throughout this period it is not clear in how far this expansion stems from changes in Europe from elite to mass higher education signalling an increase of the proportion of the population obtaining a higher education degree from less than $5 \%$ to $20-30 \%$ (Trow, 2000, 2005). A proportional increase of student numbers across all fields and subjects cannot be assumed. In fact, some of the numerical growth in planning education programmes is likely due to the Bologna agreement (1999) and reforms initiating a harmonisation of education structures into three cycles across the participating nations. This led to many five-year programmes being split into first and second cycle programmes leading to a significant increase in programme numbers. In turn, this might or might not translate into a growth of planning graduates. Unfortunately data on student numbers studying planning is currently not collected in any systematic manner across Europe. The quantitative element of our review therefore focuses on institutions rather than programmes.

Within this time period, the demise of communism led to an upheaval in urban and economic planning and development requiring a review of planning approaches and education for planning in Central and Eastern Europe. In countries like Poland, Slovakia, Croatia, Albania, Romania, Bulgaria and so forth, autonomous planning education programmes started to emerge from the $1990 \mathrm{~s}$ onward (Frank \& Mironowicz, 2009; see Sections 4.4 and 4.5). Development has been uneven, however, with some transition countries wholeheartedly embracing the idea of independent planning programmes (e.g., Poland), whereas elsewhere education opportunities for planning remain rare and continue to be associated with traditional cognate subjects (Brković, 2012).

It is the influence of the European developments on the structure, content and provision of planning 
education that we will focus on in this study - although, of course, they should not be viewed in isolation. Globalisation, internationalisation and universal trends towards performativity, managerialism, and commercialisation of knowledge and education associated with reduced government support for mass and universal higher education contribute likewise to changes in the HE sector (e.g., Barnett, 2004; Etzkowitz et al., 2000; Etzkowitz \& Leydesdorff, 2000; Fitzgerald, White, \& Gunder, 2012; Trow, 2005).

\subsubsection{European integration and mobility}

Seeds of the European project were sown early in the 20th century and started to take shape in form of limited economic alliances post WWII, but only gained momentum towards the end of the 20th century (Faludi, 2010). Relevant to higher education, from 1987 onward the European Commission (EC) promoted a set of programmes such as ERASMUS, which were to help develop a European identity amongst its residents (Sigalas, 2010) and encourage economic cooperation, innovation and cultural awareness. A key element of the ERASMUS programme is mobility support for professionals, academic staff and students under the premise that a period of study and work abroad will not only improve an individual's qualifications and language competencies but also peoples' understanding of other cultures.

Data from 2011 show that under the ERASMUS Scheme 2.2 million students and 250,000 academic staff received funding for study abroad, intensive programmes, work placements and teaching exchanges between 1987 and 2010 (European Commission, Directorate General for Education and Culture, 2010). Individuals and institutions from 33 countries (EU plus Iceland, Liechtenstein, Norway, Turkey and the Former Yugoslav Republic of Macedonia) participated. ${ }^{12}$ Statistics are insufficiently detailed to deduce the number of planning students and academics that have participated, but anecdotal evidence suggests that planning schools are active participants at all levels (individual mobility, institutional networks, and intensive programmes) (Williams, 1989). Especially intensive programmes (IP) which offer funding for collaborative inter-institutional projects are popular with planning academics. Records from 2009/2010 indicate that around $4 \%$ of all IP projects (15/385) involved planning departments. ${ }^{13}$ As guidelines for IPs

\footnotetext{
$12 \mathrm{http} / / / \mathrm{ww} w . g o e t h e . d e / w i s / f u t / u h s / e n 7280600 . \mathrm{htm}$.

${ }^{13}$ A list of 2009/10 IP projects can be found at http://ec.europa.eu/ education/erasmus/doc/ip1011/comp_en.pdf.
}

stipulate a minimum of three partners as well as innovative pedagogy, educators have adjusted learning outcomes and curricula to incorporate cross-national topics, multi-national group work and field research activities in a number of creative ways.

Planning academics have also engaged with the ERASMUS Mundus scheme (EACEA, n.d.), which supports the development of inter-institutional master programmes. To date, schools have been successful in gaining funding for five (of 104) degrees, which provide planning education in new and niche areas delivered jointly by at least three institutions in different European countries (Table 1).

\subsubsection{European spatial planning and degree portability}

European spatial planning, regional, transnational and European-wide (strategic) planning is becoming increasingly accepted and its impacts on national and municipal planning are being felt. The implementation of the European Spatial Development Perspective (CSD, 1999), supported through programmes and cooperation networks, provides not only economic stimuli but also platforms for knowledge creation and exchange that subtly influence approaches to regional planning and governance arrangements (Giannakourou, 2005). EU directives such as the Habitats Directive 92/ 43/EEC, Air Quality Directive 2008/50/EC, Water Framework Directive 2000/60/EC or the Public Procurement Directive 2004/18/EC are perhaps the measures that impact on planning most directly. The directives outline targets for, and approaches to, environmental and economic issues for which a coordinated European approach is deemed beneficial and which Member States have to implement within their national legal frameworks (e.g., Hedelin, 2005; Martin, Hartley, \& Cox, 1999). In this sense, transEuropean cooperation and coordination in planning, especially within the framework of territorial cohesion is already a professional reality. EU projects and programmes that require cooperation between different institutions, cities, and regions represent an opportunity for planners to acquire supranational grants and to be mobile across national boundaries. As a result, planning education programmes at master level have begun to introduce European planning issues in curricula and a few rare programmes have been created focusing exclusively on European spatial and comparative issues. Mangels and Cotella (2012) however argued that more European planning ought to be taught and that the current provision is inadequate to prepare graduates for planning in practice environments that increasingly 
Table 1

Erasmus Mundus programmes for education in planning.

\begin{tabular}{|c|c|c|c|}
\hline Programme name & Length/language & Partners & Description/focus \\
\hline $\begin{array}{l}\text { MUNDUS URBANO Interdisciplinary } \\
\text { Master Course on International } \\
\text { Cooperation and Urban Development }\end{array}$ & $\begin{array}{l}\text { Length: } 2 \text { Years } \\
\text { Language: English/ } \\
\text { specialisations in } \\
\text { 2nd year in the } \\
\text { national languages }\end{array}$ & $\begin{array}{l}\text { + Technical University Darmstadt (DE) } \\
\text { + International University of Catalunya (ES) } \\
\text { + University Pierre Mendez (FR) } \\
\text { + University of Rome Tor Vergata (IT). }\end{array}$ & $\begin{array}{l}\text { This Master seeks to train } \\
\text { professionals for work in the } \\
\text { international development } \\
\text { context. Students are taught to } \\
\text { conceive, oversee and evaluate } \\
\text { urban projects within the } \\
\text { framework of sustainable } \\
\text { development. Year } 1 \text { is delivered } \\
\text { in Germany. In year } 2 \text {, students } \\
\text { choose a partner university to } \\
\text { develop their specialism (Spain, } \\
\text { France or Italy). }\end{array}$ \\
\hline
\end{tabular}

MACLANDS: MAster of Cultural LANDScapes

EURMed (Etudes Urbaines en Régions Méditerranéennes)

PLANET Europe

ERASMUS MUNDUS: EuroAquae
Length: 2 Years + University of Saint Etienne (FR),

Languages: French/ + University of Stuttgart (DE)

Italian/German; + University Federico II of Naples (IT) students need to

certify French

(DALF C1), Italian

(CELI 3), \& German

(ZD) competencies

Capacity: 30

Length: 2 Years + Université Paul Cézanne

Languages: Spanish, Aix-Marseille III (FR)

French, Italian and + Universidad De Sevilla (ES)

Portuguese. + Università Degli Studi Di Genova (IT)

Capacity: up to 60, + Universidade Técnica De Lisboa (PT) including 19 students from non-European countries.
+ Radboud University Nijmegen (NL)

+ Cardiff University (UK)

+ Blekenige Institute of Technology (SE)

This Master focuses on sustainable preservation, management and development of cultural heritage. MACLANDS seeks to train students in analysis, management and preservation (preventive and curative) as well as design of sustainable solutions for planning involving cultural heritage.

This Master provides specialised education in sustainable development planning of Mediterranean coastal regions. The programme is highly interdisciplinary comprising urban and rural planning, political sciences, sociology, regional studies, geography, and architecture. Students are required to study in at least 2 partner institutions.

This Master focuses on European spatial planning, environmental policies and regional development. Students start in Nijmegen and continue their studies either in Cardiff or Stockholm.

Length: 2 Years Language: English
+ University of Nice - Sophia Antipolis (FR),

+ Brandenburg University of Technology

at Cottbus (DE),

+ Budapest University of Technology

\& Economics (HU),

+ Polytechnic University of Catalonia (ES),

+ Newcastle University (UK)
This Master prepares consultants for working on environmental and hydrotechnological projects for the public or private sector at local, regional, national and international scale. require them to be familiar with European planning dimensions.

The decree of free professional mobility posits interesting challenges for cross-national recognition of degrees and professional qualification which has recently been taken up by professional associations such as the European Council of Spatial Planners (ECTP-CEU). At present the profession is treated differently across nations. Its status ranges from partially regulated via self-regulated to unregulated. An ECTP-CEU working group on the Recognition of Planning Qualifications in Europe is reviewing the 
situation and preparing proposals on the mutual recognition of qualifications and mobility of planners across Europe (ECTP-CEU, 2013a, 2013b). The basis of recognition of planners throughout Europe has to be the recognition of professional qualifications, which is linked to planning education, curricula and the legal framework that defines who can work as a planner. The issue of context specific versus global or even European planning education has never been resolved and remains complex (Afshar, 2001; Burayidi, 1993; Peel \& Frank, 2008). APERAU and AESOP have defined generic curriculum criteria but overall local context prevails with national professional bodies determining the learning outcomes and competencies for future planners in their national contexts. European-wide agreed criteria for planning programme accreditation leading to a qualification recognised by all member states but complemented by nationally focused assessment of competencies prior to full practice eligibility may be a potential solution.

\subsubsection{Bologna agreement and higher education reforms}

Major implications for European higher education derive from the Bologna Declaration (1999), which is the culmination of an intergovernmental (non-European Union) initiative of European education ministers. The agreement, initially signed by 29 European countries, now includes 47. The aim of Bologna (1999) is to remove obstacles to (cross-institutional, horizontal) staff and student mobility associated with different degree structures and to make higher education in Europe more attractive and competitive, globally. The agreement entailed the set-up of the so-called common EHEA within which a harmonised tertiary education structure and a credit transfer system facilitates the mutual recognition of learning achievements. In addition, agreed principles of quality assurance systems provide confidence in the quality of the provision while transcripts (labelled Diploma Supplement) allow employers to compare qualifications with greater clarity. By creating three cycles of education, the reform creates more access paths and greater flexibility in higher education.

Originally the Bologna reforms were to be completed within a decade (by 2010), an ambitious target considering the stark differences in higher education systems in European countries. As many more nations signed up over time this goal became rather unrealistic and reforms are ongoing. Implementing Bologna has comparatively fewer implications for countries where already a system of multiple cycles - that is, a Bachelor (undergraduate, 3-4 years) followed by a Master (graduate, 1-2 years) - prevailed such as the UK. In many continental European countries long continuous programmes (typically referred to as undergraduate, first degree) with a minimum duration of 4-5 years depending on the type of institution and/or country had to be entirely rethought (Westerheijden et al., 2010). Fig. 2 depicts generalised education pathways for planners pre- and post-Bologna.

Institutions in many countries have now successfully implemented the required two cycles (plus a third cycle for the doctorate) in the planning field (Ache \& Jarenko, 2010). Among the group of early signatory countries, delays in implementation exist in Portugal and Spain, where legislation integrating the changes in national HE laws were introduced only in 2006 and 2007, respectively (see Sections 4.1 and 4.2). Top-up specialist post-graduate programmes targeting professionals with a traditional first (diploma) degree or masters to gain additional qualifications over 12-18 months full-time (Gospodini \& Skayannis, 2005, p. 362 ) which existed in many countries prior to the reform have been incorporated into the new framework as second cycle degrees or CPD certificates depending on the number of credits. Throughout Europe, doctoral studies on topics relevant to planning were and are possible. They typically require at least 3 years of fulltime study. The degree title may or may not be under the auspices of planning, but architecture or geography instead, again depending on the national framework. One could argue that it would be helpful for the recognition of the field to have planning as a free-standing research degree but this may only be achievable in the longer term.

One of the ideas of Bologna was that first cycle degrees would prepare students sufficiently for employment. Yet, for planning as well as architecture or engineering, professional bodies and associations in many nations, with the exception perhaps of Finland, have resisted this concept (Frank \& Kurth, 2010). Some academics have equally condemned the reforms (e.g., Kunzmann, 2004) voicing fears that the quality of qualifications will decline due to a less coherent and shorter education. In contrast, Frank and Kurth (2010) have argued that for an interdisciplinary profession like planning there may also be advantages as the new arrangements allow for the accumulation of more interdisciplinary knowledge and skills, something that Scholl (2012) also endorses.

In sum, the idea of an entirely flexible approach where students can freely change subjects after the first degree has not been achieved, particularly in professional subjects. In planning, this has led to the creation 


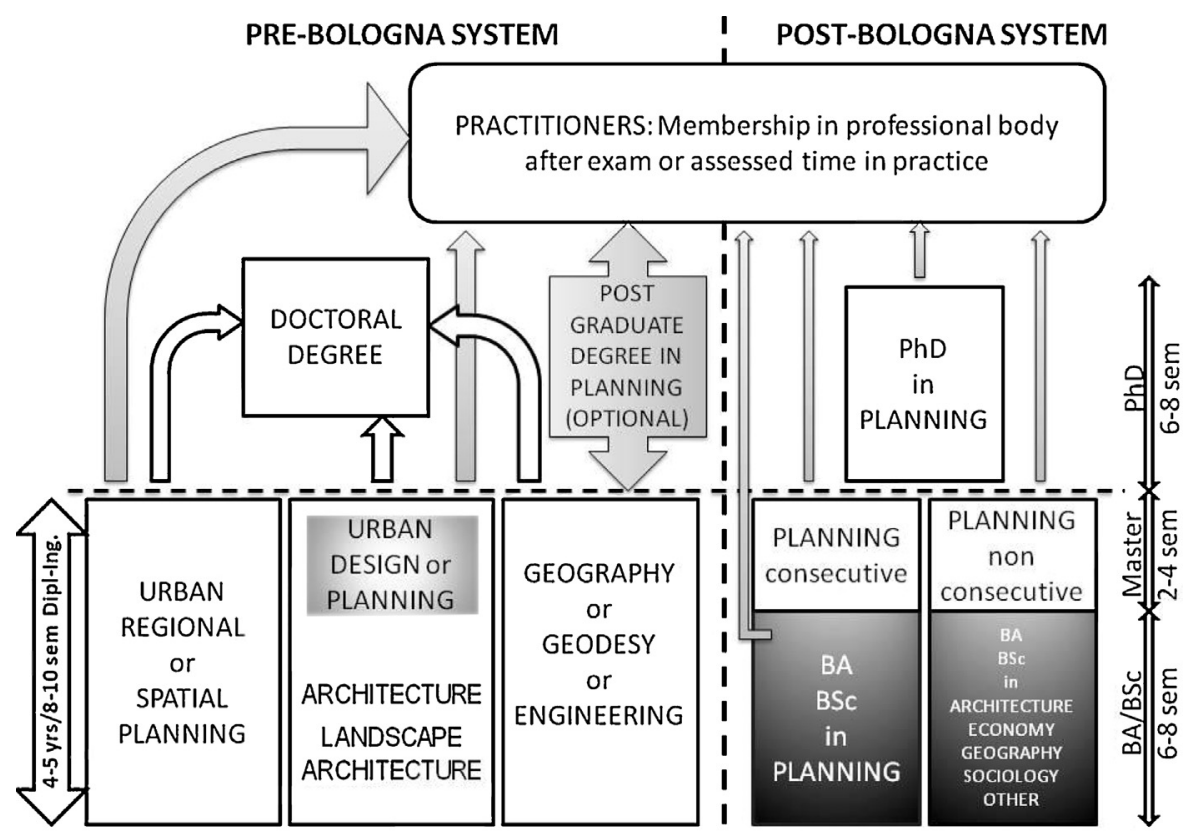

Fig. 2. Degree structures pre- and post-Bologna.

of different routes to a planning qualification in the two cycle system. In many countries entry onto a planning master is restricted to applicants with a background in planning or cognate field such as geography, or architecture. This can be seen as a sort of 'specialisation' (that existed within the 5-year degree) made explicit. Decisions, whether a student will be accepted or not may be made on a case by case basis or following particular criteria where students are allowed to enter a planning master with any degree that matches a certain percentage of the compulsory credits from a planning bachelor. A few countries allow students to enter a planning master with any bachelor degree but typically distinguish then between consecutive and non-consecutive Master programmes. In order for students to be accepted onto a consecutive (UK: specialist) masters they have to hold a first degree in planning. Students, who hold a first degree in a field other than planning, are only allowed to enrol in a non-consecutive (UK: spatial) planning master.

An unintentional effect of the reforms has been a decline of individual ERASMUS student mobility. Especially, at Master level, where programmes are exceedingly condensed into 12 or 18 months there is little time and opportunity to study abroad. Students can apply for mobility support at the earliest in the first semester and they will be towards the end of their second semester when receiving approval. This would allow only for doing the Master theses abroad which often puts greater requirements on students (such as securing two supervisors: one each from the Alma Mater and the hosting institution). Considering that ERASMUS mobility is an EU programme but the Bologna agreement an intergovernmental initiative unexpected side effects may not be surprising - although Keeling (2006, p. 208) highlighted that the EC nevertheless has played an active role in shaping Bologna from the start and used it as a vehicle to mainstream its own solutions. One educational response to redress the issue of limited mobility opportunities has been a greater focus on IP programmes; another is to integrate mobility into the curriculum instead of having students organise it themselves although this will reduce no doubt certain learning experiences linked to students' personal development.

There are also a growing number of universities teaching in English. Whether this is related to Bologna or a drive for global competitiveness is unclear. It will in any case facilitate mobility and make European higher education more attractive globally. For a contextspecific profession such as planning, however, nonnative language education will widen the gap between planning practice, education and academic research. Legal traditions and the local cultural context are deeply rooted in language. Anybody trying to translate planning concepts from one language to another can attest to this. Practitioners are unlikely to access research published in English while academics will struggle to publish accessible local language texts as well as quality English language research articles in an increasingly time pressured environment. Sadly, there is 
little hope to reverse this trend (Kunzmann, 2004) which will impede the effective university-industry knowledge transfer deemed essential in today's society (Etzkowitz et al., 2000) in certain countries as a result. The challenge is how to embed important local context (not only local case studies) and make students truly benefit from intercultural exchange. Indeed some employers have identified competencies in several languages as highly advantageous for working in private planning consultancies (Greif, 2012, p. 122).

On the positive side, Bologna helped progress the development (and implementation) of an EHEA-wide framework for quality assurance (Frank, Kurth, \& Mironowicz, 2012; Schwarz \& Westerheijden, 2004; Westerheijden et al., 2010). While national sovereignty on implementation has been ensured, it has in some countries initiated a debate on requirements for planning education and the establishment of nationally universal criteria for planning education degrees. It also has opened a window for a wider debate of curriculum requirements across national boundaries.

Overall, the Bologna reform can be considered a success, despite creating much turmoil (Frank \& Kurth, 2010). The 2010 report of the anniversary Bologna conference acknowledges the need for further work to nurture progress and address remaining problems (Weltgruber \& Csekel, 2011). For example, while there is a common system of credits not all institutions have yet implemented it locally, or they have implemented a different version which leads to problems in credit transfer and recognition. Problems are also created by different semester starting dates and teaching periods. Yet, Adelman (2008) notes that many ideas such as the Diploma supplement, different access routes to higher education, a uniform currency of credits allowing accumulation and the establishment of a quality assurance framework are practices for other regions to emulate. Similar reforms are contemplated to be introduced throughout Africa (Weltgruber \& Csekel, 2011).

\subsection{Overview of European planning education}

This study sought to compile information on the number and characteristics of planning education providers and, as far as possible, on pedagogies, delivery modes and emerging new knowledge and skills areas in curricula. We also looked at networking opportunities amongst providers. Information below is complemented by a detailed list of institution and programmes in the online resources, and auxiliary information in the national case studies (Section 4).

\subsubsection{Number of planning schools and regional distribution}

Data from 2011/2012 indicates that at least 218 institutions ${ }^{14}$ in the 47 Council of Europe member states (plus Kosovo) are offering planning education in one form or another. With the exception of very small nations such as Liechtenstein, Monaco, Luxemburg, San Marino or Andorra and seven countries for which no verifiable information could be obtained, some planning education is provided by at least one institution in each of the remaining 36 countries (Table 2). Merely focusing on institution numbers we defined three categories of provision for planning education corresponding to a population (in million)/institution ratio of less than 5 (good to excellent), between 5 and 10 (medium) and greater than 10 (underdeveloped).

Accordingly, good to excellent per capita provision of interdisciplinary, professionally orientated planning education programmes exists in 26 countries including France, the Netherlands, Italy, Ireland, Finland, Denmark, Norway and the United Kingdom. For example, in the UK we find 28 universities that offer a proliferation of professionally accredited degrees; there is also one institution which is satisfying the AESOP core curriculum requirements for membership but not the more narrowly defined RTPI criteria. This results in a population to institution ratio of 2.2. In Central Europe, the picture is mixed with some countries offering very good professional, interdisciplinary provision such as Poland and Estonia but also countries where planning is only a specialisation within architecture, surveying, or geography, e.g. Slovenia, Macedonia or the like and while they still satisfy the ratio ranking the quality of the education may be less comprehensive.

A medium level provision has been calculated for five countries, that is Turkey, Slovakia, Serbia, Bulgaria and, perhaps surprisingly Germany. This may be caused by relative large planning schools in respect to student numbers and a tradition in the south of Germany to provide planning education predominantly as specialisation of architecture (Frank \& Kurth, 2010). An underdeveloped provision has been detected for Hungary, Romania, Russia, Spain and the Ukraine, although, this assessment is based on rather sparse information particularly for Russia or the Ukraine. Some institutions are said to offer programmes and new curricula have been developed with the support from

\footnotetext{
${ }^{14}$ Not all institutions contributing to Erasmus Mundus degrees in planning are counted as some merely provide specialist modules and not full planning programmes.
} 
Table 2

Institutions offering planning education in Europe.

\begin{tabular}{|c|c|c|c|c|c|c|c|}
\hline Country & Institutions & Pop (mio) & $\begin{array}{l}\text { Ratio } \\
\text { Pop:Inst }\end{array}$ & Country & Institutions & Pop (mio) & $\begin{array}{l}\text { Ratio } \\
\text { Pop:Inst }\end{array}$ \\
\hline Albania & 3 & 3 & 1 & Lithuania & 1 & 3,5 & 3,5 \\
\hline Andorra & 0 & 0,08 & - & Luxembourg & 0 & 0,5 & - \\
\hline Armenia & 1 & 3 & 3 & Malta & 1 & 0,4 & 0,4 \\
\hline Austria & 3 & 8,2 & 2,7 & Moldova & $\mathrm{Nd}$ & 3,7 & - \\
\hline Azerbaijan & $\mathrm{Nd}$ & 9,5 & - & Monaco & 0 & 0.03 & - \\
\hline Belgium & 3 & 10,4 & 3,5 & Montenegro & $\mathrm{Nd}$ & 0,65 & - \\
\hline $\begin{array}{l}\text { Bosnia \& } \\
\text { Herzegovina }\end{array}$ & $\mathrm{Nd}$ & 4,6 & - & Netherlands & 9 & 16,7 & 1,5 \\
\hline Bulgaria & 1 & 7 & 7 & Norway & 7 & 4,7 & 0,7 \\
\hline Croatia & 1 & 4,5 & 4,5 & Poland & 40 & 38,4 & 1 \\
\hline Cyprus & $\mathrm{Nd}$ & 1,1 & - & Portugal & 9 & 10,8 & 1,1 \\
\hline Czech Republic & 3 & 10,2 & 3,4 & Romania & 2 & 22,9 & 22,9 \\
\hline Denmark & 2 & 5,5 & 2,7 & Russian Federation & 8 & 138 & 17,3 \\
\hline Estonia & 2 & 1,3 & 0,6 & San Marino & 0 & 0,03 & - \\
\hline Finland & 4 & 5,3 & 1,3 & Serbia & 1 & 7,3 & 7,3 \\
\hline France & 20 & 65,6 & 3,3 & Slovakia & 1 & 5,5 & 5,5 \\
\hline Georgia & $\mathrm{Nd}$ & 4,6 & - & Slovenia & 1 & 2 & 2 \\
\hline Germany & 10 & 81 & 8,1 & Spain & 3 & 47 & 15,7 \\
\hline Greece & 6 & 10,8 & 1,2 & Sweden & 7 & 9 & 1,5 \\
\hline Hungary & 1 & 10 & 10 & Switzerland & 7 & 7,7 & 1 \\
\hline Iceland & $\mathrm{Nd}$ & 0.3 & - & $\begin{array}{l}\text { The former Yugoslav } \\
\text { Republic of Macedonia }\end{array}$ & 1 & 2 & 2 \\
\hline Ireland & 3 & 4,7 & 1,5 & Turkey & 12 & 80 & 6,6 \\
\hline Italy & 12 & 61 & 4,7 & Ukraine & 1 & 45 & 45 \\
\hline Latvia & 1 & 2,2 & 2,2 & United Kingdom & 29 & 63 & 2,2 \\
\hline Lichtenstein & 0 & 0,04 & - & Kosovo (not CoE) & 1 & 2 & 2 \\
\hline Total : 218 & & & & & & & \\
\hline
\end{tabular}

$\mathrm{Nd}=$ no data; Pop: Institution ratio <5: good to excellent; Pop: Institution ratio 5-10: medium; Pop: Institution ratio >10: underdeveloped. 
Western academics (Hirt \& Stanilov, 2009; Forsyth \& Gross, 1998). However, Vaytens (2012, p. 188) asserts that planning education in Russia consists mostly of urban design taught in architecture schools.

\subsubsection{Institutional characteristics}

Planning degrees are offered through a wide range of academic schools and faculties ranging from architecture to the social sciences. Only in a few rare cases has planning managed to carve out its own (intellectual) space as with the Faculty of Spatial Planning at the University of Dortmund (Germany) which brings with it both opportunities and challenges (Frank, 2012).

The majority of planning education is delivered through public institutions, which form the backbone of higher education in Europe. Institutions usually have considerable autonomy, a right to self-governance and academic freedom although this is increasingly constrained via regulations, government demands for relevance of research and performance measures attached to funding arrangements (Fitzgerald et al., 2012). Following a Humboldtian tradition, institutions engage in both, research and teaching, albeit to varying degrees. It is common to distinguish between researchoriented and practice-based teaching institutions, or between institutions focusing on technical subjects and those specialising in humanities or arts. Naming conventions are country-specific and can be misleading. It is prudent not to make assumptions of equivalency when comparing cross-nationally. For example, in the UK former polytechnics, also known as "post-92 universities", are considered teaching-oriented institutions, while in other countries a similar sounding label Politechnika (Poland), or Politecnico (Italy) is used for top-ranked (technical) research universities. Planning is taught at research and practice oriented institutions alike.

Across Europe, national policies for privately delivered higher education range from conservative and a constitutional ban on establishing private universities (Greece) to a neoliberal approach that readily permits the creation of private institutions of higher education (e.g., Poland, Portugal, Spain). In contrast to the USA, private HEIs in Europe are typically less well regarded, small and specialised. They tend to run programmes such as marketing or business studies which do not require major investment in physical infrastructure while attracting large student numbers. Especially in post-communist countries the introduction of private HEIs in the 1990s helped to satisfy the exploding demand for tertiary education without further burdening government resources.
In Poland, the number of higher education institutions nearly quadrupled from $124(1992 / 193)$ to 470 (2010/2011) due to the newly founded private HEIs (Central Statistical Office, 2011). Although, public institutions still provide the majority of study places, private HEIs educate now about $25 \%$ of all Polish students. They are also increasingly entering the planning education market. In 2008/2009 only three private HEIs in Poland were running planning programmes, whereas in 2011/2012 this grew to 19 . A mixed provision of planning education through public and private HEIs can also be observed in Portugal and Albania.

There are stark differences in cost and access to higher education across Europe. Although, the UN International Covenant on Economic, Social and Cultural Rights (Article 13) as well as Article 2 of the First Protocol of the European Convention on Human Rights obliges all signatory countries to guarantee the right to (free) education, this usually applies only to primary and secondary education. Tertiary education is generally considered non-compulsory. Thus, universities can select which students they accept based on criteria such as entry exams, interviews or grades. The policy on tuition for higher education varies. In a few countries the right to free education extends to university level (i.e., Greece, Finland, Norway), in others a mixed system has been implemented (i.e., in Poland or Spain where public universities charge no fees while private institutions do). Finally, in some nations all institutions are charging fees (i.e., UK or the Netherlands). Regardless of national policies all students from EU member states must be treated equal to students of the country where an institution is located. Peculiarly, there is no clear interpretation whether free tertiary education applies only to Bachelor or also to Master level education. In Greece, first cycle higher education is free, but universities charge students for the second cycle. $\mathrm{PhD}$ students successfully sued universities (Skayannis, 2011) for free provision of doctoral studies. As a result, first and third cycle studies in Greece are free, whereas students have to pay for second cycle degrees.

The size of planning programmes varies from an annual intake of 10-15 students to 100 and more. In many countries core university staff members (fulltime) are expected to hold a doctorate, whereas practice-related teaching is covered by part-time tutors working in practice. In teaching and practice oriented institutions the proportion of teaching covered by parttimers can be substantial. 


\subsubsection{Curricula, delivery modes, pedagogy and emerging content}

There are no common core curricula or even universally agreed guidelines for planning education. The content of curricula is generally shaped by the overall approach towards planning. Especially, the level of design teaching differs greatly. Southern Mediterranean institutions tend to follow an urbanism tradition with a strong emphasis on urban and physical planning practice and education (Dühr, Colomb, \& Nadin, 2010, p.181) although this is changing gradually (Balducci, Fedeli, \& Pasqui, 2011; Giannakourou, 2005). In French and UK based programmes we find far less design teaching in planning due to their land management and strategic approaches in planning. Results from a recent study show considerable differences when comparing curricula in Europe along eight components (planning theory, planning techniques, social/economic environment, built environment, natural environment, planning products, planning instruments and thesis). For example, the proportion of planning curricula dedicated to teach planning techniques ranges from $2 \%$ to $39 \%$ and knowledge provision in respect to natural environmental factors ranges from $3 \%$ to $17 \%$ for selected exemplary programmes (ECTP-CEU, 2013b).

As for the purpose of planning we can detect an ever greater pluralism. In particular, the liberation of Central and Eastern Europe sparked a discourse which variably highlighted ecological, place based, market-oriented, communicative, pragmatic, or socially responsive paradigms (Gospodini \& Skayannis, 2005; Keller et al., 1996). Key themes in most European planning education programmes include urban renewal, (brown field) regeneration and shrinking cities, sustainability, environmental issues with related methods and techniques such as environmental impact assessment. New emerging topics are the link between planning and health, planning and food (security), and planning for continuous or abrupt changes in the environment and resiliency, planning for low carbon, energy efficient cities and European planning (Blanco et al., 2009a, 2009b; Morgan, 2009). While national legal frameworks increasingly require citizens' involvement in planning decisions and research evidence suggests that community planning can be highly effective, teaching of community involvement and participatory techniques as part of planning curricula is still not very prevalent. In countries such as Croatia and Albania which are transitioning from communism to capitalism, planning practitioners (and future planning graduates) need planning skills in managing illegal and uncontrolled development and uncertainty.
Associations like APERAU and AESOP have developed criteria and learning outcomes on which they evaluate and judge membership applications and/ or accredit planning programmes (Fig. 3). Yet, these are stated only at a conceptual level to allow for the incorporation of specific guidance at national level for programme and professional accreditation. Undergraduate programmes in planning typically introduce students to the basic concepts of urban and spatial planning. At master level two models can be observed: a specialist curriculum (e.g., MSc in Spatial Analysis and Environmental Management) primarily for students having already some spatial planning (or related) background or a generalist curriculum (MSc in City and Regional Planning) (see also Section 3.3.3). As a rule, master degree curricula have a more theoretical profile and focus on developing students' research skills.

The degree to which specialisations are captured in programmes and their visibility differs. In part, this is a function of the way degrees are named and marketed. For example, in the UK, Ireland or Greece programme foci, especially at Master level, are readily discernible from programme titles, whereas elsewhere themes become only apparent through different specialisations under general degree labels.

Pedagogically, planning programmes incorporate a wide variety of teaching methods. The balance between classical formats such as lectures, seminars and design studios or project work varies. Some master programmes have adopted large integrative projects as signature pedagogy (Peel, 2011) seeking to offer students a simulated practice setting. Projects may be client-based ('life') projects whereby students are directly engaged in developing a solution to a contemporary problem in a locality or community. Group work is common and interdisciplinary modules are explored on occasions (Ellis et al., 2008) but not standard. Some programmes also include assessed periods in practice of different lengths as a means to complement theoretical knowledge with practical professional skills development. Practically all planning education programmes in Europe are residential programmes, which can be studied either fullor part-time. Programmes increasingly employ blended learning but this does not change the main delivery mode of face-to-face instruction. One exception is the Joint Distance Learning MA in Town and Country Planning, established in 1985 and delivered through a consortium of four UK planning schools together with the UK's Open University (see Section 4.6). Universities also employ more and more block teaching to cater for professionals' and their needs (Keller \& Blaser, 2005). As one would expect, planning is taught in many different languages, 


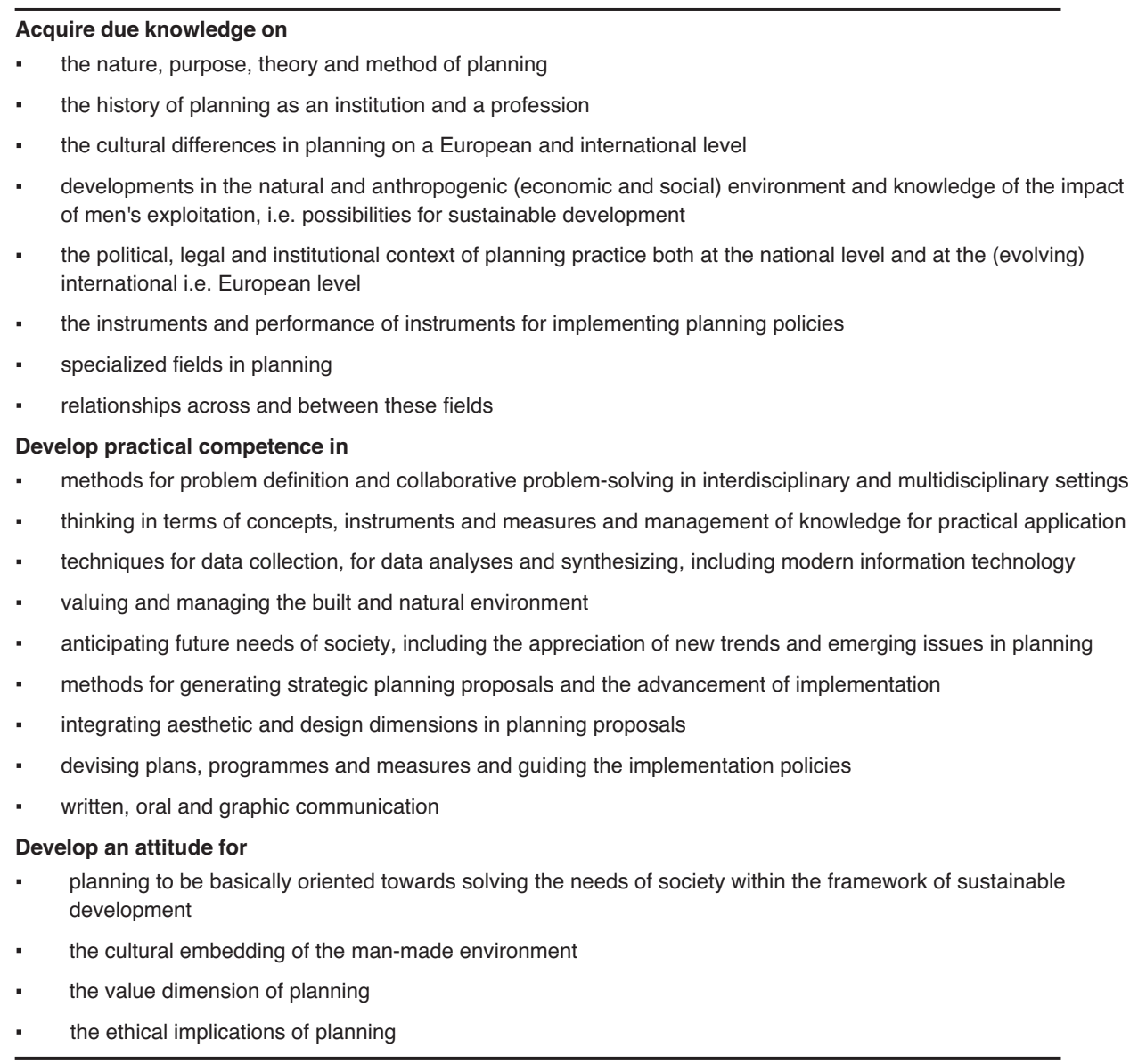

Fig. 3. AESOP's core curriculum (Geppert \& Verhage, 2008. pp. 24-25).

yet, especially at universities in Northern Europe ${ }^{15}$ there is a trend to teach at master level partially or entirely in English (see Section 3.3.3).

Post 1989, Kunzmann (1991) detected a change in focus of planning education and research by European providers away from international and development planning towards Eastern Europe and European affairs. On one hand the demise of communism created a new set of interesting topics and issues for planners and on the other, many developing countries started to develop their own capacities in planning education. Nevertheless, a range of institutions still offer international development planning degrees at postgraduate or master level, mostly taught in English. UK programmes have been and remain attractive to students from the developing world (Godfrey \& Glasson, 1997). As of

\footnotetext{
${ }^{15}$ See for example: Delft University of Technology, Department of Urbanism (The Netherlands) or Royal Institute of Technology (KTH), Division of Regional Planning, Stockholm (Sweden).
}

2012 six UK planning schools offered degrees in this area: Cardiff University, MSc International Planning and Development; London South Bank University, MA in Spatial Planning in Developing Countries; Oxford Brookes University: MSc Urban Planning in Developing and Transitional Regions; University College London, MSc International Planning; The University of Sheffield, MA International Development and Planning; University of Westminster, MA International Planning and Sustainable Development. In the Netherlands, the MSc in Geographic Information Management and Application provided jointly by four Dutch institutions seeks to educate GIS specialists including those from abroad. ${ }^{16}$ One of the partners, the International Institute of Geo-Information Science and Earth Observation (Enschede), specialises in capacity building for participants from economically and/or technologically less developed countries through

\footnotetext{
16 http://www.msc-gima.nl/index.php/distinguishing-features.
} 
postgraduate programmes which alternate short intensive face-to-face classroom periods with extended periods of self-study. The Technical University of Dortmund (Germany) runs an International Joint Degree, the MSc Spatial Planning for Regions of Growing Economies (SPRING) since 1984 in partnership with universities in Ghana, Tanzania, the Philippines and Chile. In 2007, Portuguese universities started short intensive programmes for Portuguese speaking countries in sustainable planning and the Mundus Urbano (see Section 3.3.1) also caters for people aspiring to work in international development. A new trend is to deliver programmes at European Institution's foreign campuses or in cooperation with allied institutions locally in China, Asia-pacific countries or the Arab world rather than bringing foreign students in great numbers to European institutions. Planning education programmes are so far not the main subjects but some exist. ${ }^{17}$

\subsubsection{Academic and professional networks}

Networking is important for any field to progress ideas, disseminate research, exchange experiences, benchmark quality standards and stimulate innovations. Many, but not all, institutions offering planning education in Europe are members of one or more (international) planning schools associations. Two of the largest networks are AESOP founded in 1987 with nearly 150 European members, and APERAU. The latter caters to institutions providing planning education in French with 20 schools from France and other French language regions in Europe as well as additional members from North Africa, Canada and Asia. Associations organise conferences, summer schools for students and planning professionals, workshops for $\mathrm{PhD}$ students, prizes for papers and teaching, and offer a platform to advertise jobs, publications and education programmes. AESOP's effort to recruit schools from Eastern European countries (e.g., Russia, Ukraine, Latvia, etc.) has had only limited success to date (Banachowicz, 2012). Other European regions with low membership in international associations are Spain, the Western Balkans and Turkey (although the Turkish Planning Schools Association - TUPOB - offers a national platform for exchange). Costs, language, and politics have been identified as factors contributing to the low take-up of membership. Lack of understanding the value of membership may prevent schools from joining although many Central European countries have

\footnotetext{
${ }^{17}$ http://www.xjtlu.edu.cn/en/admissions/postgraduate/masters-degree/ programmesmaster-degree.html?layout=edit\#10.
}

found their participation in international networks invaluable for the development of their programmes (Frank \& Mironowicz, 2009). Overall there is partial overlap between the geographical coverage of APERAU, AESOP and TUPOB. Some institutions maintain dual memberships. Both AESOP and APERAU were founding members of an international network of associations established in 2001, the Global Planning Education Association Network (GPEAN) which seeks to foster communication and exchange amongst planning educators and researchers, globally (Stiftel et al., 2009).

Additionally, many schools also maintain links with professional associations and societies at national and international level such as ECTP-CEU. Some professional bodies are involved in programme accreditation, but in other cases this is a task taken on by the state. There are also countries where planning schools are free to develop curricula as they see fit without being bound by accreditation guidance.

\section{Country case studies}

The case studies below provide descriptions of the education for planning in seven European countries (Portugal, Spain, Finland, Poland, Slovakia, United Kingdom and Switzerland). The cases offer insights into how the planning education provision has been influenced and altered through European policies, the Bologna declaration, and general trends affecting the higher education sector. The two case studies from different transition countries (Poland and Slovakia) illustrate that the approaches to adapting and developing the provision for planning education post communism diverge. We have also included two countries with a technical urbanism and design focus in respect to planning to explore if pathways for future development of planning education would be predictable in the context of European drivers. Finland, United Kingdom and Switzerland were chosen to complete the range of planning families and traditions identified by comparative studies of European planning traditions (Newman \& Thornley, 1996).

Case studies are narrative and follow a simple template with a preamble, an overview of the higher education structures in the country concerned, the history of planning education and a section on the current planning education provision. This section covers issues such as guidelines or curriculum requirements, undergraduate and postgraduate provision as well as continued professional development and doctoral education opportunities. As there are considerable differences amongst countries not all subsections of 
the template are equally applicable. While each case concludes with a brief summary, the wider discussion has been reserved for Section 5 .

\subsection{Portugal}

Planning in Portugal, although widely practiced, is not fully recognised as an independent profession. Education for planning exists but remains to large extent (albeit not entirely) a specialisation or specialist stream within architecture or civil engineering. The provision reflects the dominant character of planning practice which typically emphasises blue print plans, morphology, physical layout and aesthetical concepts over socio-economic or regional science-based approaches (e.g., Rodriquez-Bachiller, 1988). Although graduates holding autonomous planning degrees are slowly emerging in key positions, the majority of individuals in senior planning posts are still architects and civil engineers complemented by the occasional geographer and landscape architect (Correia, 2004).

The social status of the profession has seen significant ups and downs. It was, for example, prestigious to work as a planner during the 1980s when Portugal joined the European Economic Community (EEC). At that time, legislation in Portugal instigated that plans had to be produced for all Portuguese municipalities and town centres (Correia, 2004) which made planning an important technical and political task for local governments. Deregulation policies of the 1990s had adverse effects on the reputation of the profession but similar to elsewhere a rising awareness of environmental problems and a need to develop plans for sustainable urban and rural environments has helped to recover the image of planners and planning.

\subsubsection{Higher education structures}

In Portugal, as of 2011, there were 28 institutions of higher education (13 universities and 15 polytechnics which developed from former industrial, administrative or vocational schools); they are either public (state-run), or privately (including church) operated. The major centres for higher education are Lisbon and Porto, although new higher education institutions were established in late 1970s and 1980s in secondary towns such as Minho, Aveiro, Évora, Nova de Lisboa, Trás-osMontes and Beira Interior to enrich the Portuguese higher education landscape.

The implementation of Bologna reforms was slow and up to 2005/2006, universities offered only programmes, which followed the standard continental structure leading to a degree equivalent of a Masters
(Dima, 2005) over 4-6 years. Many universities have since restructured their degrees offering a first cycle Bachelor of 3 years (180 ECTS) (Portuguese: licentiatura) and a second cycle Master degree (90-120 ECTS) (Portuguese: mestrado). Confusingly, a number of institutions also kept the traditional long-cycle programmes running in parallel. A trend from 2005 onward has been to discontinue undergraduate planning degrees and offer only Masters. Moreover, a number of programmes that run specialisations in planning within the first cycle (undergraduate) have dropped these in the process of restructuring focusing only on the parent or main discipline such as geography, engineering or architecture. It seems that the Bologna reform in Portugal has led to a reduction of the provision of planning education, especially at the Bachelor level.

\subsubsection{History of planning education}

First elements of formal planning education emerged in Portugal in the mid-1940s, when optional onesemester modules in planning were introduced by three universities, including 'Improvements in Urban Planning' at the University of Porto (Faculty of Engineering), and 'Urbanology' at the College of Fine Arts in Lisbon and Oporto (Dos Santos, 1998; Lourenço, 2003). It then took nearly 30 years until in 1973 the first specialisations in (spatial) planning were approved within the Civil Engineering programme at Lisbon Technical University (Correia, 2004) and at the University of Porto. In 1980, a 4-year undergraduate programme in geography with a specialisation in regional planning was established at the University Nova de Lisboa in the Faculty of Social Sciences. Finally, in 1982 and 1983, respectively, the first autonomous planning programmes were established: a 2-year postgraduate degree in urban and regional planning at the Technical University of Lisbon (Instituto Superior Técnico) (Correia, 2004; Dos Santos, 1998; Lourenço, 2003) and a 5-year degree in urban and regional planning at the University of Aveiro.

From thereon, opportunities to obtain an education for planning became more plentiful either via:

1) autonomous programmes in planning as first degree (4- to 5 years),

2) post-graduate/postprofessional programmes (1-2 years), and

3) specialisations within architecture, geography or civil engineering degrees, both at undergraduate and master level (Lourenço \& Klein, 2001; Lourenço, Guedes, Filipe, Almeida, \& Moreira, 2007). 


\subsubsection{Planning education now}

Developing a comprehensive overview of the provision of planning education in Portugal is difficult due to the variety of ways to obtain a degree in planning and the fact that even today Bologna related restructuring of programmes is not completed. Table 3 lists the programmes offered in the academic year 2010/2011. While there are 10 institutions offering education for planning, only one (private!) institution University Lusófona de Humanidades e Tecnologias in Lisbon - runs at the moment an autonomous programme in planning at the Bachelor level (3 years, 180 ECTS). The other two institutions (University of Azores; Lisboa Technical University) offer merely undergraduate degrees with a planning specialisation option. The remainder of planning education programmes are at master level as this fits better with the institutional and legal framework of Portuguese higher education.

\subsubsection{Guidelines and accreditation}

Higher education provision in Portugal is regulated and accredited by the Ministry of Education on the basis of state approved guidance and standards. For civil engineering or architecture programmes, accreditation is conducted through government-recognised professional bodies and their respective National Boards (NB of Civil Engineers, NB of Architects). Professional bodies regulate the profession and approve legally recognised professional titles. Three professional planning associations exist: the Portuguese Association of Town Planners, the Portuguese Association of Spatial Planners, and the Professional Association of Portuguese Urban Planners, but while they have been collaborating to gain National Board status for planning and legal recognition of the profession, they have not succeeded to date. As a result, the Ministry of Education has not issued state guidance and standards for planning.

Table 3

Planning education programmes in Portugal in 2010/2011.

\begin{tabular}{|c|c|c|c|}
\hline Institution & Bachelor/1st cycle & Master/2nd cycle & AESOP \\
\hline University of Aveiro & & Urban and Regional Planning (Masters, 2 yrs) & Yes \\
\hline University of Minho & & Master in Urban Engineering (Masters, 2 yrs) & \\
\hline $\begin{array}{l}\text { University of Porto (Faculty of } \\
\text { Engineering and Architecture) }\end{array}$ & & $\begin{array}{l}\text { Civil Engineering with specialisation in } \\
\text { Planning (Masters, } 2 \text { yrs) }\end{array}$ & Yes \\
\hline University of Coimbra & & $\begin{array}{l}\text { Civil Engineering with specialisation in } \\
\text { Transport \& Urban Planning (Masters, } 2 \text { yrs) }\end{array}$ & \\
\hline $\begin{array}{l}\text { Lisbon Technical University } \\
\text { (Faculty of Architecture) }\end{array}$ & $\begin{array}{l}\text { Architecture: with specialisation in } \\
\text { Urban \& Regional Planning } \\
\text { (Bachelor, } 5 \text { yrs) } \\
\text { Architecture: with specialisation in } \\
\text { Urban management (Bachelor, } 5 \text { yrs) }\end{array}$ & & Yes \\
\hline $\begin{array}{l}\text { Technical University Lisbon } \\
\text { (multiple faculties including } \\
\text { Architecture, Social and } \\
\text { Political Sciences, } \\
\text { Economics, etc.) }\end{array}$ & & Master in Territorial Planning (Masters, 2 yrs) & Yes \\
\hline Lisbon New University & & $\begin{array}{l}\text { Human Geography and Regional Planning - } \\
\text { Territorial Management (Masters, } 2 \text { yrs) }\end{array}$ & Yes \\
\hline University of Lisbon & & $\begin{array}{l}\text { Human Geography, Urban and Regional } \\
\text { Planning (Masters, postgraduate, } 1 \text { yr) }\end{array}$ & Yes \\
\hline University of Azores & $\begin{array}{l}\text { BA in Environmental Management } \\
\text { and Engineering ( } 3 \text { yrs) } \\
\text { BA in Nature Management and } \\
\text { Conservation ( } 3 \text { yrs) }\end{array}$ & $\begin{array}{l}\text { MA in Nature Management and } \\
\text { Conservation ( } 2 \mathrm{yrs}) \\
\text { MA in Environmental Engineering ( } 2 \mathrm{yrs}) \\
\text { MA in Landscape, Biodiversity and } \\
\text { Society ( } 2 \text { yrs) }\end{array}$ & \\
\hline $\begin{array}{l}\text { University Lusófona de } \\
\text { Humanidades e Tecnologias } \\
\text { in Lisbon (private institution) }\end{array}$ & Bachelor in Planning ( 3 yrs) & Master in Planning (2 yrs) & Yes \\
\hline
\end{tabular}


With no National Board for planners and no guidance and standards for planning education, universities teaching planning are theoretically free to develop curricula as they see fit. However, this freedom comes at a price: there is no legal framework to accredit planning programmes. As students favour accredited programmes, planning is at a distinct disadvantage. Therefore, universities usually try to develop planning curricula, which meet the framework requirements as defined by the NB for Engineers or Architects for programmes in engineering or architecture. These requirements provide guidance on minimum numbers of credits associated with particular categories of knowledge (preparatory, technical or design). The differences in the weighting of these knowledge categories for Architecture and Civil Engineering are considerable at undergraduate level but become relatively minor at master level. Overall, in architecture more focus is placed on design, whereas in civil engineering technical aspects receive greater weighting (Table 4).

In addition to following framework requirements from the NB of Architects and Civil Engineers, planning programme providers have also extracted learning outcomes from guidelines of cognate fields such as Architecture (ARCH), Landscape Architecture (LAND), Economics (ECON), Engineering (ENG), Environmental Studies (ENV), Geography (GEO), and Sociology (SOC) to define a pseudo core curriculum for planning masters. This list serves as informal guide and quality assurance benchmark (Fig. 4).

Table 4

Framework structure and requirements for architecture and civil engineering programmes in Portugal.

\begin{tabular}{lcc}
\hline & $\begin{array}{l}\text { Architecture } \\
\text { ECTS }\end{array}$ & $\begin{array}{l}\text { Civil Engineering } \\
\text { ECTS }\end{array}$ \\
\hline $\begin{array}{l}\text { Bachelor } \\
\begin{array}{l}\text { Preparatory: Basic science } \\
\text { and drawing }\end{array}\end{array}$ & 80 & 70 \\
$\begin{array}{l}\text { Technical: Building, structures } \\
\text { and infrastructures }\end{array}$ & 50 & 100 \\
$\begin{array}{l}\text { Design: Composition, projects } \\
\text { and urban planning }\end{array}$ & 50 & 10 \\
$\begin{array}{l}\text { Total } \\
\text { Master } \\
\text { Technical section: Building. } \\
\quad \text { Structure. Infrastructures }\end{array}$ & 50 & 180 \\
$\begin{array}{l}\text { Design section: Composition. } \\
\text { Projects. Urban Planning }\end{array}$ & 40 & 60 \\
Master Thesis & 30 & 30 \\
\begin{tabular}{l} 
Total \\
\hline
\end{tabular} & 120 & 30 \\
\hline
\end{tabular}

\subsubsection{Master in planning}

Within the framework requirements (Table 4) and the list of learning outcomes (Fig. 4), considerable freedom and flexibility remains to develop master programmes in planning. This is illustrated via three exemplary programmes from the University of Aveiro, Lisbon Technical University, and the University of Minho (Table 5). The dearth of practice-oriented modules corroborates Correia's (2004, p. 437) statement about the theoretical focus of Portuguese higher education. Project work or placements are only listed for the Master in Urban and Regional Planning at Aveiro, and the Master in Territorial Planning at Lisbon. In both cases this element takes up only $10 \%$ of the programme. Another characteristic is the lack of optional courses with practically none for the Master in Territorial Planning at Lisbon (although keen students can widen their knowledge by taking additional credits) and while there are specialisation streams available for the Master at Minho, within these streams there is no choice. The credits for master theses vary from 21 to 60 ECTS suggesting significant differences in research expectations at different institutions. Further examples of curricula offering planning as a specialisation within Masters of Civil Engineering and Architecture are provided in the online resources (Table II).

\subsubsection{Doctoral studies}

Given the strong research focus and theoretical orientation of higher education in Portugal is it not surprising that support for and interest in doctoral studies is well developed. A doctoral qualification is already a de facto requirement for a position in academia. Since the mid-1990s, the majority of $\mathrm{PhD}$ students are fully funded. In some cases candidates are employed as teaching assistants. In recent years, industry funded $\mathrm{PhDs}$ have come on stream and a few enterprises are supporting employees wishing to upgrade their qualifications. The number of individuals engaged in doctoral studies in planning is difficult to determine though, as with the exception of the University of Aveiro (Urban and Regional Planning) and Lisbon Technical University (Spatial Engineering), there are no specific planning PhD programmes. In fact, many planning-related theses are conferred in Civil Engineering, Architecture or Geography, respectively. A conservative estimate is an output of 20 planning PhDs per annum.

\subsubsection{Conclusion, evaluation and outlook}

The number of full programmes (undergraduate or graduate) in planning in Portugal is relatively limited 


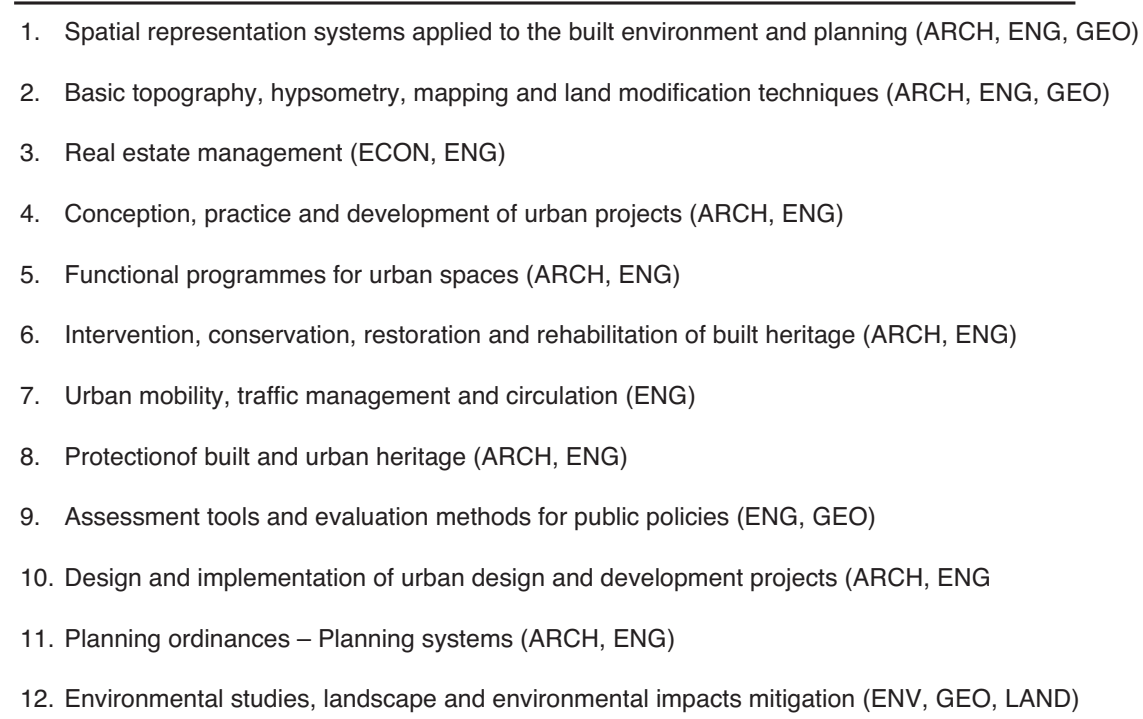

13. General theories on form, composition and architectural types (ARCH, ENG)

14. Studies on social needs, quality of life, liveability and housing (ARCH, ENG, GEO, ECON)

15. Ecology, sustainability and conservation of energy and environmental resources (ENV, GEO, ENG, LAND)

16. Urban and regional planning and landscape traditions in Western culture and their technical, climatic, economic, social and ideological underpinnings (ENG, ARCH, LAND)

17. Architects cultural patterns and social responsibilities $(\mathrm{ARCH})$

18. Urban sociology, theory, economics and history (ECON, SOC)

19. Urban, regional and metropolitan planning methodological principles (ENG, GEO, ARCH)

20. Urban planning drawings and plan management (ENG, ARCH)

21. Civil, administrative, planning, building and industry regulations related to professional practice (ENG, $\mathrm{ARCH})$

Fig. 4. Key learning outcomes, knowledge and skills for masters in planning in Portugal.

and planning-related programmes are centred at institutions with a technical profile (architecture or civil engineering). University Lusófona de Humanidades e Tecnologias in Lisbon is the only institution offering planning degrees at all levels: Bachelor, Master and Doctoral. All other HEIs offer only Master and doctoral level planning education or planning as a specialisation of another discipline.

Planning practice, in spite of the existence of three professional associations, is (still) dominated by professionals trained as civil engineers or architects and the planning profession is not fully recognised. There is no professional body empowered to accredit programmes in planning. At the Bachelor level there are no guidelines for planning programmes and the definition of the core curriculum in planning at Master level has an informal character and is not institutionally approved.
One may hope that this ambiguous situation is resolved in the not too distant future as many young, highly qualified planning academics (many with $\mathrm{PhDs}$ from countries other than Portugal) can be seen to engage actively in planning education discourses at European level, especially in AESOP while planning professionals are participating in international planning organisations and practitioner networks (i.e., ECTPCEU, IFHP, ISOCARP).

\subsection{Spain}

Since the establishment of a planning system in the mid 1950 (Ryser \& Franchini, 2008), the planning process in Spain is characterised by an emphasis on zoning, master and detailed plans for infrastructure development. There is no spatial planning profession 
Table 5

Selected programmes in planning at master level 2011/2012.

Technical University Lisbon:

Master in Territorial Planning ${ }^{a}$

Compulsory modules (Total 120 ECTS)

Law of Urbanism and Environment

4,5 ECTS

Traffic Engineering

6 ECTS

Management and Evaluation Systems and Projects

6 ECTS

Urban Planning

4,5 ECTS

Seminars on Sustainable Development

3 ECTS

Urban Sociology

3 ECTS

Theories and History of the City

3 ECTS

Urban and Regional Economics

3 ECTS

Communal Facilities

3 ECTS

Urban Management

3 ECTS

Environmental Impacts

6 ECTS

Met-Project

9 ECTS

Geographic Information Systems

4,5 ECTS

Analysis and Data Processing

4,5 ECTS

Regional Development and Community Policies

4,5 ECTS

Integrated Watershed Management

4,5 ECTS

Applied Ecology

Strategic Environmental Assessment

4,5 ECTS

Performance Evaluation

4,5 ECTS

Eco-hydraulics

Management of Urban Mobility

4,5 ECTS

4,5 ECTS

Solid Waste Management

4,5 ECTS

Dissertation

4,5 ECTS

21 ECTS

Optional (Total 9 ECTS)

Coastal Zone Management

Regions and Networks

4,5 ECTS

University of Aveiro: Master in Urban and Regional Planning

Compulsory modules (Total 108 ECTS)

Urban Forms

6 ECTS

Strategic Territorial Planning

6 ECTS

Environmental Systems and Sustainability

6 ECTS

Planning Support Techniques

6 ECTS

Mobility Planning

6 ECTS

Environmental Development Strategies

6 ECTS

Socio-Economic and Territorial Dynamics

6 ECTS

Urban Planning

6 ECTS

Planning Systems and Policies

6 ECTS

Legislation and Urban Administration

6 ECTS

Territorial, Regional Policies and Innovation

6 ECTS

Project/Placement

12 ECTS

Dissertation

30 ECTS

Optional modules (Total 12 ECTS)

Option I

6 ECTS

Option II

6 ECTS

University of Minho: Master in Urban

Engineering $^{\mathrm{b}}$

Compulsory modules (Total 120 ECTS)

Geographical Information Systems

7,5 ECTS

Investment Assessment

7,5 ECTS

Urban Planning

7,5 ECTS

Water Resources Management

7,5 ECTS

Research \& Development Project - Dissertation

60 ECTS

Specialization Area (students select either A, B, or C):

A - Sustainable Cities:

Environmental Urban Management

Research Methodologies

7,5 ECTS

Sustainable Mobility

7,5 ECTS 
Table 5 (Continued)

University of Minho: Master in Urban Engineering ${ }^{\mathrm{b}}$

B- Environmental Hydraulics:

Management of Solid Waste and Water Infrastructure

7,5 ECTS

Research Methodologies

7,5 ECTS

Waster Waste Treatment

7,5 ECTS

Water Treatment

C - Roads Infrastructures:

Design and Construction of Pavements in Urban Roads

7,5 ECTS

7,5 ECTS

Management and Rehabilitation of Urban Roads

7,5 ECTS

Research Methodologies

7,5 ECTS

Trenches: Design, Security, Construction and Quality Control

7,5 ECTS

\footnotetext{
${ }^{\text {a }}$ https://fenix.ist.utl.pt/cursos/met (accessed Aug 2012).

b http://www.civil.uminho.pt/meu_uk.htm (accessed October 2010).
}

per se and planning in Spain is predominantly led by architects who have specialised in urban design and larger scale planning (Lamiquiz, 2004, p. 321; Rodriquez-Bachiller, 1988). Deregulation policies in the 1990 and early 21 st century together with a lack of clarity in administrative policies have led to widespread sprawl, development scandals and rampant real estate speculation, which have in turn reflected negatively on urban and spatial planning and brought the planning profession into disrepute. Whether the profession can capitalise on the renewed interest in planning based on its acknowledge role in creating sustainable cities and communities is unclear as higher education and education for planning remains strongly bound to past traditions.

\subsubsection{Higher education structures}

Spain's university tradition is legendary: the University of Salamanca (established 1218) and University of Valladolid (established 1241) are among the oldest institutions in Europe. As of 2011/2012 there were 78 institutions providing higher education in Spain of which 13 are church-operated, 15 private and the remaining 50 are public institutions. Regardless of their ownership status, universities are structured into schools, where technical studies are offered (i.e., architecture and engineering), and faculties, which are devoted to other sciences (geography, law, economics, sociology, medicine, etc.).

The Bologna reforms proofed to be difficult to implement in Spain as the structure of higher education degrees differs significantly from other models in Europe. Spanish universities usually offer 4- to 5-year 1st cycle programmes for academic and engineering subjects and shorter professional degrees of 3 years, for example, in Nursing or Social Work. These are not considered equivalent to a bachelor. It was not until 2006, when second cycle (Masters) and 2008, when first cycle (Bachelor) degrees were to be introduced (Parliament of the Kingdom of Spain, 2007a) with the implementation to be completed in 2010/2011. Following resistance from academics and professionals in the fields of architecture and engineering the postBologna national framework in Spain was revised and now differs from frameworks adopted elsewhere in Europe by allowing longer first cycle degrees of 4- to 5-year duration in architecture and engineering. Second and third degree cycles are however in line with the requirements in other Bologna signatory countries (Table 6).

\subsubsection{History of planning education}

Traditionally, in Spain, urban and regional planning education has been delivered exclusively through Schools of Architecture focusing on the design of urban environments and, to a lesser extent, on urban planning, land management and environment (Ninot Pie, 2005). Around $40 \%$ of all institutions in Spain (17 public, 14 private) offer some level of planning education as a minor or major component of programmes in architecture. From the mid-1970s onward planning-related modules have been also introduced within the faculties of geography as well as civil engineering, law and environmental sciences. This broadened the perspective of planning as a field of study and profession. Nevertheless, schools of architecture still offer the highest number of credits for modules relating to planning.

The sector is very slow to embrace change. A case in point is, that despite of the University Reform Act of 1983 which specifically created the possibility of establishing degrees in the field of urban planning, traditional affiliations and naming conventions prevailed for nearly 25 years until the first autonomous Masters in Urban Design, Planning and Sustainability at the University of Madrid was established just recently.

\subsubsection{Planning education now}

Even today, Spain has no independent undergraduate programme in planning. The model of planning education remains that of planning as a specialism or 
Table 6

General degree structures in higher education (post-Bologna).

\begin{tabular}{lll}
\hline Undergraduate level & $\begin{array}{l}\text { Licentiates and engineers } \\
\text { (both Bachelor), architects }\end{array}$ & $8-10$ semesters \\
Postgraduate level & $\begin{array}{l}\text { Specialisation modules } \\
\text { Master modules }\end{array}$ & $1-2$ semesters \\
Doctorate level & Compulsory modules & $4-6$ semesters \\
& PhD research & - \\
\hline
\end{tabular}

extension of other disciplines or fields. So, aside from planning education as a specialisation in first cycle degrees, a range of institutions offer postgraduate (postprofessional) diplomas, degrees, or certificates to upskill architects, geographers or lawyers. For example, the Technical University of Madrid through its Urban and Regional Planning Department runs two such programmes: Urban Planning and Urban Studies. These programmes, lasting generally 1 year and exceptionally 2 , offer specialised training in urban legislation, construction legislation, real estate management, urban design, public administration, urban anthropology, etc. and target recent graduates and professionals practicing planning. The newly created 2-year Master in Urban Design, Planning and Sustainability at the University of Madrid represents a departure from this approach offering a more comprehensive and generalist education for planning, yet it is the only such programme at present.

\subsubsection{Guidelines and accreditation}

The legislation for adapting study programmes to the Bologna framework (Parliament of the Kingdom of Spain, 2007a) initially foresaw curricula leading to a Bachelor of 180-240 ECTS and the curriculum leading to a Master degree requiring 60-120 ECTS in both compulsory and optional courses in a variety of teaching forms (seminars, tutorials, external professional practice). Additional activities may be required for those seeking to obtain a professional title, e.g., an internship. For a master degree students also need to prepare and publicly defend a thesis comprising of 6-30 ECTS. The proposed structure $(3+2$ years for undergraduate and master levels, respectively) was however deemed insufficient for studies in architecture and vehemently opposed. As a result, the education requirements to practice the profession of architecture (and by association planning) was increased to 300 ECTS (5 years) for the first cycle and 60 for the second cycle (1 year) distributed in different subject areas (Table 7) (Parliament of the Kingdom of Spain, 2010). In respect to planning, specific sets of skills and learning outcomes for
Table 7

Compulsory modules ${ }^{\mathrm{a}}$ and ECTS for studies in architecture in Spain.

\begin{tabular}{lc}
\hline & ECTS \\
\hline Bachelor/1st cycle & 60 \\
Preparatory: Basic science and drawing & 60 \\
Technical: Building, structures and infrastructures & 100 \\
Design: Composition, projects and urban planning & 6 \\
Final degree project & $226(300)^{\mathrm{a}}$ \\
Total &
\end{tabular}

Master/2nd cycle

Technical section: Building. Structure. Infrastructures $\quad 8$

Design section: Composition. Projects. Urban planning 12

Master Thesis

30

Total

$50(60)^{\mathrm{a}}$

${ }^{a}$ The discrepancy of 74 ECTS at undergraduate and 10 ECTS at master level can be allocated according to the preference of each institution.

urban and spatial studies at schools of architecture were also defined (Parliament of the Kingdom of Spain, 2007b) for first cycle degrees (Fig. 5). However, similar guidance for the master level does not exist.

Considering that the majority of planning education is provided within architecture undergraduate degrees and no further guidance exists for 2nd cycle degrees, it is instructive to review selected undergraduate architecture programmes with a planning specialisation to better understand the character of the provision (Table 8). Module titles provide little detail and focus generically on urban design and urban/physical planning. They are typically intended to be studied in the later years of the first cycle with a progression from the local (neighbourhood) to regional scale. It is to be expected that knowledge in planning topics will be relatively basic as planning modules account for merely $10-15 \%$ of the entire degree (for example: $\max 36 / 300$ ECTS in CEU San Pablo, 51/300 ECTS at Polytechnic University of Valencia and 42/300 at Granada).

\subsubsection{Doctoral studies}

The list of scientific disciplines in Spain does not specify the field of planning per se. Universities confer a doctorate with the reference to the institution and faculty (which can be for example a department of urban and regional planning or architecture). Doctoral studies are highly individualised and students develop a plan for research training and activities together with their supervisors. Thus it is impossible to gauge the number of doctoral students engaged in planning related research topics. 


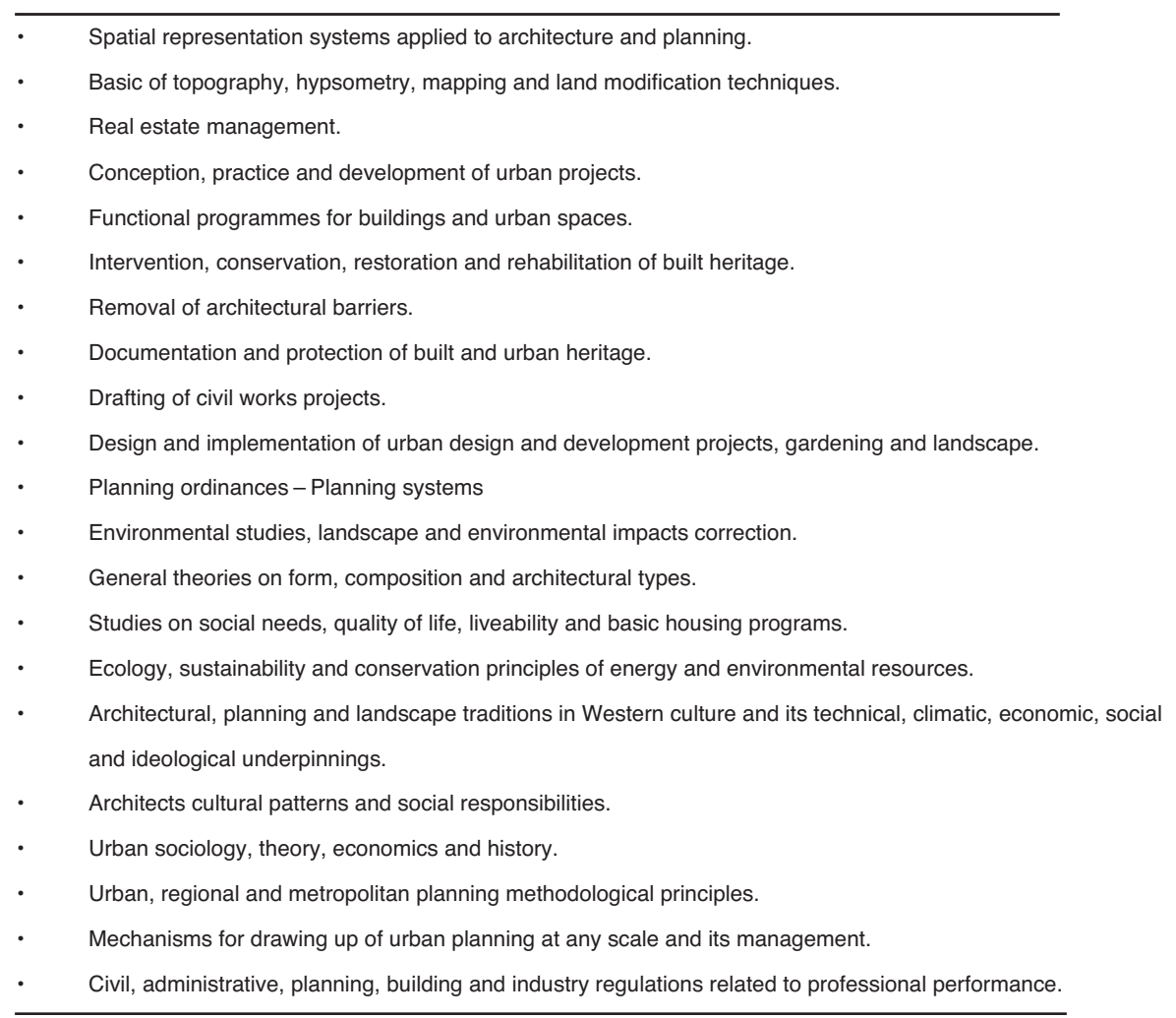

Fig. 5. Key learning content in urban studies at schools of architecture in Spain (Translated by Franchini).

\subsubsection{Conclusion, evaluation and outlook}

Similarly to the situation in other European countries, planning has not gained full legal or social recognition as an independent field of study, which underlines the concerns raised in the introduction in regard to the profile and status of planning as an independent field of work and study. Planning education in Spain does not exist as autonomous undergraduate programme. Planning-related modules at bachelor level are centred in schools of architecture and are a part of programmes in architecture. Yet, planning-related modules are also offered within programmes in geography, environmental studies, social sciences or law. A few universities offer postgraduate specialised and master programmes. The only institution in Spain delivering a comprehensive master programme in planning is the Technical University of Madrid, Department of Urban and Regional Planning.

There is no curriculum in planning as autonomous discipline, and unlike in Portugal not even an attempt to develop subject-specific guidelines for planning education informally. There is no professional body empowered to accredit programmes in planning, and for those programmes where planning is offered as a specialisation within architecture, curricula conform to the standards defined for Architects.

Finally, Bologna agreement implementation in Spain resulted in substantially different structures than in other European countries. In many fields the reforms have been rejected and the long-cycle programmes (associated with requirements for undergraduate level) remain in place. The second cycle has also a different profile than in other countries with mostly 1 year and only occasionally two-year degrees.

Sadly, at present, Spanish universities are not very active in European or international networks of planning educators or practitioners (AESOP, EURA, ECTP-CEU, IFHP, ISOCARP). There are only 5 institutional AESOP members and involvement hinges on a few individuals.

\subsection{Finland}

Planning in Finland is an established professional practice and receives much political and public attention. The city of Helsinki, for instance, has been carefully designed and planned since its establishment as capital in 1812. The modern Finnish Planning System is composed of a set of interlocking plans, 
Table 8

Examples of planning modules at the Bachelor level in Spain.

\begin{tabular}{|c|c|c|c|}
\hline \multicolumn{4}{|c|}{ Higher Polytechnic School, CEU San Pablo University, Madrid } \\
\hline Compulsory modules & Introduction to urban planning I & 3 ECTS & Year 2 \\
\hline \multirow[t]{7}{*}{ (Total 24 ECTS) } & Introduction to urban planning II & 3 ECTS & Year 2 \\
\hline & Urban design I & 3 ECTS & Year 3 \\
\hline & Urban design II & 3 ECTS & Year 3 \\
\hline & Urban planning I & 3 ECTS & Year 4 \\
\hline & Urban planning II & 3 ECTS & Year 4 \\
\hline & Urban and regional project I & 3 ECTS & Year 5 \\
\hline & Urban and regional project I & 3 ECTS & Year 5 \\
\hline Optional & Planning landscape & 6 ECTS & Year 5 \\
\hline (Total 12 ECTS) & Planning contemporary city & 6 ECTS & Year 5 \\
\hline \multicolumn{4}{|c|}{ Higher Technical School of Architecture of Valencia, Polytechnic University of Valencia } \\
\hline \multirow{4}{*}{$\begin{array}{l}\text { Compulsory modules } \\
\text { (Total } 33 \text { ECTS) }\end{array}$} & Urban planning I & 9 ECTS & Year 2 \\
\hline & Urban planning II & 9 ECTS & Year 3 \\
\hline & Urban planning III & 9 ECTS & Year 4 \\
\hline & Legal architecture, urban legislation and valuation & 6 ECTS & Year 5 \\
\hline \multirow{4}{*}{$\begin{array}{l}\text { Optional modules } \\
\text { (Total } 18 \text { ECTS) }\end{array}$} & Planning management & 4.5 ECTS & Year 5 \\
\hline & Informatics applied to planning & 4.5 ECTS & Year 5 \\
\hline & Environment and regional planning & 4.5 ECTS & Year 5 \\
\hline & Landscape and urban projects & 4.5 ECTS & Year 5 \\
\hline \multicolumn{4}{|c|}{ Higher Technical School of Architecture of Granada, University of Granada } \\
\hline \multirow{5}{*}{$\begin{array}{l}\text { Compulsory modules } \\
\text { (Total } 30 \text { ECTS) }\end{array}$} & Urban planning I & 6 ECTS & Year 3 \\
\hline & Urban planning II & 6 ECTS & Year 3 \\
\hline & Urban planning III & 6 ECTS & Year 4 \\
\hline & Urban planning IV & 6 ECTS & Year 4 \\
\hline & Urban planning $\mathrm{V}$ & 6 ECTS & Year 5 \\
\hline \multirow{2}{*}{$\begin{array}{l}\text { Optional modules } \\
\text { (Total } 12 \text { ECTS) }\end{array}$} & Urban history & 6 ECTS & Year $3,4,5$ \\
\hline & Planning and landscape & 6 ECTS & Year $3,4,5$ \\
\hline
\end{tabular}

legal obligations and procedures, as well as strategic documents guiding development with an orientation to the future. Following existing typologies, the Finnish Planning system has been characterised as comprehensive-integrated (European Commission, 1997; University of Valencia et al., 2006) or simply as Nordic (Newman \& Thornley, 1996), alluding to the similarity between Nordic states and especially the Nordic welfare systems. The most recent land-use and building law was ratified in 1999 fully replacing earlier legislation from 1959. One reason for the update was a perceived need to embed the communicative planning paradigm in legislation and strengthen public participation in planning processes.

\subsubsection{Higher education structures}

Finland has sixteen universities, which operate on principles of academic freedom and autonomy. The majority of universities are state-run with the government providing around $70 \%$ of their budgets. However, as of 2009, Aalto University and the Technical University of Tampere, have been converted into foundations mimicking economically independent funding models of universities in the USA and elsewhere. The introduction of this new model will likely lead to further changes in Finnish higher education, where so far universities, polytechnics/ universities of applied science, colleges, and a host of other higher education institutions for police and military exist side by side. All of them are supervised by the Ministry of Education but operated by different bodies. At present, university education (1st and 2 nd cycle) is still free of charge with the exception of a small annual membership fee that students at Bachelor and Master level are obliged to pay to the student union and for which they receive in return discounted meals, health care services and other social benefits. The emergence of the new foundation universities has triggered a public debate around the introduction of tuition fees - yet a decision on levels and models is still outstanding.

The Bologna declaration and proposals have been widely implemented although there are some differences for the two major routes through the system (Fig. 6). For the classical (more theoretically oriented) 


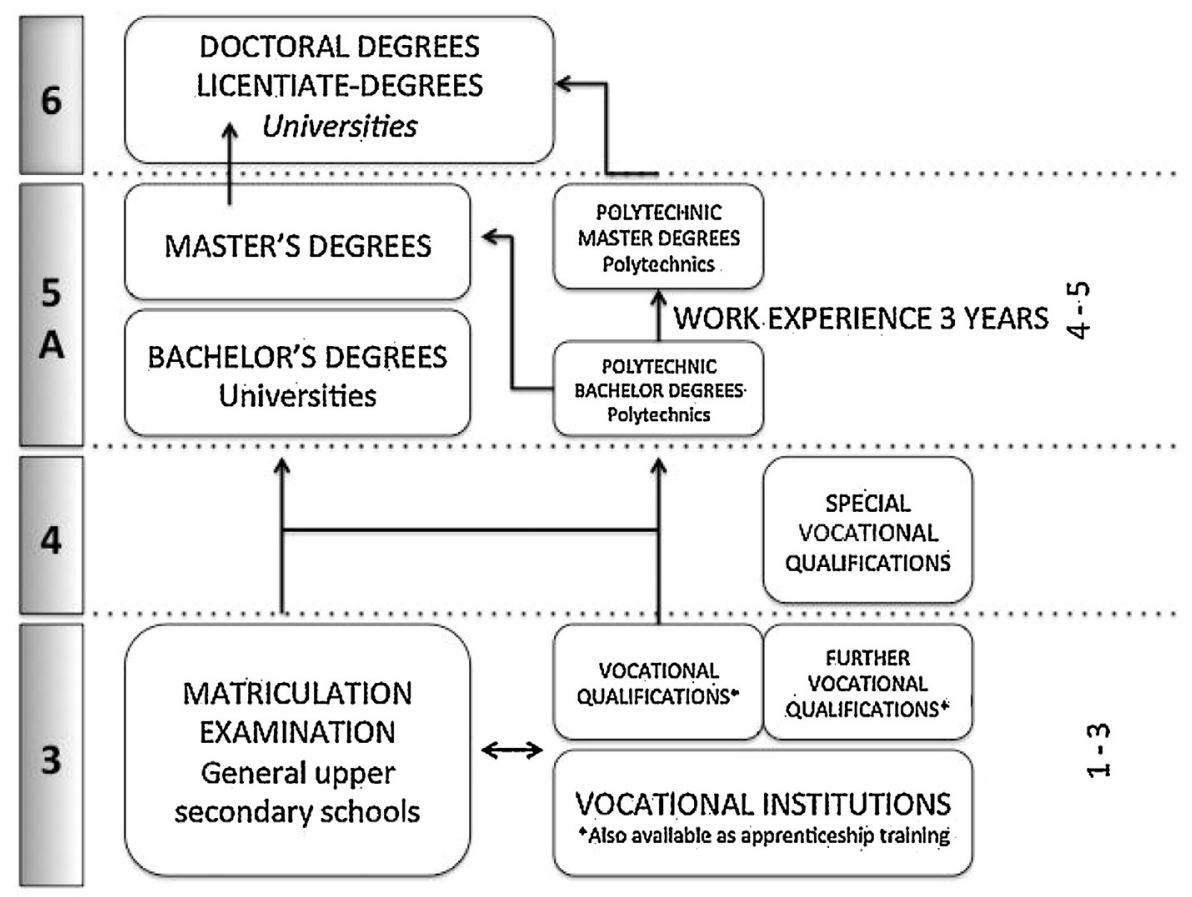

Fig. 6. Higher education in Finland (http://www.minedu.fi/export/sites/default/OPM/Koulutus/koulutusjaerjestelmae/liitteet/finnish_education.pdf Accessed 5.12.11). ISCED classification: 3 Upper secondary education, 4 post-secondary non-tertiary education, 5 first stage of tertiary education, 6 second stage of tertiary education.

university stream most of the programmes have nowadays a Bachelor (six semester) and Master (four semester) structure. Degree programmes at Polytechnics average eight semester for a Bachelor in Science, and are followed by at least three years of relevant work experience (Finnish National Board of Education, 2008). This will then again be followed by four semesters for a Masters. Regardless of these guide times, in planning and specifically in architecture, average times to degree completion vary considerably and tend to exceed minimum standards as students spend extended periods working in architectural offices to gain practical experience. The formal qualification frequently comes at a later stage.

\subsubsection{History of planning education}

Considering the high standing of planning in Finish society, it is rather surprising that planning education does not exist in the form of independent programmes in Finland but is historically offered within various (planning-related) disciplines as a major or partial subject. The main contribution comes from architecture leading by and large to an 'urban design' approach towards planning. Historically, Finnish architect-planners such as Aalto (1898-1976) and Saarinen (18731950) have designed and shaped not only individual buildings but also cities and regions. This tradition is continuing through today. Nearly two thirds of all practising urban planners in Finland have an architecture background (Kangasoja et al., 2010). The second largest group of planning professionals has a surveying background reflecting a well-known historical root of planning. However, surveying has changed over the years, focusing nowadays more on land and property markets. The remaining planning practitioners have other backgrounds including geography, engineering or construction (Kangasoja et al., 2010). This division is also visible in the provision of education for planning which is offered at both universities and polytechnics (also referred to as universities of applied science).

\subsubsection{Planning education now}

The most prominent planning education providers are the departments of Architecture at Aalto University (urban planning and design), Oulu University (planning and urban design), and Tampere University (architecture), offering both undergraduate and master programmes with a strong foundation in planning (Table 9). Due to the structure of the degrees it is not possible to provide numbers for students taking planning majors. Overall, Alto University Foundation had the largest student cohort with around 550 architecture, 120 landscape architecture 
Table 9

Planning majors taught within architecture/engineering/surveying.

\begin{tabular}{lll}
\hline Institution & Bachelor & Masters \\
\hline $\begin{array}{l}\text { Aalto University } \text {, School of Engineering, } \\
\begin{array}{l}\text { Department of Architecture-, Urban } \\
\text { planning and design }\end{array}\end{array}$ & $\begin{array}{l}\text { BSc Architecture } \\
\text { min. 180 ECTS }\end{array}$ & $\begin{array}{l}\text { MSc Architecture or MSc } \\
\text { Landscape Architecture } \\
\text { min. 120 ECTS }\end{array}$ \\
$\begin{array}{l}\text { Aalto University, School of Engineering, } \\
\begin{array}{l}\text { Department of Real Estate, Planning and } \\
\text { Geoinformatics and Department of Civil } \\
\text { and Environmental Engineering }\end{array}\end{array}$ & $\begin{array}{l}\text { MSc Managing Spatial Change } \\
\text { min. 120 ECTS }\end{array}$ \\
$\begin{array}{l}\text { University of Oulu, Faculty of Technology, } \\
\begin{array}{l}\text { Department of Architecture, Laboratory } \\
\text { of planning and urban design }\end{array}\end{array}$ & $\begin{array}{l}\text { BSc Architecture } \\
\text { min. 180 ECTS }\end{array}$ & $\begin{array}{l}\text { MSc Architecture } \\
\text { min. 120 ECTS }\end{array}$ \\
$\begin{array}{l}\text { Tampere University of Technology, Faculty } \\
\text { of Built Environment, School of Architecture }\end{array}$ & $\begin{array}{l}\text { BSc Architecture } \\
\text { min. 180 ECTS }\end{array}$ & $\begin{array}{l}\text { MSc Architecture } \\
\text { min. 120 ECTS }\end{array}$ \\
\hline
\end{tabular}

${ }^{\mathrm{a}}$ Aalto University has a long history dating back to 1872 and beyond when it was a Polytechnic providing architecture education. In 1908 the institution was given a wider remit as Helsinki University of Technology (TKK) which then was transformed in 2010 into Aalto University (one of two Finnish foundation universities). Programmes at Oulu and Tampere were established in 1959 and 1969 respectively.

and approximately 70 postgraduate research students (Alto University, 2011); Oulu and Tampere have each about 300 degree students (2011).

In addition to the above provision within architecture, planning is also taught as part of surveying or engineering degrees. For example, at Aalto University's School of Engineering further planning related programmes are provided through the Department of Surveying (Geomatics, real estate economics) and the Department of Civil and Environmental Engineering (Transportation and Highway Engineering). The planning major of transportation and highway engineering aims to educate 'skillful Masters of Science in Technology for domestic and international planning, research and expert tasks in consulting firms and building companies of the private sector as well in public and municipal authorities' ${ }^{18}$ Similar provision can be found at other universities, for example, the Department of Civil Engineering at Tampere University of Technology offers municipal technology and transport planning. At the University of Helsinki, Department of Geosciences and Geography programmes in Regional Studies with specialisations in geography planning, tourism planning, urban geography and development geography are offered.

One recent noteworthy addition to the master suite at Aalto University is the programme 'Managing Spatial Change' (from Autumn 2011) with an intake of circa 20 students. The objective of the degree is to educate

\footnotetext{
${ }^{18}$ https://into.aalto.fi/display/enyyt/Degree+structure+and+major+subjects, v 05.12.2011.
}

managers of spatial change: with a comprehensive understanding of the complexity of contemporary spatial challenges; a capacity to integrate spatial planning techniques from different disciplines; and a capacity to implement policies that represent the interests and realities of all stakeholders. Graduates will be able to understand the general cultural meaningfulness of the environment and to promote strategic and sustainable development. A vision of spatial development based on efficient and sustainable use of resources, good governance, inclusiveness and effective investing will be fostered throughout the studies. As knowledge gained in higher education can quite quickly become outdated and thereby losing its immediate value for working life, the curriculum deliberately employs a problem based learning approach. This approach prepares students for independent knowledge acquisition and application, problem solving, cooperation, based on multidimensional professional skills, and the capacity to continue learning. The programme will consist of an introductory module (20 ECTS), a shared project (20 ECTS) and an advanced module (20 ECTS) in either land economy or urban engineering. In addition students take free elective studies (20 ECTS), methodological studies (10 ECTS) and do a Master's thesis (30 ECTS).

A number of Polytechnics and Universities of Applied Science also offer planning related education. Key providers are listed in Table 10. After graduating as an engineer (4-year degree, see Fig. 6) and a few years of working experience, it is possible to continue in higher education with postgraduate studies. The biggest difference compared to universities is the amount of 
Table 10

Examples of planning related programmes at Universities of Applied Science/Polytechnics.

\begin{tabular}{lll}
\hline Institution & Programme & Orientations \\
\hline $\begin{array}{l}\text { Metropolia University of Applied Science - School of } \\
\text { Civil Engineering and Building Services (Helsinki) }\end{array}$ & $\begin{array}{l}\text { Land surveying technology } \\
\text { programme, Construction } \\
\text { engineer programme }\end{array}$ & $\begin{array}{l}\text { "The professional field of land surveying is extensive } \\
\text { and multidisciplinary. It includes surveying and mapping } \\
\text { techniques, Geoinformatics, cadastral surveying and } \\
\text { land use planning. The different sectors often interact }\end{array}$ \\
& & $\begin{array}{l}\text { and the aim is to provide the land surveying engineers } \\
\text { e general competence in this field." } \\
\bullet \text { One of the professional orientations of the } \\
\text { Construction engineer programme is }\end{array}$ \\
"infraconstruction". The focus includes building and \\
planning of streets, bridges, houses, etc.
\end{tabular}

Rovaniemi University of Applied Science - Discipline for Technology and Transportation (Rovaniemi)

NOVIA, University of Applied Science (Vaasa region)

HAMK, University of Applied Science (Hämeen ammattikorkeakoulu)

Lahti University of Applied Science - Faculty of Technology (Lahti)
Land surveying technology programme and Construction engineering programme

Land surveying technology programme, Construction engineering programme

Building and Construction engineering programme, Traffic and Transport management

Environmental planning
See above, construction engineers plan and build housing, roads, streets and water and waste management services.

As above

HAMK is the only Finnish university of applied sciences which offers traffic and transport management as a major, in contrast to others where transport planning under is a focus in, for example, construction engineering studies

Central studies: inventory of the landscape, natural circumstances and built environment, ecology, landscape planning, community planning, developing the built environment (http://www.lpt.fi/tl/miljoosuunnittelu/), including methods relating to observing, making an inventory of the environment and participatory planning as well as assessment of the environmental effects. (http://www.lpt.fi/tl/miljoosuunnittelu/) compulsory practical training which can be between 30 and 60 credits. Graduates of those programmes also qualify as planners and can work in the professional field on specific tasks (see 4.3.5, below).

\subsubsection{Guidelines and accreditation}

In lieu of any prescribed guidelines for planning education, Alto University's approach is used to illustrate a typical architecture or urban planning and design curriculum structure. ${ }^{19}$ The programmes do not provide a fixed diet of courses which are obligatory in a narrow sense, but follow the departmental ethos for the education of architects and urban planners which declares that "architecture is an art, requiring learning of professional practice, personal artistic development and technical knowledge of building" (Alto University, n.d.). Programmes cover several thematic fields:

\footnotetext{
${ }^{19}$ Due to the creation of a new School that integrates Art, Architecture and Design, a new programme will be shaped for the future with at the time of finally editing the article - not yet known structures.
}

History and Theory of Architecture, Building Design, Urban Planning and Design, Wood in Architecture and Construction, History of Finnish Architecture, European Metropolitan Planning, Local Development and Globalisation, Sustainable Urban Design, Cities in Crisis, Building Structures, Planning Theory, Methodology and Scientific Communication, Basics and Theory of Architecture, Introduction to Architectural Research, Architectural IT, Sustainable Building Design. Many courses, like housing design, wood construction or urban renewal are taught using a studio format. Additional and more specific inputs come from surveying and civil engineering. The landscape architecture programme adds elements related to landscape design, planning and management. A two cycle degree structure was introduced in 2005. Since then, students first complete a Bachelor of Science in Architecture, after which they can continue with a Master of Science in Architecture or Landscape Architecture and ultimately progress to a Doctorate, i.e. Doctor of Science (Architecture) [D.Sc. (Archit.)], or a Doctor of Philosophy (Ph.D.). 
The curriculum for the Bachelor (three years, fulltime) consist of

1) scientific, mathematical and other basic studies needed for the degree programme and the necessary module of artistic studies (80 ECTS);

2) general studies module for the Bachelor's degree (20 ECTS);

$3)$ three modules, in architecture $(3 \times 20$ ECTS $)$; within this element, for architecture students 20 ECTS are compulsory in urban and regional planning,

4) elective studies (at least 10 ECTS), and

5) Bachelor's seminar and thesis (10 ECTS).

The curriculum for the Master in Architecture or Landscape Architecture (two years, full-time) consist of

1) studies of scientific method (10 ECTS);

2) three modules, of which at least one shall be an advanced module in the student's major subject - i.e. architecture or landscape architecture $(3 \times 20$ ECTS $)$;

3 ) elective studies (at least 20 ECTS), and

4) Master's thesis (30 ECTS).

Master students of architecture with a major in urban and regional planning have to take $2 \times 20$ ECTS in advanced modules in planning. Topics include basics in urban and regional planning, regeneration, professional perspectives, planning theory, globalisation and local development, and sustainable urban design.

\subsubsection{Professional recognition}

There is no requirement to register or become chartered as a planner in Finland, however a voluntary register exists since 2002, when FISE (Rakennus-, LVI- ja kiinteistöalan henkilöpätevyydet FISE Oy), a network of eighteen stakeholder associations, representing approximately forty different professions, was established as a voluntary certification body for the recognition of qualifications of built environment professionals (other than architects which are registered by the Finnish architectural association) including planning. Recognition is granted for seven years and can also be withdrawn. In particular, an individual can be listed on the planners' register as qualified planner if s/he:

1) has completed a degree as architect, landscape architect or Master of Science in surveying technology (also from abroad) where the programme contains modules in community planning (including legislation as well as information technology skills) and, depending of the particular degree, either real-estate technology, landscape planning or construction planning or studies and/or professional skills of community planning, of which the board approves accumulating a minimum of

a) 105 ECTS, of which at least 60 ECTS should be about community planning and at least two years community planning work experience after graduating, or

b) 75 ECTS, of which at least 53 ECTS are community planning, and at least four years community planning work experience after graduating, $o r$

c) 45 ECTS, of which at least 30 ECTS should be community planning and at least six years community planning work experience after graduating, or

d) eight years of community planning work experience after graduating; or

2) has completed a degree of construction architect or engineer in surveying technology, or engineer in community planning in a domestic technical educational institute or university of applied science, or a degree which can be comparable to those and which is completed in a domestic or foreign educational institute and has carried out complementary studies in community planning (60 ECTS) (content of those studies must be approved by the professional board) and who has worked in community planning at least 4 years post graduation; or

3) has completed a degree of construction architect or engineer in surveying technology, or engineer in community planning in a domestic technical educational institute or university of applied science, or a degree which can be comparable to those and which is completed in a domestic or foreign educational institute and who has worked in community planning 8 years post graduation; or

4) has completed complementary studies in community planning (60 ECTS) as outlined in Section 2, and can prove to the professional board that s/he has the same professional level which has been defined in Sections 1,2 and 3, and has been working in community planning at least 12 years.

Note: This required experience does not yet exist because the land use and building act came only into force in 1999. Moreover, in order to get registered in the Finnish section of the European community planners register the degree has to be supplemented so that it fulfils section 2 (FISE, 2011; Translation by J. Ståhl).

\subsubsection{Doctoral studies}

Doctoral studies in planning are administered by the RYM-TK Centre, the nation-wide operating doctoral 
programme for built environment disciplines. The Centre is funded through the Academy of Finland and the Ministry of Education. RYM-TK supports the development of a new generation of business-aware researchers, who are capable of dealing with and resolving problems of strategic value to the built environment. It does so by solely concentrating on doctoral level research. Seven universities, Aalto University (coordinator), Hanken School of Economics, Helsinki University, University of Oulu, Tampere University of Technology, Turku School of Economics and Business Administration (University of Turku), University of Eastern Finland, and two research institutes (VTT, Finnish Geodetic Institution) from all over Finland bring their expertise into RYM-TK with about 70 affiliated professors. At the time of writing around 100 full and part-time $\mathrm{PhD}$ students are eligible to take part in RYM-TK activities; a fraction of those receives a grant or other support. The aim of the doctoral programme is to effectively support built environment research through scholarships, travel and research exchange grants to strengthen international networking, as well as research seminars and courses to provide guidance and support for multidisciplinary research and methods training. The centre is managed by a head of programme and a coordinator with the administration organised through Helsinki University of Technology, while the programme is overseen by an Executive Board consisting of professors of the participating universities.

\subsubsection{Post-graduate and continued professional education}

Since 1968, the Centre of Urban and Regional Planning at Alto University offers multidisciplinary continuing and post-graduate education in planning, which comes closest to existing planning education in other parts of Europe. The main target group is practicing planners from Finland who want to up-grade and critically reflect on their practical planning knowledge. Over the past 40 years more than 1600 planners have benefited from the Centres' offerings.

\subsubsection{Conclusion, evaluation and outlook}

There seems to be a peculiar disconnect between the educational provision for planning which has a strong urban design focus and rewards individual creativity on one hand and planning practice in Finland which clearly embraces an interdisciplinary and communicative conception of planning on the other. Indeed, planning is well recognised and professional competencies for planners are clearly defined as part of the 1999 Land use and building act (Maankäyttö-ja rakennuslaki). In Section 3 of the decree' (MRA 3§) it is stated that the "establisher of a plan needs to have a higher education which is suitable for the planning task, and an adequate experience and competence which correlates with the particular task at hand" (translation by J. Ståhl). Education and work experience of a planner should provide knowledge in areas such as community structures, construction culture, urban planning, environment, landscape, transportation, finance and social questions as well as in cooperation and decision making processes. Perhaps more crucial than the lack of independent planning education degrees may be the fact that there has been little change in planning education (Virtanen, 2004, p. 400) over the past decades. Kangasoja et al. (2010) studying the competencies identified by practitioners as most important, corroborate statements in background documents (Jääskeläinen \& Syrjänen, 2003). Both Virtanen (2004) and Kangasoja et al. (2010) propose that the planning majors need to include more learning and skills for project management, and communication as well as IT and law rather than $\mathrm{CAD}$ and design. Negotiation and interdisciplinary team working are nowadays essential for planning and particularly large scale planning tasks. So far only Alto University has started to respond to these challenges with the new Master in Managing Spatial Change.

\subsection{Poland}

Following nearly half a century of totalitarian communist power, Central European countries, such as Poland, started to develop more market oriented planning systems in the 1990s. One of the first changes introduced by the new democratic governments was the restitution of land, the creation of land markets and a decentralisation of planning competencies in line with pre WWII practices when planning systems in this part of Europe were strongly influenced by Germanic, Austrian-Hungarian legislation requiring detailed land use plan preparation and planning skills at the local level (Ryser and Franchini, 2008).

One consequence of 45 years of centralist totalitarian planning experience was that "planning" throughout Central Europe developed a very negative reputation associated with 'central (socio-economic) planning' as well as government restrictions and interference. It is commonly resented by land owners who feel they should be free to exercise their property rights and develop land without external control. This did not bode well for the re-establishment of a planning profession and development of planning education programmes. 


\subsubsection{Higher education structures}

Higher education institutions in Poland and those of many other former communist countries are typically highly specialised and focused on programmes in a particular set of associated fields. This peculiar institutional landscape of universities of the humanities, universities of economics, universities for natural sciences, or technical and medical universities and so forth was established under communist rule and prevails until today. Other aspects of higher education have changed swiftly post 1989 (Fulton et al., 2007). For example, the autonomy of Polish universities was reestablished for the larger institutions by the 1990 Higher Education Act (Butler \& Kritsonis, 2006; Parliament of the Republic of Poland, 1990) and the state also relinquished its monopoly on $\mathrm{HE}$ leading to the establishment of many new private institutions of higher education (Frank \& Mironowicz, 2009). In fact, higher education is one of the most dynamic sectors in Poland. While in 1992/1993, Poland had 124 HEIs of which 18 were non-public, around twenty years later (2010/2011) there were 470, including 338 non-public institutions providing tertiary education (Central Statistical Office of Poland, 2007a, 2007b, 2011; Polish Ministry of Education, 2012). Still, the bulk of students are educated at public institutions, which also dominate research.

When Poland became a Bologna signatory country in 1999, the required three cycle degree programmes were introduced efficiently. As part of the Higher Education Act (Parliament of the Republic of Poland, 2005) all traditional four- and five-year programmes were transformed into Bachelor and Master degrees with the exception of a few subjects such a medicine and pharmacy. The modern post-Bologna structure follows that outlined in Fig. 2 with six to seven semesters (180 ECTS for non-technical degrees and 210 ECTS for technical degrees carrying the professional title of 'Engineer') for undergraduate studies, and three to four semesters (90 or 120 ECTS) for Masters.

\subsubsection{History of planning education}

Autonomous city, regional or spatial planning programmes are fairly new in Poland. Throughout the communist era, planning merely was a professional specialisation of either, architecture and engineering with a focus on physical and technical aspects of plan preparation. The links with the urbanism tradition were quite evident. Although planning was not taught and fully established as an independent field of study until the early 1990s, planning-related modules, and especially, planning research started in Poland at the same time as in other European countries. For example, a Department of Town Building was established as early as 1913 at Lvov Technical University ${ }^{20}$ (Pawłowski, 1973).

After WWII, with no planning education programmes in existence, planning became a professional specialisation for graduates of architecture or engineering. Despite the lack of planning education, planning theory and planning-related research nevertheless prospered. In 1958, the Polish Academy of Science established the Committee for Spatial Economy and Regional Planning $(\mathrm{CSERP})^{21}$ with the objective to inspire and define new studies in spatial economy and planning in Poland.

The post 1989 emergence of a new market-driven planning system in Poland had not only wide-ranging implications for urban and economic development but resulted in dramatic changes in planning practices and philosophies for which planners were ill prepared, lacking familiarity with the planning approaches and instruments suitable for such a system (Hirt \& Stanilov, 2009). Fortunately, Polish planning academics recognised that the collapse of communism created both a need and an opportunity to establish modern planning education programmes. As planning in the 1990s had a negative connotation conjuring memories of a "centrally planned, state managed (=communist) economy", diplomatically a neutral title was adopted for these new programmes: Gospodarka Przestrzenna - which translates to something like "Spatial Economics", "Spatial Economy" or "Land Economy". The inspiration for this expression stems from the French term 'aménagement territoire' which embraces all aspects of planning.

Based on the initiative of members from the CSERP, the first guidelines for planning education and the first two five-year (MA or Dipl-Ing.) programmes in spatial planning and land economy were established in 1991. Significantly, the first two universities, which opened planning education programmes, have a different scientific background (Adam Mickiewicz University in Poznań at the Faculty of Geography and Wroclaw University of Technology at the Faculty of Architecture) which led to different but complementary curricula profiles. From 2002 onwards, all new planning degrees adopted the new Bologna structure, whereas existing programmes were gradually restructured to fit the new framework.

\footnotetext{
${ }^{20}$ Although in 1913 Poland was not an independent state and Lvov was a part of the Habsburg Monarchy, academic staff of Lvov Technical University - like the majority of Lvov citizens - consisted of many scientists of Polish nationality.

${ }^{21}$ Polish name for the institution is Komitet Przestrzennego Zagospodarowania Kraju, more at: www.kpzk.pan.pl.
} 
Table 11

Planning schools in Poland offering Master degrees in planning (2012). ${ }^{\mathrm{a}}$

\begin{tabular}{|c|c|c|c|c|}
\hline Institution & $\begin{array}{l}\text { Year } \\
\text { established }\end{array}$ & $\begin{array}{l}\text { 1st cycle } \\
\text { (Bachelor) }\end{array}$ & $\begin{array}{l}\text { 2nd cycle } \\
\text { (Master) }\end{array}$ & AESOP \\
\hline Wroclaw University of Technology & 1991 & 3.5 & 1.5 & Yes \\
\hline \multicolumn{5}{|l|}{ Faculty of Architecture } \\
\hline Adam Mickiewicz University Poznań & 1991 & 3 & 2 & Yes \\
\hline Faculty of Geographical and Geological Science Collegium Polonicum in Slubice & 2000 & 3 & 2 & \\
\hline Cracow University of Economics & 1996 & 3 & 2 & Yes \\
\hline \multicolumn{5}{|l|}{ Faculty of Finance } \\
\hline University of Warsaw & 1997 & - & 2 & \\
\hline \multicolumn{5}{|l|}{ Centre for European Regional and Local Studies } \\
\hline Higher School of Finance and Management in Białystok & 1998 & 3 & 2 & \\
\hline Faculty of Spatial Economics & & 3.5 & & \\
\hline University of Łódź & 1998 & 3 & 2 & Yes \\
\hline $\begin{array}{l}\text { Faculty of Economics and Sociology Faculty of Geography and Faculty of } \\
\text { Management (Interdepartrmental Programme) }\end{array}$ & 1998 & 3 & 2 & \\
\hline University of Warmia and Mazury in Olsztyn & 1998 & 3.5 & 1.5 & \\
\hline \multicolumn{5}{|l|}{ Faculty of Geodesy and Land Management } \\
\hline Warsaw University of Life Sciences (SGGW) & 1998 & 3.5 & 1.5 & \\
\hline Poznań University of Economics & 2003 & 3 & 2 & \\
\hline \multicolumn{5}{|l|}{ Faculty of Management } \\
\hline University of Warsaw & 2003 & 3 & 2 & \\
\hline \multicolumn{5}{|l|}{ Faculty of Geography and Regional Studies } \\
\hline Warsaw School of Economics (SGH) & 2003 & 3 & 2 & \\
\hline Warsaw University of Technology & 2005 & 3.5 & 1.5 & Yes \\
\hline \multicolumn{5}{|l|}{ Faculty of Geodesy and Cartography in cooperation with Faculty of Architecture } \\
\hline $\begin{array}{l}\text { Karol Adamiecki University of Economics in Katowice } \\
\text { Faculty of Economics }\end{array}$ & 2006 & 3 & 2 & \\
\hline
\end{tabular}

\subsubsection{Planning education now}

As of 2010/2011 nearly 50 planning programmes have been established across 43 Polish universities and higher education institutions. Of those, thirteen institutions offer planning education at Master level. With the exception for the Higher School of Finance and Management in Bialystok they all are public universities (Table 11). Programmes in planning at undergraduate level are currently offered at three universities of technology (Wroclaw, Warsaw, Gdansk, Bialystok), six universities (Gdansk, Poznan, Lodz, Opole, Olsztyn, Warsaw), four universities of economics (Warsaw, Katowice, Cracow, Poznan), five universities of life sciences/agricultural universities (Warsaw, Lublin, Poznan Wroclaw, Cracow), one university of applied sciences (Fachschule, Walbrzych) and 19 private institutions all over Poland (see online resource). The Centre for European, Regional and Local Studies at the University of Warsaw offers exclusively Masters level programmes. All programmes are regularly evaluated and accredited by the State Accreditation Committee and programmes deemed of unacceptable quality will be closed (Frank et al., 2012). In 2012, the largest 17 planning schools in Poland signed a formal agreement to form a national association of planning schools with the aim of promoting planning and excellence in planning education.

\subsubsection{Guidelines and accreditation}

Higher education in Poland used to be highly regulated, with state level guidance and standards for each of the 118 state recognised fields of study. The latest guidelines for planning education were completed and ratified by the Ministry of Science and Higher Education in July 2007. The standards defined the name of the field, degree programmes and detailed requirements such as the number of semesters and hours of study, a graduate's profile in terms of skills and competencies, required content and learning outcomes, and minimum number of hours and ECTS for specified modules. The guidance distinguished between Bachelor and Master programmes and a comparison of learning outcomes (Figs. 7 and 8) shows an anticipated progression to higher level skills and greater depth of knowledge from Bachelor to Master level (Markowski \& Mironowicz, 2008; Mironowicz, 2006).

In 2011, a radically new version of the Act on Higher Education (Parliament of the Republic of Poland, 2010, 2011) was issued, revoking all existing guidelines and creating a different framework for all fields of study. 


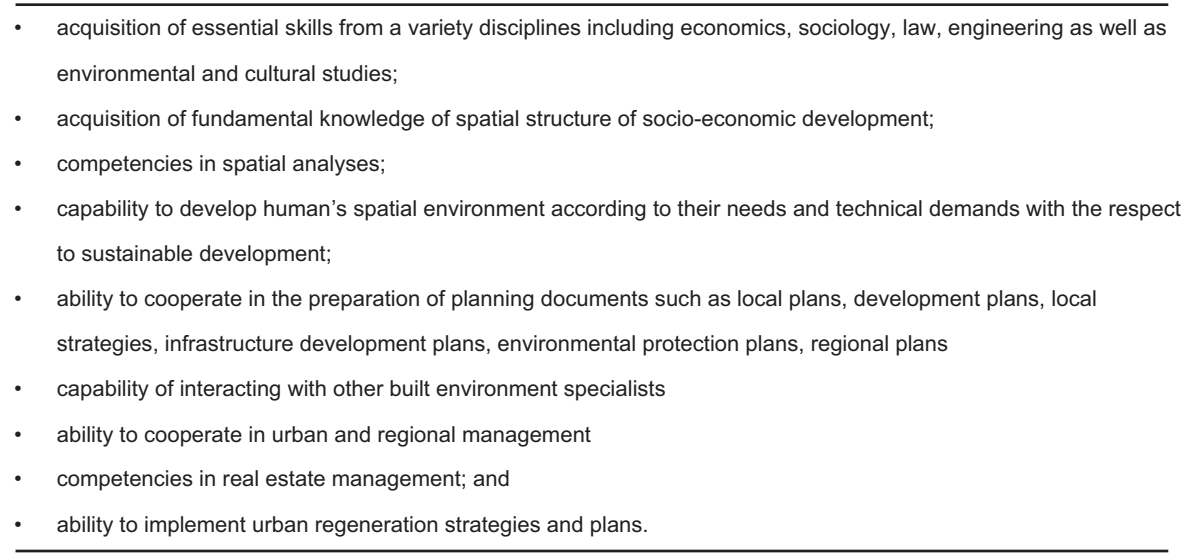

Fig. 7. Key learning outcomes and competencies for the Bachelor in planning (2007 guidelines).

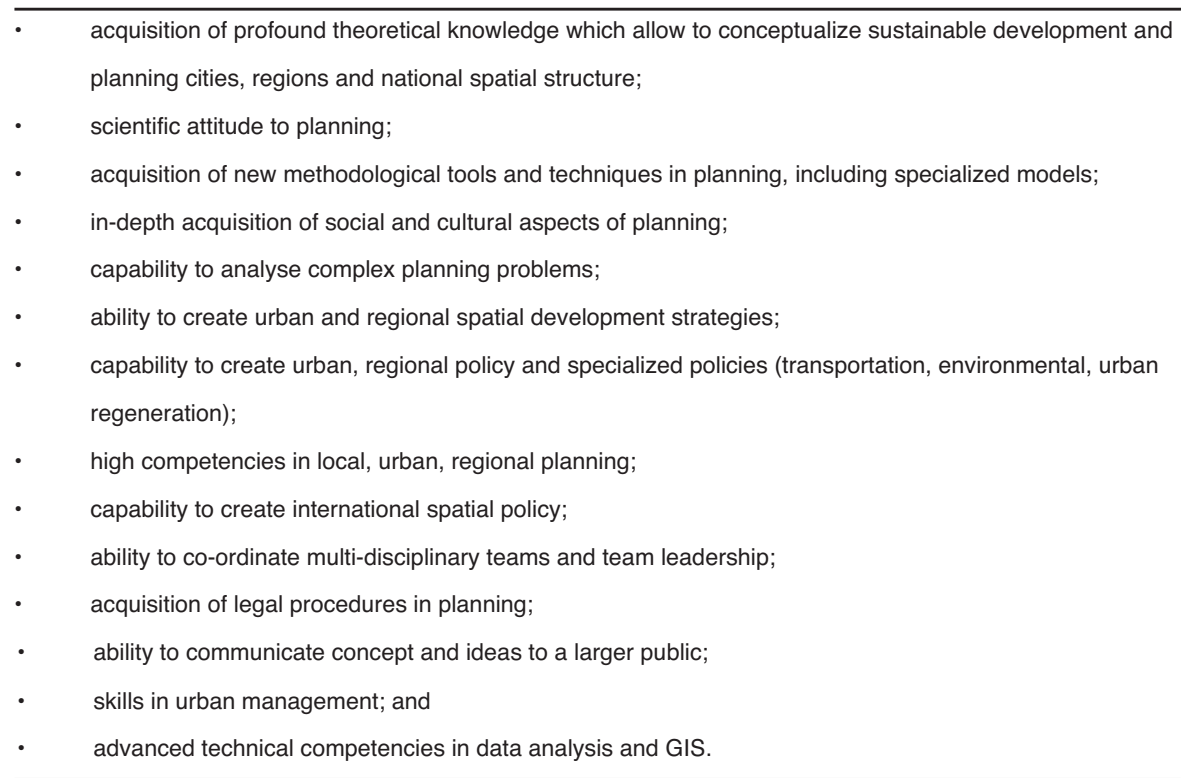

Fig. 8. Key learning outcomes and competencies for a Master in Planning (2007 guidelines).

Under the new framework the programme descriptions have to identify learning outcomes classed as knowledge, skills or social competencies. These learning outcomes will be the basis for future quality assessment. Moreover, any university entity (faculty, department) that had the right to confer habilitations ${ }^{22}$ is now empowered to establish programmes and curricula independent of ministerial guidance. Higher education entities, without the right to confer habilitations are also allowed to run new programmes, but these have to

\footnotetext{
${ }^{22}$ The degree of habilitated doctor exists also in Germany, France and Austria and generally is bestowed on individuals with significant scientific achievement after being post $\mathrm{PhD}$.
}

comply with (1) the generic learning outcomes for the applicable field of study issued by the Ministry ${ }^{23}$, and (2) get the approval of the Ministry and State Accreditation Committee. In both cases there is a requirement for a minimum number of academic (full time) staff specialised in a particular field of study and associated with the programme (as their main teaching activity). Radical changes in planning education due to these new policies are unlikely. The right to confer habilitations is linked to research status and sufficient academics holding degrees in a defined area of study.

\footnotetext{
${ }^{23}$ If no state guidelines exist for a field of study, the institution's Senate has to approve learning outcomes.
} 
At present, only three planning education providers (Universities of Technology in Cracow, Wrocław and Warsaw) do qualify to take advantage of the rule. The majority of planning schools will merely adjust existing programmes by translating requirements into learning outcomes and it is thus useful to explore these in more detail.

\subsubsection{Bachelor in planning}

Bachelor/undergraduate degree requirements vary depending on the type of conferring institution. At nontechnical universities a minimum of six semesters (three years) of study and $2200 \mathrm{~h}$ (180 ECTS) are required, leading to a professional title of "licentiate" (licencjat). At technical universities, a bachelor in planning requires a minimum of seven semesters (3.5 years) and $2500 \mathrm{~h}$ (210 ECTS) leading to the professional title of "engineer" (inzynier). According to a university's profile, institutions may have 'additional' requirements like for example modules in mathematics and physics for universities of technology, or management for universities of economics (Mironowicz, 2010).

The guidelines in planning, which are legally out of date, but still in practical use, define two groups of compulsory modules (Table 12). The first group (fundamental sciences) comprises of general subjects (mathematics, statistics, economics, sociology, physics) providing a wide intellectual background for graduates as well as modules that develop a theoretical base for specialised modules (economic geography, technical and planning drawing, urban history, introduction to law). Planning drawing/graphics and physics modules were required only in technical universities. The second group (specialised modules) provided essential planning knowledge and skills. The latter constitute a kind of "core curriculum". Students also are required to complete a minimum of four weeks practical training when studying at a technical university and three weeks when studying at a non-technical university. From 2011, 30\% of all ECTS are to be gained from optional modules.

Table 12

Compulsory topics for Bachelor in Poland (2007 guidelines).

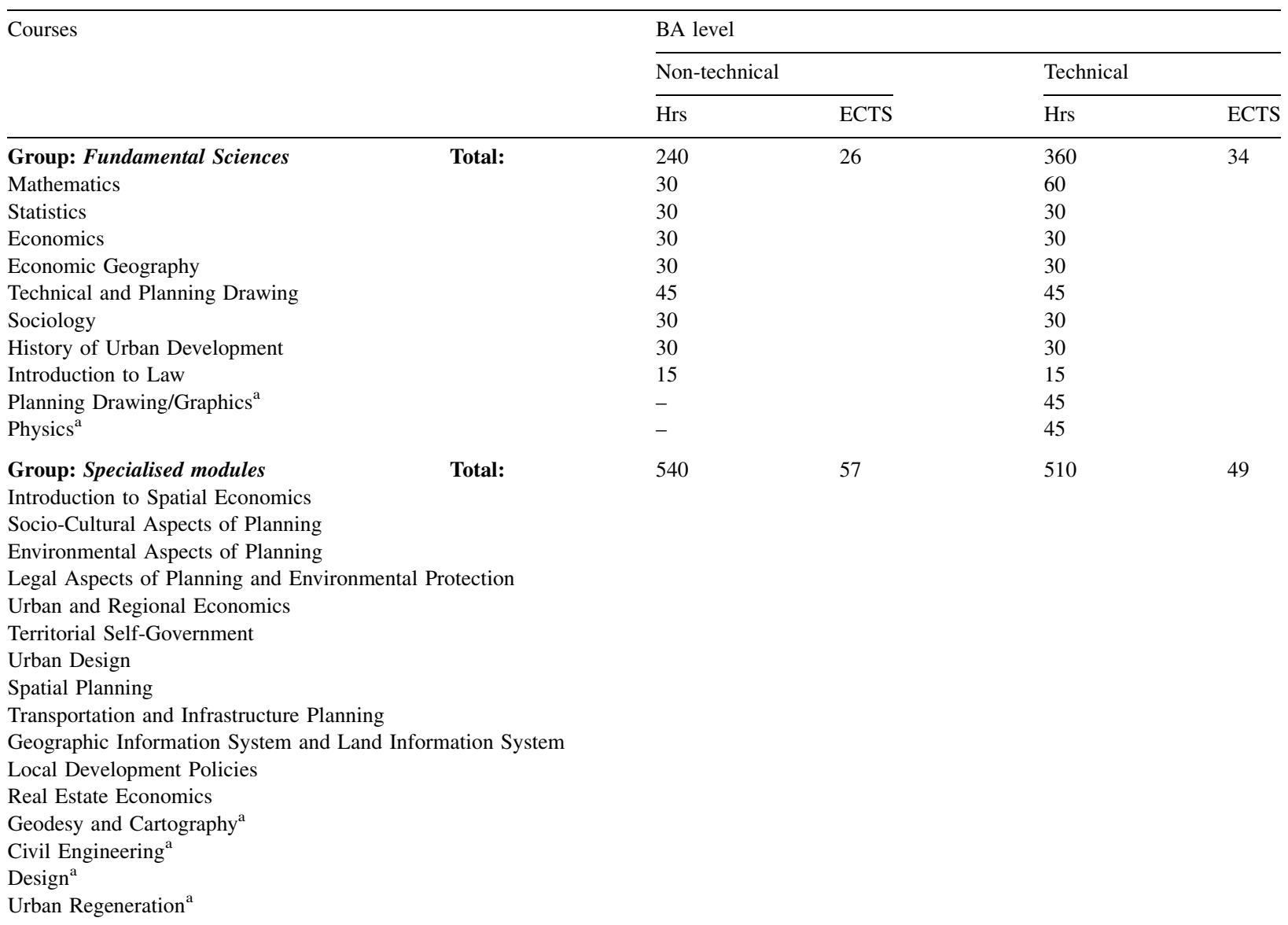

\footnotetext{
${ }^{\text {a }}$ Required courses only for HEIs with technical profile.
} 


\subsubsection{Master in planning}

HEIs wishing to offer a master degree must employ no less than 6 full professors and 6 assistant/associate professors (holding a doctoral degree), who are research active and form the core of the academic teaching staff. This requirement limits the institutions that can legally offer such a degree in planning and explains the focus of private institutions on 1st cycle provision. For secondcycle programmes a minimum of four semesters and $1000 \mathrm{~h}$ (120 ECTS) for students with a Bachelor degree from a non-technical university, and a minimum of three semesters (1.5 years) and $900 \mathrm{~h}$ (90 ECTS) for students with a professional title "engineer" is required. Masters in planning are open to students with a non-planning background as long as they have completed $60 \%$ of all compulsory modules of an 1st cycle planning degree. This is relatively easy to achieve for students in environmental studies, geography or architecture. After the 2011 reform, universities can determine their own institutional criteria, yet so far most institutions continue to use the tried and tested formula.

Basic/general modules (Table 13) provide education in systems thinking and complexity (systems theory, environmental science) as well as prepare students for leadership (management). Specialised modules provided planning specific knowledge preparing students for practice with topics in planning policy (town planning, regional policy, EU spatial policy and marketing places), planning law and technical plan preparation. Classes covering models in spatial policy and spatial economics seek to equip students with methodological tools for spatial analysis and scenario development (Mironowicz, 2007). A master thesis (can be also a professional project, plan or strategy) exploring a planning research topic must be produced as a final part of any second-cycle programme. The

Table 13

Compulsory courses for Master in planning (2007 guidelines).

\begin{tabular}{lll}
\hline Modules & MA Level & \\
\cline { 2 - 3 } & Hrs & ECTS \\
\hline Group: Basic modules & 75 & 8 \\
Systems Theory & 15 & \\
Environmental Science & 30 & \\
Management & 30 & 22 \\
Group: Specialised modules & 210 & \\
EU Spatial Policy & & \\
Marketing Places & & \\
Regional Policy & & \\
Techniques of Plan Preparation & & \\
Town Planning & & \\
Models in Spatial Planning and Spatial Economics & \\
\hline
\end{tabular}

thesis has to be presented in both written and oral form to a committee of academics for examination.

\subsubsection{Doctoral studies}

In Poland, individuals engaged in doctoral studies are not considered students in the classical sense, but researchers or teaching assistants under supervision of senior academics. With no designated research discipline in planning, candidates work in a variety of fields of study (human geography, economics, etc.). The number of individuals studying for a doctorate in planning is unknown, but it is estimated that roughly 20 PhDs graduate annually. For most teaching positions a $\mathrm{PhD}$ is a requirement.

\subsubsection{Continued professional development}

A requirement for continued professional development (defined by the Chamber) exists for registered practicing planners, which can be satisfied by participating in conferences, seminars and professional workshops and training. In addition, several planning schools (e.g., Wrocław University of Technology or Gdansk University of Technology) offer postgraduate studies (for professionals holding already a master degree) leading to a certificate or diploma in spatial planning or urban management and urban regeneration, respectively as a means to address the considerable demand to up-skill the workforce.

\subsubsection{Conclusions, evaluation and outlook}

In contrast to other Central European countries, Polish universities offer a considerable number of planning programmes not only in design and engineering oriented institutions but also in universities specialising in economics or environmental sciences. As a result, Poland has a broad spread of planning programme foci, which is helpful in addressing the issues that the nation has been facing in the past decades of economic transition (Mironowicz, 2007, 2010). As planning academics engage very actively in international networks there is a constant flow of ideas and knowledge exchange which benefits programme development.

Although the current provision is well developed there is room for improvement. The establishment of a common system of accreditation for planning education across all different types of institutions would be helpful (Frank et al., 2012). Also, at present, planning practitioners have no formal influence on the planning curriculum, which in the long term could result in graduates lacking skills that the market demands. However, with a shortfall of qualified planners, 
employability is not yet a problem. The decentralisation of power post 1989 resulted in the establishment of a new planning tier with over 2400 communes requiring a host of spatial plans and only members of the Chamber of Town Planners (established 2000 by the State) can produce certain necessary and legally binding planning documents. As of 2008, there were approximately 1200 members of the Chamber of Town Planners. ${ }^{24}$

\subsection{Slovakia}

Similar to other countries in the former communist part of Europe, structural changes post 1989 led to far reaching substantive and procedural changes in the planning system of Slovakia. Amendments to the Spatial Planning and Building Act in 2003 established a progressive, hierarchical planning system which supports environmental and nature protection, town regeneration as well as seeking an even territorial distribution of development through urban-rural partnerships (Ryser \& Franchini, 2008). This system requires planners to integrate land use planning, landscape planning and socio-economic strategic planning across all levels local, regional, national and trans-national.

\subsubsection{Higher education structures}

Significant changes also occurred in the higher education sector. Firstly, following liberation from communist rule, the Federal Parliament of the (then) Czechoslovak Republic re-established the autonomy, freedom of scientific and artistic work and education, freedom of political and religious convictions and selfgovernance of higher education institutions (Parliament of the Czechoslovak Republic, 1990). After cessation in 1993, the new autonomous Slovakia commenced to modernise its higher education system, although, like in Poland, the system of specialised higher education with separate institutions for the humanities, natural sciences or formal sciences, "technical universities" and "universities of technology", medical universities, agricultural universities, universities of economics, pedagogical universities and art academies, that was put in place under communist rule was retained (Frank \& Mironowicz, 2009). The ECTS was introduced in 1998 followed by legislation enabling the establishment of private HEIs (Parliament of the Slovak Republic, 2002). Also in 2002 Slovakia joined the signatories of the Bologna declaration. Thus, HEIs in Slovakia nowadays offer degree programmes in accordance with the Bologna

\footnotetext{
${ }^{24}$ Chamber of Town Planners, n.d.
}

agreement: 3-4 years bachelor (Bc.), 2-3 years master (Mgr., Ing.) and 3-4 years doctoral studies.

Of the 33 institutions of higher education in present day Slovakia 20 are public, three are state and ten are private institutions (Matulíková \& Rehorovská, 2010). Public institutions are established by parliamentary law, financed by government and their own business activities. State universities are specialised, government funded institutions (e.g., medicine, military, police) established by respective state ministries. Private institutions, although not financially supported by the state, must nevertheless be approved by the Ministry of Education. Educational provision is restricted to disciplines defined in an official list of fields of study approved by the Ministry. New programmes must be accepted by the State Accreditation Committee and comply with the core curriculum issued by the Ministry.

\subsubsection{History of planning education}

While the first university in present-day Slovakia was founded in the middle of the 15th century (Sikorová, 2007), higher education for technical fields began in the middle of the 18th century with the establishment of the Mining Academy in Banska Stiavnica, which in 1937 became the Slovak University of Technology (STU). The beginnings of planning education can be traced to the Academy in Banska Stiavnica, and its involvement in the creation of the system of artificial lakes, canals and technical works supporting the regional mining industry as well as infrastructure development and land reclamations along the rivers Danube and Vah.

The modern era of planning education is generally associated with the establishment of the Institute of Urban and Municipal Development in the Faculty of Architecture and Civil Engineering at the STU in 1948. The institute was developed into a Department of Urbanism under Emanuel Hruska, president of the National UNESCO Committee. Consistent with central European culture, spatial planning was conceptualised as a part of architecture. Specifically, "urbanism" representing urban design and land use planning has been recognised as an architectural but relatively autonomous profession and study specialisation focused on physical and technical aspects of spatial development throughout the latter half of the 20th century.

\subsubsection{Planning education now}

Post 1989 changes to the planning system represent a clear shift in skills and competency demands for the profession which recently led to the establishment of a separate, independent study field called "Spatial 
Planning" in 2002 as part the legislation that also implemented the 1999 Bologna Declaration (Parliament of the Slovak Republic, 2002). In other words, spatial planning was introduced into the list of officially recognised study fields as autonomous degree at all three levels. In parallel, the study fields "Urbanism" and "Architecture" were merged into one: "Architecture and Urbanism." As planning education also continues to be offered as part of Architecture, Environmental Management and Landscape Architecture, the planning profession in Slovakia can draw on graduates with a rich set of generic and specialist skills and knowledge.

At the time of writing, the Slovak University of Technology in Bratislava with its Institute of Management is the only university in Slovakia offering programmes in spatial planning with approximately 200 students across all levels and years. The university also offers a Master in Urbanism as part of the architecture programme with about 20-30 students. Overall, there are over 100 different programmes dealing with planning-related issues (transport planning, environmental planning, landscape planning, regional development, etc.) or with fields supporting planning processes (e.g., analytical activities, evaluation) at the STU and other HEIs in Slovakia.

\subsubsection{Guidelines for planning education}

The introduction of the study field "Spatial Planning" meant that guidelines were issued which describe the new field in the context of related fields. The guidelines include information on the minimum number of semesters and hours of study for each degree level, a typical graduate's profile in terms of skills and competencies, mandatory curriculum content and learning outcomes, minimum number of hours for specified knowledge areas and the content of the state exams.

Aside from "Spatial Planning" two other study fields are relevant for education in planning; these are Architecture and Urbanism and Landscape Architecture and Environmental Management. As Architecture and Urbanism covers only structural and land use planning focusing predominantly on urban design, and Landscape Architecture and Environmental Management focusing on landscape planning and management, Spatial Planning is the degree that offers the most comprehensive set of skills. For Bachelor (Bc.) studies guidelines require 3 years of study (180 ETCS), for Master (Ing.) 2 years (120 ETCS) and for doctoral studies 3 years full time and 5 years part time (180 ETCS). For students with a background other than Spatial Planning institutions can extend the nominal duration of a master to 3 years to allow students more time for study.

The definition of spatial planning in the official description follows the European Charter on Spatial/ Regional Planning (European Commission, 1983) where spatial planning is understood as a synthesising discipline. It is characterised as the geographic expression of the economic, social, cultural and ecological policies of society. Spatial planning is at the same time a scientific discipline, an administrative technique and a policy developed as an interdisciplinary and comprehensive approach aimed at well-balanced spatial development and a physical organisation of space which supports sustainability. The core of spatial planning is seen to comprise three integrative activities - land use planning, landscape planning and strategic socio-economic development planning. It includes activities such as environmental, transport, and infrastructure planning.

Spatial planning graduates therefore need to be able to manage spatial development across the entire spectrum of spatial scales. Special attention is paid to prepare graduates for their role as facilitators of public participation and mediators of conflicts among different stakeholders in spatial development.

\subsubsection{Bachelor in spatial planning}

A bachelor is to be equipped with selected basic theoretical knowledge from natural and environmental, technical and social sciences, economics and urbanism as well as methods and instruments of landscape planning, socio-economic, land use, infrastructure and transport planning accompanied by an understanding of information and communication technologies. The education is completed by a state exam (Fig. 9). The state defined undergraduate curriculum consists of around $60 \%$ of mandatory subjects; the remaining $40 \%$ of credits and hours can be defined by the institution based on topics addressing current problems in spatial development.

\subsubsection{Master in spatial planning}

According to the profile, a spatial planning graduate is to be able to analyse the conditions, features and values associated with territorial systems from natural and socio-economic aspects; s/he is able to assess the development, cultural and, ecological conditions, social and economic structures, historic assets, landscape aesthetics, land use and level of urbanisation. A master in Spatial Planning is trained in ethics, and organisational and professional aspects of planning. Individuals are able to execute projects, and conduct managerial as 


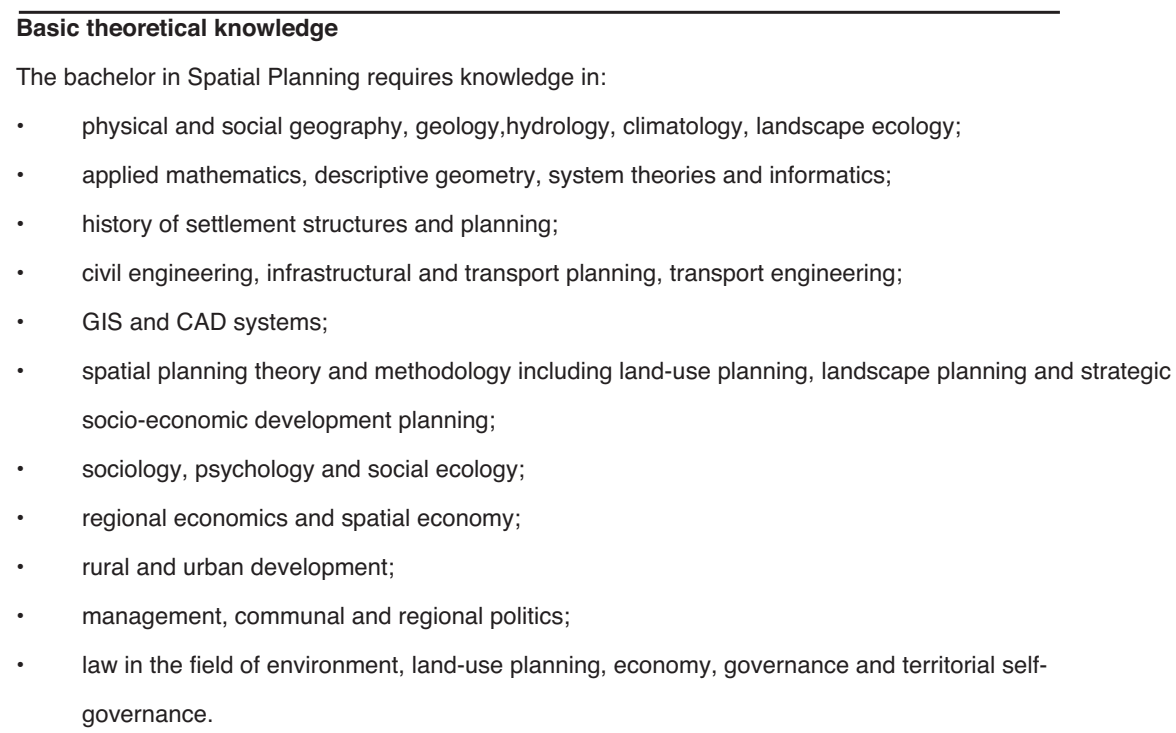

Basic skills and abilities

The bachelor in Spatial Planning requires skills and abilities in:

- evaluation and identification of the development potentials of territorial units across different scales from district to national;

- assessment of spatial-structural characteristics of landscape with the focus on the identification of functional, socio-cultural and natural systems;

- implementation of spatial planning methods and instruments, including an understanding of their potentials and limits; and

- management of basic creative and implementation processes in spatial development.

\section{Complementary knowledge, skills and abilities}

The bachelor in Spatial Planning is able to:

- organize his/her professional development and study,

- use information systems;

- communicate professionally with other disciplines, including the communication in a foreign language;

- collaborate in interdisciplinary teams; and

- manage public participation in the phase of decision making and plan implementation.

\section{The state exam consists of}

- elaboration and defence of the Bachelor thesis - the strategy of the social and economic development and land use plan for a mid-sized city;

- $\quad$ assessment in four subjects: 1. Infrastructural and Transport Planning, 2. Spatial Planning, 3. Landscape Planning, 4. Strategic Planning.

Fig. 9. Requirements for the Slovakian Spatial Planning Bachelor and Associated State Exam.

well as research activities. With expertise in the field of spatial development, environmental protection and strategic environmental assessment this individual is able to commence studies towards a $\mathrm{PhD}$. The master curriculum allows graduates to develop an individual profile through a set of optional modules and choosing a topic for the master thesis. Basic and complementary knowledge and skill requirements as well as content of the state exam for a master degree in spatial planning are presented in Fig. 10.

\subsubsection{Doctoral studies}

A PhD in Spatial Planning is expected to be able to apply various scientific methods to inventory, research, 


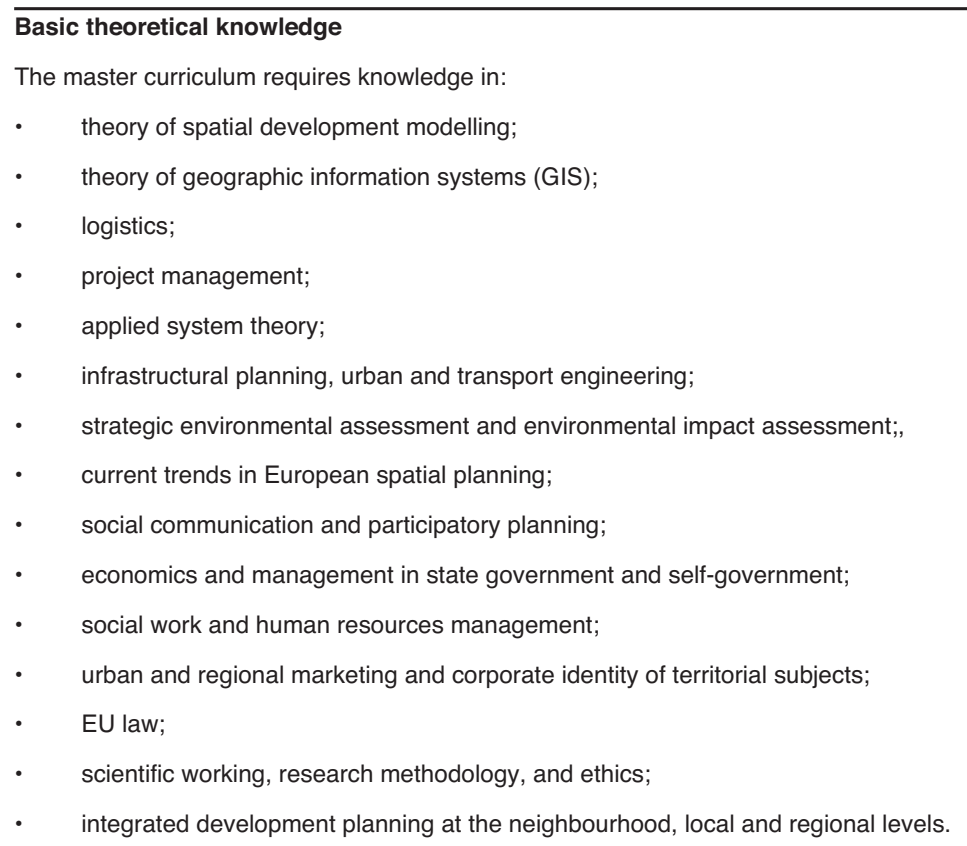

\section{Basic skills and abilities}

The master curriculum requires skills and abilities in:

- coordination of interdisciplinary teams in the field of strategic socio-economic development, landscape and land-use planning;

- coordination of cross-border spatial development and collaboration,

- $\quad$ evaluation of cultural, aesthetic and environmental values of the landscape;

- $\quad$ planning, management and development of instruments for the implementation of spatial development plans; and

- moderation of participatory planning processes and mediation of conflicts in spatial development.

\section{Complementary knowledge, skills and abilities}

The master is able to:

- work efficiently as individual, as team member or leader in the private, government or non-government sector;

- develop original theoretical knowledge and skills and creative potential in a sustainable way;

- be professionally and linguistically competitive in the European labour market.

The state exam consists of: an elaboration and defence of the master thesis containing a theoretical exploration of a self-defined spatial problem and practical implementation in an appropriate territorial scale.

- $\quad$ an assessment in theory and methodology of spatial planning.

Fig. 10. Requirements for the Slovakian Spatial Planning Master (Ing.) and associated state exam.

analyse and evaluate spatial development processes and structures as well as develop, propose and implement new approaches, instruments and methods in spatial development.

The $\mathrm{PhD}$ curriculum contains selected knowledge from a range of disciplines with emphasis on the integration of socio-economic, landscape-ecological, technological and psychosocial aspects, current problems and trends in spatial development. This is complemented by skills and knowledge on principles, approaches and methodology of scientific work. Graduates are able to develop creatively knowledge 
in respective areas of spatial planning theory and methodology, to formulate research problems, hypotheses, goals, procedures and instruments and to contribute to knowledge development in the discipline of spatial planning and practice.

\subsubsection{Programme curriculum in spatial planning: case study}

The curricula and programmes in spatial planning at the Slovak University of Technology in Bratislava are used to illustrate the implementation of state guidelines in spatial planning across the three cycles of higher education (Table 14). Precondition of programme accreditation is that state guidelines, which prescribe $60 \%$ of the curriculum are met. The remaining $40 \%$ can be divided between classes drawing on the research specialisations of the institution and the individual interests of the student. The proportion of individual choice of subjects and modules by students increases from BSc (6\%), via Master (14\%) towards PhD level $(75 \%)$.

\subsubsection{Conclusion, evaluation and outlook}

The number of planning education programmes in Slovakia and hence planning graduates is limited. Autonomous spatial planning degrees are supplemented by a range of planning-related programmes offered at institutions with a technical profile. The recently developed definition of the core curriculum in planning was accomplished in close collaboration between

Table 14

Programme structure for spatial planning education at STU, Bratislava.

\begin{tabular}{|c|c|c|c|c|}
\hline & Hours & ECTS & $\%$ Hours & $\%$ ECTS \\
\hline \multicolumn{5}{|c|}{ Bachelor (Bc.) } \\
\hline Basic knowledge & 280 & 24 & 16 & 13 \\
\hline Procedural, theoretical subjects & 448 & 44 & 25 & 24 \\
\hline Substantial theoretical subjects & 252 & 23 & 15 & 13 \\
\hline Projecting, planning, designing & 672 & 85 & 38 & 47 \\
\hline Complementary subjects/individual profile & 112 & 4 & 6 & 3 \\
\hline Total in the BSc & 1764 & 180 & 100 & 100 \\
\hline
\end{tabular}

State exam including

BSc diploma thesis (strategic development plan and land-use plan) defence

Exam on land use (territorial) planning

Exam on strategic planning and management

Exam on landscape and infrastructural planning

Basic knowledge

Procedural theoretical subjects

Projecting, planning, designing

Complementary subjects/individual profile

Masters (Ing.)

Total in the MSc (Ing.)

$\begin{array}{llll}84 & 12 & 8 & 10 \\ 140 & 20 & 14 & 17 \\ 644 & 70 & 64 & 58 \\ 140 & 18 & 14 & 15 \\ 1008 & 120 & 100 & 100\end{array}$

State exam including

Master diploma thesis defence (dealing with specific problems of spatial development/planning practice)

Exam on theory and methodology of spatial planning

Study part

Doctoral

Theory and Methodology in Spatial Planning Research

Spatial Development Theories and Policies

Selected Problems in Spatial Planning Theory and Practice

Interdisciplinary Aspects of Spatial Planning

State exam including the defence of the research concept and methodology

Teaching practice

\section{4}

$144-10$

144

144

60

300

Research part

Research on selected topics as the basis for the thesis elaboration

Thesis elaboration and submission

Total in the $\mathrm{PhD}$
1000

3292
$10 \quad 4.5$

$10 \quad 4.5$

$10 \quad 4.5$

5

20

20

$$
2
$$

9 
academics and planning practitioners. This is a remarkable achievement in light of the fact that spatial planning practice is (still) dominated by professionals trained as architects with a specialisation in land use planning. For now this dominance is safeguarded by a tradition which authorises architects to design and plan anything ranging from interior architecture to transnational spatial structures, irrespective of the fact that graduates with a background in architecture and urbanism are really not adequately prepared for the tasks of modern spatial planning and even land use planning.

After years of debate, the Slovak Chamber of Architects has recently recognised spatial planning as an independent profession and announced its willingness to introduce a special authorisation to accept graduates in spatial planning as potential members. Activities at the European level, including recent documents of the EC (i.e., EU Sustainable Development Strategy, Leipzig Charter), and activities of planning organisations such as AESOP or European Council of Spatial Planners (ECTP-CEU) have played an important role in this process. There is hope that this special authorisation will be embedded in legislation in the near future.

\subsection{United Kingdom}

The UK planning system is well established with the twofold purpose of regulating land use and supporting sustainable development (Ryser \& Franchini, 2008). This is done via national planning policy guidance which is interpreted and implemented at local level. Unique amongst European nations, the UK operates a liberal, discretionary system for development control whereby most applications are decided on a case-bycase basis at local level (Booth, 2003; Nadin \& Stead, 2008). Planning as profession is self-regulated by the Royal Town Planning Institute ${ }^{25}$ which exerts significant influence on planning legislation as well as planning education.

\subsubsection{Higher education structures}

The United Kingdom, comprising of England Scotland, Northern Ireland and Wales, features 115 universities and some 45 other higher education institutions (Universities UK, 2010). Universities have considerable autonomy and there are substantial

\footnotetext{
${ }^{25}$ RTPI was initially the town planning institute; Royal Charter was granted in 1959.
}

differences in the emphasis institutions place on research, education or outreach. Reflecting these portfolios, institutions are commonly categorised into research (old, red-brick) and teaching ("new", post 1992) universities. The latter were Polytechnics prior to the 1992 Further and Higher Education Act and focused primarily on practice-based education. Since then, however, many "new" universities have also developed a significant profile in applied research and consultancy. Planning education at bachelor, master as well as doctoral level is offered at both kinds of universities in equal measure; overall though programmes mirror institutional characteristics, i.e., being research-led or having a "practitioner-teacher" focus (Ellis et al., 2010). As in UK higher education the multiple cycle approach as well as quality assurance monitoring predated the Bologna declaration, the agreement created far less upheaval than on the continent. Indeed many disciplines perceived little need to review degree structures and as a result several anomalies and not entirely Bologna conform degrees continue to exist.

In England, Northern Ireland and Wales the first cycle is normally a three-year bachelor degree (or Diploma which is equivalent). In Scotland, a first cycle degree typically lasts three to four years depending on a student's entry qualifications and may be called Bachelor or confusingly MA (undergrad). The longer degree compensates for less specialisation in secondary education with Scottish Highers being only one year compared to the two-year qualification of the English or Welsh A-levels. The second cycle represents master degrees, which normally require 12 months full-time study. Thus, UK masters are at the lower end for second cycle degrees with only 90 ECTS $(3 \times 30$ ECTS $)$. Practically, students complete two taught terms worth each 30 ECTS followed by a thesis over the summer worth the remaining 30 ECTS. UK institutions also offer so-called integrated masters which require four years of study and lead to, for example, an MPlan (Master in Planning). Integrated master degrees fall 30 ECTS short of the minimum sum of credits required for a first and second cycle degree and are typically classed as undergraduate degrees. The comparatively shorter time to complete an integrated master is justified by greater specialisation in the initial years of the degree. In times when master degrees in the UK required two years of study, integrated masters represented a shorter and cheaper route. However, as standalone (nonintegrated) master degrees take nowadays generally only 12 months, savings are less substantial than in the past. Third cycle doctorate degrees take normally three years (full-time) to complete. 


\subsubsection{History of planning education}

The world-wide first formal planning education degree was established in 1909 at the University of Liverpool's Department of Civic Design (Batey, 1985), placing the UK firmly at the vanguard of advancing planning as profession and independent discipline. This degree was a postgraduate programme catering to professional architects, engineers and surveyors. The curriculum addressed issues of land use, street layout, legislation and hygiene in order to promote quality planning and design of town extensions. In 1914, a second postgraduate programme was established at University College London and in 1939 a further four recognised programmes were on offer at the Universities of Newcastle, Manchester and Leeds, and the Edinburgh College of Art alongside an equal number of unrecognised planning related degrees preparing students for the RTPI's entry exams (Healey \& Samuels, 1981).

As the discipline matured, the conceptualisation of planning and planning education changed (e.g. Dalton, 2001; Frank, 2006; Healey, 1985). A significant change occurred after WWII when in 1945 and 1947 the first five-year undergraduate degrees were established at Newcastle and Manchester (Healey \& Samuels, 1981). The demand for qualified planners was bolstered by a new planning Act ratified in 1947. Moreover, a first major review of planners' qualifications (and their educational pathways) was published (Schuster, 1950), progressively promoting the interdisciplinarity of planning which was operationalised by the introduction of two-year Master degrees (Batey, 1985). Student intake was widened allowing not only architecture, landscape architecture and engineering but also geography, politics, economics and social science graduates to enrol and foster interdisciplinary discourse and teamwork. The curriculum shifted from a mere design and development control focus (Chandler, 1985) to include economics and geographical and statistical analysis methods. Planning practice began to embrace the rational-planning model as well as to consider issues such as transport, social issues and policy (Amos et al., 1973; Brown, Claydon, \& Nadin, 2003; Stiftel et al., 2009, p. 187). All of this led to a consolidation of the profession and planning education. By the early 1970s there were not only eighteen RTPI accredited master programmes producing more than three hundred planners annually, but also ten undergraduate programmes with a student output of around sixty per year (Amos et al., 1973; Batey, 1985, p. 411). Many more degrees with closely related subjects existed in urban studies or transport planning but these were not sufficiently compliant with the stringent core curriculum of the RTPI to exempt students from the Institute's entry exams (Amos et al., 1973). With government cuts in postgraduate scholarships the ratio of undergraduate to postgraduate students in planning reversed by the mid-1980s (Batey, 1985). However, overall growth in programmes and student numbers continued more or less steadily and by 2001/2002 around 3000 students were enrolled in RTPI accredited degree programmes across 30 institutions throughout the UK (Shaw et al., 2003).

At the start of the 21st century, UK planning education experienced wide-ranging changes triggered by the RTPI's comprehensive review of its membership and education approach (Brown et al., 2003; RTPI, 2003, 2004). Embracing the concept of life-long learning, the Institute now requires individuals seeking chartered membership not only to have an RTPI accredited degree but to complete an assessment of professional competencies (APC) and to regularly engage in continued professional development. Conversely, the RTPI eased its requirements in respect to university education. The length of UG and PG courses was reduced to bring planning education in line with other professional degrees. This resulted in the abandoning of the time-tested two-year master and replacing it with a 12 months master, as well as introducing three-year bachelors. Education providers also gained more freedom in determining how and what they include in curricula as long as RTPI's learning outcomes were met. Formal accreditation audits for already accredited degrees were replaced by annual visits of partnership boards which consist of academics and practitioner members (Brown et al., 2003; RTPI, 2003, 2004). The reform spurred the development of new master degrees offering contemporary new specialisms such as an MSc in Sustainable cities or an MSc in Planning and Climate Change while raising the attractiveness of planning and student intake.

\subsubsection{Planning education now}

Planning education provision in the UK is extensive and diverse (Ellis et al., 2010). As of September 2011, a total of 26 undergraduate, 45 spatial or combined and 30 specialist master degrees are offered across 28 UK higher education institutions (Table 15). Student intake per annum varies widely by institution from 15 to over 200 students at schools offering first and second cycle degrees. Three schools offer undergraduate degrees that include a full year in practice that can contribute to the APC requirement for RTPI membership (Frank, 2010) while many others include shorter periods of workbased learning (Higgins \& Simpson, 1997). 
Table 15

UK institutions offering RTPI accredited planning degrees/AESOP membership.

\begin{tabular}{|c|c|c|c|c|c|c|}
\hline University & Department name & UG & $\begin{array}{l}\text { PG } \\
\text { comb }\end{array}$ & $\begin{array}{l}\text { PG } \\
\text { special }\end{array}$ & Doctoral & AESOP \\
\hline Anglia Ruskin University & Department of the Built Environment & & 1 & & & \\
\hline Birmingham City University & School of Property, Construction \& Planning & 1 & 1 & & & YES \\
\hline Cardiff University (Wales) & School of City and Regional Planning & 1 & 2 & c) +5 & レ & YES \\
\hline Heriot-Watt University (Scotland) & School of the Built Environment & 1 & 2 & & レ & YES \\
\hline Kingston University & School of Surveying and Planning & & 2 & & レ & YES \\
\hline Leeds Metropolitan University & School of the Built Environment & & a) +1 & 1 & & \\
\hline Liverpool John Moores University & School of the Built Environment & & 1 & & & \\
\hline London South Bank University & $\begin{array}{l}\text { Department of Urban, Environment and } \\
\text { Leisure Studies }\end{array}$ & 1 & a) +1 & 2 & & \\
\hline Newcastle University & $\begin{array}{l}\text { School of Architecture, Planning and } \\
\text { Landscape }\end{array}$ & 1 & 4 & 2 & レ & YES \\
\hline Oxford Brookes University & School of the Built Environment & 3 & 2 & 7 & $\boldsymbol{\nu}$ & YES \\
\hline Queens University Belfast (NIreland) & School of Planning, Architecture \& Civil Eng & 1 & 1 & 2 & レ & YES \\
\hline Sheffield Hallam University & Faculty of Development and Society & MPLAN 1 & 1 & 1 & & YES \\
\hline University of Cambridge & Department of Land Economy & & 1 & & $\boldsymbol{\nu}$ & YES \\
\hline University College London & Bartlett School of Planning & 1 & 3 & 2 & レ & YES \\
\hline University of Aberdeen (Scotland) & $\begin{array}{l}\text { School of Geosciences } \\
\text { Department of Geography and Environment }\end{array}$ & 4 & 2 & & レ & \\
\hline University of Birmingham & Centre for Urban and Regional Studies & & 1 & & レ & YES \\
\hline University of Brighton & School of Environment and Technology & & 1 & & & \\
\hline University of Dundee (Scotland) & $\begin{array}{l}\text { College of Arts \& Sciences, School of } \\
\text { the Built Envrnm. }\end{array}$ & MPLAN 1 & 1 & & $\boldsymbol{V}$ & \\
\hline University of Glasgow (Scotland) & School of Social and Political Studies & & 3 & & レ & YES \\
\hline University of Liverpool & $\begin{array}{l}\text { School of Env. Sciences, Department } \\
\text { of Civic Design }\end{array}$ & 1 & 1 & & レ & YES \\
\hline University of Manchester & School of Environment and Development & $\begin{array}{l}\text { BSc \& } \\
\text { MPLAN } 2\end{array}$ & 1 & 3 & レ & YES \\
\hline University of Plymouth & Faculty of Science and Technology & & b) 1 & & レ & \\
\hline University of Reading & $\begin{array}{l}\text { School of Business, Dept. of Real } \\
\text { Estate \& Planning }\end{array}$ & MPLAN 1 & 3 & & レ & YES \\
\hline University of Sheffield & Department of town and regional planning & MPLAN 1 & 3 & & レ & YES \\
\hline University of Strath-clyde (Scotland) & Department of Architecture & & & 1 & レ & \\
\hline University of Ulster (NIre) & School of the Built Environment & MPLAN 1 & & & $\boldsymbol{\nu}$ & \\
\hline University of the West of England & Faculty of Environment \& Technology & $\begin{array}{l}\text { BSc \& } \\
\text { MPLAN } 4\end{array}$ & a) +2 & 3 & レ & YES \\
\hline University of Westminister & $\begin{array}{l}\text { School of Architecture \& the } \\
\text { Built Environment }\end{array}$ & & 2 & 1 & レ & YES \\
\hline
\end{tabular}

(a) Partner in the Joint Distance learning MA in town Planning, (b) provisional accreditation (source: RTPI, 2011b), and (c) PLANET Europe. Erasmus Mundus partner. Also note: London School of Economics offers a planning masters and is listed in the online resource table but not above as the programme is not RTPI accredited.

Planning schools at four institutions (University of the West of England, Leeds Metropolitan University, London South Bank University and University of Dundee) and the Open University collaboratively offer Europe's only distance learning programme in planning (RTPI, 2011b) catering to a mix of international and non-traditional students. The programme was established in 1985 based on a commission by the Royal Town Planning Institute seeking to "replace professional examinations as a means to obtain chartered membership" (Allinson, 2008). The programme can be completed over a period of 3-7 years. Assessment is by a mixture of examinations, tutor-marked assignment and participation in university-based sessions for which each student is allocated to a study base at one of the consortium members' campuses. The main delivery mode was and is paper-based, allowing students considerable flexibility, but there are now attempts to modernise programme delivery with extensive use of an online, interactive, virtual learning environment. The programme has around 200 students registered at any given point in time $-20 \%$ of which are overseas students with a majority from Cyprus, Malta, Singapore, the USA and Canada.

While, many UK planning schools are active members of AESOP, they often struggle to engage in 
EU mobility programmes. Differences in semester schedules, degree length and tuition fee levels create considerable barriers to participation. That said, Cardiff University has become a partner in an Erasmus Mundus masters for which students complete different elements of the degree at different institutions (Table 1, PLANET Europe). A recent trend is to design courses suitable for professional recognition from more than one professional body to increase a degree's market value. Typical combinations are RTPI and Royal Institution of Chartered Surveyors (RICS), RTPI and Chartered Institute of Housing $(\mathrm{CIH})$, or RTPI and Institute for Logistic and Transport (ILT; for Transport planning masters).

\subsubsection{Guidelines and accreditation}

Quality assurance and accreditation of planning education is conducted via two parallel processes. On one hand all degree courses have to fulfil general quality assurance criteria and subject benchmarks set out by the host institution and the UK's quality assurance agency (QAA). On the other hand, there is the professional accreditation (or recognition) through the RTPI whereby course providers need to ascertain that RTPI's learning outcomes are met. Aside from undergraduate degrees, two types of master degrees are distinguished: the "spatial planning master" and a "specialist master" offering different pathways into the profession. A spatial planning master offers a general planning education for individuals with a background other than a RTPI accredited undergraduate degree. Specialist masters cater to students with a general undergraduate planning degree. This reflects the philosophy that planners' generalist knowledge should be complemented with specialist knowledge for professional practice (Perloff, 1957). Degree titles typically provide clues in this respect with spatial degrees being labelled Master in Town and Regional Planning, or Master in Spatial Planning and specialist degree titles being $M S c$ in Transport Planning, MA in Urban Design or MSc in Environmental and Sustainable Development and so forth. The most recent RTPI learning outcomes for planning curricula addresses this difference (RTPI, 2011a) (Fig. 11).

\subsubsection{Continued professional education}

Members of the RTPI are required to engage regularly in continued professional education (CPD). However, such activities are broadly defined ranging from attending a lecture or conference to certificate programmes. While, some universities offer CPD on specialist topics to practitioners, not all universities find it economically viable to engage in this kind of provision and much CPD is provided through specialist consultants.

\subsubsection{Doctoral studies}

Most institutions offer the possibility to gain a doctorate in planning. Intake is small with around 2-8 students annually per institution. To date there is no specific guidance for doctoral degrees in planning beyond that which is in place for third cycle degrees more generally in terms of research methods training, supervision, mentoring and progress monitoring. Similar to developments elsewhere in Europe, doctoral education in the UK has been shifting away from the individualised relationship between the supervisor and the student to include at least a second supervisor and regular progress checks. These developments seek to overcome the trap of the isolated research student, improve completion rates and offer doctoral candidates a wider forum for intellectual stimuli and exchange. However, the structure is not yet as developed as in other European countries where doctoral candidates are required to spent time in a different national context to acquire an international outlook (e.g., Denmark) or to accrue formal credits (e.g., Slovakia, Section 4.5.7).

\subsubsection{Conclusion, evaluation and outlook}

Planning in the UK is well recognised as a distinct profession with established mechanisms for selfregulation through its professional body. As membership in the professional body offers considerable benefits in furthering a planner's career and completing an accredited planning degree is the main pathway to membership, the RTPI's influence on planning education has been and is significant (Higgins, 2004). The Institute's approach to programme design has been criticised by academics (Amos et al., 1973; Healey, 1985) as over-prescriptive but it has undoubtedly helped to create and cement the demand for independent planning degrees. With the latest reforms to educational guidance in the first decade of the 21 st century, planning schools obtained greater flexibility in curriculum design (Batey, 2003). This made dual accreditation of degree courses with two or more professional bodies more feasible and planning providers have increasingly moved into this direction. The dual recognition offers students greater career choices upon graduation while also making explicit any specialist planning knowledge a graduate may have. This improves both student employability and marketability of the degree. In terms of knowledge and skills areas the RTPI introduced some new topics such as climate change (rather than 
Typical graduates from spatial planning programmes should be able to:

1. Explain and demonstrate how spatial planning operates within the context of institutional and legal frameworks.

2. Generate integrated and well substantiated responses to spatial planning challenges.

3. Reflect on the arguments for and against spatial planning and particular theoretical approaches, and assess what can be learnt from experience of spatial planning in different contexts and spatial scales.

4. Demonstrate how efficient resource management helps to deliver effective spatial planning.

5. Explain the political and ethical nature of spatial planning and reflect on how planners work effectively within democratic decision-making structures.

6. Explain the contribution that planning can make to the built and natural environment and in particular recognise the implications of climate change.

7. Debate the concept of rights and the legal and practical implications of representing these rights in planning decision making process.

8. Evaluate different development strategies and the practical application of development finance; assess the implications for generating added value for the community.

9. Explain the principles of equality and equality of opportunity in relation to spatial planning in order to positively promote the involvement of different communities, and evaluate the importance and effectiveness of community engagement in the planning process.

10. Evaluate the principles and processes of design for creating high quality places and enhancing the public realm for the benefit of all in society.

11. Demonstrate effective research, analytical, evaluative and appraisal skills and the ability to reach appropriate evidence based decisions.

12. Recognise the role of communication skills in the planning process and the importance of working in an interdisciplinary context, and be able to demonstrate negotiation, mediation, advocacy and leadership skills.

13. Distinguish the characteristics of a professional, including the importance of upholding the highest standards of ethical behaviour and a commitment to lifelong learning and critical reflection so as to maintain and develop professional competence.

Typical graduates from specialist planning programmes should be able to:

1. Engage in theoretical, practical and ethical debate at the forefront of the area of the specialism in the context of spatial planning.

2. Evaluate the social, economic, environmental and political context for the area of specialism

3. Evaluate the distinctive contribution of the specialism to the making of place and mediation of space.

4. Demonstrate the relationship within a spatial planning context of the particular area of specialism to other specialist areas of expertise.

5. Demonstrate the type and quality of skills that would be expected of a graduate from this the specialism undertaking the practice experience period of the APC.

6. Assess the contribution of the specialism to the mitigation of and adaptation to, climate change.

Fig. 11. RTPI learning outcomes. Source: RTPI (2011a).

sustainable development) and leadership and community participation. Remarkably little reference is made to internationalisation or Europeanisation within planning education, although there is a need to develop multicultural competencies and an awareness of the influence of globalisation on planning issues. The intensity of UK programmes, concerns of students and programme providers in respect to potential problems for recognising credits earned outside the UK, and a low level of foreign language proficiency of British students has so far posed barriers to the uptake of European mobility opportunities. However, this is not an issue limited to the discipline of planning but more widespread in UK higher education. Several planning schools have actively explored means to increase international student experiences creating so called mobility semesters with option modules only. Perhaps the strongest contribution to internationalisation is the large foreign academic workforce teaching planning in the UK (Ellis et al., 2010).

\subsection{Switzerland}

Switzerland, like many European nations is facing major challenges in spatial development, including extensive urban sprawl and traffic congestion. Land is a scarce and non-renewable resource - especially since $56 \%$ of the territory of Switzerland are considered uninhabitable (Keller \& Blaser, 2005). The nation's constitution thus prescribes an economical approach to 
land use (Institute for Spatial \& Landscape Development, 2008) promoting an integrated, re-use oriented development of existing settlements.

Switzerland's federal structure with 26 cantons, each having its own spatial planning regulations and the necessity to collaborate with neighbouring nations requires considerable cross-cantonal and cross-border coordination. To improve transboundary cooperation a novel concept of "regional action spaces" is currently being trialled. A regional action space defines a functionally connected territory across (parts of) two or more cantons within which cooperation should be intensified, and allowances need be made at all government levels to support this. The shift from administrative to functional space is meant to foster cooperation between the spatially relevant actors (various levels of public government and private) especially for difficult tasks. In addition, there is also recognition that formal planning instruments need to be complemented by informal processes and instruments.

Existing classifications for planning systems in Europe do typically not include the Swiss system, but it could be classed as "continental integrative-comprehensive" (Nadin \& Stead, 2008) due to its strong similarities with German and Austrian planning systems. However, the practice of direct democracy whereby citizens are regularly invited to vote for or against infrastructure and building projects leads to an interesting planning dynamic not experienced elsewhere. The fact that Switzerland is a multilingual country with four national languages (German, French, Italian and RhaetoRomanic) and a diverse topography ranging from fertile lowlands and foothills to barren, glaciated high-alpine areas adds further complexities for planners.

\subsubsection{Higher education structure}

Switzerland has 12 universities (ten cantonal and two federal institutions) and nine universities of applied sciences as well as a host of other higher education institutions specialising in arts, music, pedagogical or theological education. Educational matters are generally under the jurisdiction of the cantonal governments and the teaching language reflects the linguistic region. Examinations are held, as a rule, in one of the four national languages (German, French, Italian and Rhaeto-Romanic) or English. In Switzerland, universities tend to provide more theoretically orientated scientific education, whereas universities of applied sciences (Fachhochschulen) have a more professionalapplied orientation.

Following Switzerland's signing of the Bologna Declaration in 1999, an extensive structural and qualitative renewal of all institutions of higher learning and their programmes was initiated. All programmes use now the ECTS and levels and qualifications for awards have become more comparable and transparent. This has aided permeability between different institutional types and students completing a bachelor at a university of applied science have far fewer problems now to continue their studies for a second cycle degree at a university and vice versa.

First cycle degrees require three years (full-time study, 180 ECTS) and second cycle degrees require 90120 ECTS or 1.5-2 years of full-time study. Requirements for third cycle doctoral degrees are set individually by the awarding institution. Doctoral education is only available at universities and not at universities of applied science. However, universities of applied science can offer postgraduate degrees or continuing education qualifications in the form of Masters of Advanced Studies (MAS), Diplomas of Advanced Studies (DAS) or Certificates of Advanced Studies (CAS). Entry requirements for any advanced degree (MAS, DAS or CAS) usually consist of a second cycle degree and several years of work experience. In contrast to second cycle masters (MA or MSc), advanced study degrees are usually not subsidised by government and therefore incur higher tuition fees than first and second cycle degrees (Fig. 12).

\subsubsection{History of planning education}

Traditionally, the majority of spatial planning specialists in active practice have achieved the corresponding professional qualifications through their practice and a postgraduate (Master) or continuing education programmes in spatial (or specialist) planning (CAS/DAS/MAS), which are extensions of a basic tertiary education in one of the spatial sciences such as architecture, engineering, or geography and were started to be offered from 1945 onward (Keller \& Blaser, 2005). This approach reflects the philosophy of spatial planning education in Switzerland, which favours a spatially relevant basic academic education before proceeding to an education in the per se interdisciplinary or specialist areas of planning. Despite the geopolitical and linguistic fragmentation of the country, specialisation in planning for a particular area in Switzerland is not endorsed. Rather, planning education should support the diversity of planning tasks and the federal structure of the country. Spatial planning graduates therefore need to be able to understand spatially important questions, solve conceptual as well as concrete problems on a regional and national level. Interdisciplinary exchanges during the 


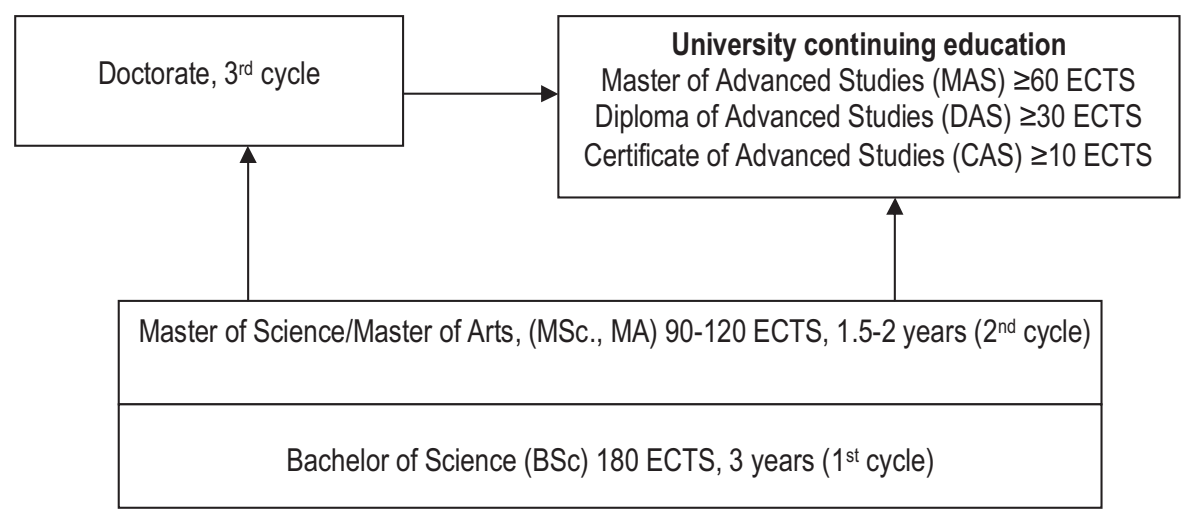

Fig. 12. Higher education degree structures in Switzerland.

study period are considered vital, because anyone who has experienced the difficulties that need to be overcome in a collaborative effort between subject areas will be sensitised for problems commonly encountered in planning practice.

In practice, planning education is structured around projects, which are based on real, unsolved planning tasks in Switzerland. In addition to using methods and planning instruments to develop solutions, the exchange with experts from public administration, management, economics and politics are part of the training. This pedagogy cultivates an integrated approach to spatial problem-solving as well as hones students' teamworking skills in preparation of professional practice.

\subsubsection{Planning education now}

Planning education opportunities in Switzerland are geographically biased - with education as well as continuing education programmes only being offered in the German- and French-speaking regions of Switzerland. Moreover, the majority of planning education provision in Switzerland is at Master (4 programmes) and advanced studies level. There is currently only one 1 st cycle general spatial planning education programme which is delivered at the University of Applied Science (UAS) of East Switzerland in Rapperswil (HSR). ${ }^{26}$ Institutions in the French-speaking part of Switzerland do not provide a first cycle planning degree that leads to professional qualification and there is no provision whatsoever in the Italian or Rhaeto-Romanic-speaking regions (Table 16). And, although post Bologna, planning education provision has increased with the establishment of new advanced studies programmes (MAS, DAS, CAS) in specialised planning topics there

\footnotetext{
${ }^{26}$ http://www.hsr.ch/spatialplanung.1151.0.html.
}

is still at present a shortage of broadly educated (generalist) planners. Further, there is a need for planners who have, in addition to their expert knowledge, competence in methods and management (Scholl, 2002, p. 47).

\subsubsection{Guidelines and accreditation}

With no state or professionally defined accreditation criteria for studies in spatial planning, institutions have considerable freedom to develop curricula in dialogue with practice stakeholders.

\subsubsection{Bachelor in spatial planning}

The University of Applied Sciences (UAS) Rapperswil is the only Swiss institution offering a BSc in Spatial Planning leading to an application-oriented professional planning qualification. Prerequisite for acceptance into the programme is a vocational diploma in a spatially relevant profession such as architectural, spatial planning, photogrammetry or civil engineering draughtsman or -woman. Alternatively, students with a federally recognised Matura diploma (college entrance qualification) are also accepted following completion of a 12 months internship in a cognate profession. Graduates of the programme have considerable practical planning skills and basic knowledge in the areas of economics, law, politics, society, environment, transport as well as architecture and design. For most students, the bachelor's degree completes their education, but especially qualified and motivated students can continue to a master's. The programme graduates circa 30-35 students per annum.

While the BSc in Spatial Planning at UAS in Rapperswil is the only general and professionally qualifying 1st cycle degree in Switzerland, there is a possibility to obtain a 1st cycle degree in a specific aspect of spatial planning with the Bachelor of Science 
in Geomatic Engineering and Planning ${ }^{27}$ at the ETH Zürich. Developed from a degree in cultural engineering, this programme is rooted in quantitative natural science and engineering with a focus on geographical information systems (GIS) as well as legal aspects. For this programme, applicants must have a federally recognised Matura diploma.

Career possibilities for graduates from both programmes include positions in private planning and engineering offices as well as in public administration.

\subsubsection{Master in spatial planning}

Entry to a master in planning will be offered to graduates from the above-described bachelor degrees or to graduates with a first cycle degree in a related discipline such as geography, engineering, environmental planning or architecture. In 2011, there were four master level programmes in spatial planning or spatial planning related disciplines on offer in Switzerland (Table 16) with an enrolment of nearly 300 students.

The MSc in Public Planning (90 ECTS, 1.5 years FT ${ }^{28}$ at UAS East Switzerland is oriented towards sustainable spatial, traffic and landscape planning, and includes cultural, economic, technical, and social knowledge area. Two projects, typically provided from contractors in the business or public sector, allow students to deepen their knowledge in a special subject and write a master's thesis. The two masters at the ETH Zürich each cover a specific aspect of planning. The MSc in Spatial Development and Infrastructure Systems (120 ECTS) ${ }^{29}$ focuses on transport and traffic planning in the context of spatial development, while the MSc in Geomatic and Planning (90 ECTS) ${ }^{30}$ provides education in geomatic and planning measurement and spatial development. Both programmes feature a project-based pedagogy. The fourth programme is a newly established degree with first student intake during the autumn 2011 at the UAS West Switzerland in Lausanne. This HES-SO (MSc) en Ingénierie du territoire (90 ECTS) ${ }^{31}$ is taught in French and focuses on built space and its environment including topics such as geomatics, planning law, environment, mobility and landscape.

\footnotetext{
${ }^{27}$ http://www.geomatik.ethz.ch/bachelor/.

${ }^{28} \mathrm{http}: / /$ www.hsr.ch/MRU-Public-Planning.1238.0.html.

29 http://re-is.ethz.ch/master.

${ }^{30}$ http://www.geomatik.ethz.ch/master/.

31 http://www.hes-so.ch/modules/formation/detail.asp?ID=289.
}

\subsubsection{Advanced studies and continued professional education}

As in Switzerland the education for spatial planners traditionally occurred at post-master level, a broad variety of advanced study degrees exist (MAS, DAS, CAS). They are usually provided via university institutes specialising in continued professional education.

In the German-speaking part of Switzerland, the Network City and Landscape (NSL) ${ }^{32}$ at the ETH Zürich, for example, offers a MAS in Spatial Planning $(90 \text { ECTS })^{33}$ which has been considered for many years the foremost professional planning education degree. This programme runs over two years part-time to accommodate working professionals with a background in architecture, geography, or planning law; prerequisite for acceptance is a minimum of two years of professional practice in spatial planning. Central to the programme are its interdisciplinary projects which typically focus on contemporary spatial problems in Switzerland and neighbouring countries. The newly established MAS in Spatial Development at the UAS in Rapperswil $^{34}$ is likewise designed for part-time study. It runs over five-semesters (60 ECTS) and focuses on project management, agglomeration planning, and questions of mobility as well as the use of GIS in planning. By contrast, the MAS in Community, City and Regional Development (60 ECTS) at Lucerne University of Applied Sciences and Arts emphasises social and economic aspects of spatial planning. In the Frenchspeaking region, the University of Lausanne in cooperation with the Universities of Geneva and Neuchâtel is offering a two-year MAS in Ecourbanism, Urban Sustainability and Governance (60 ECTS $)^{35}$ with a focus on urban ecology and sustainable development. In addition, a variety of shorter diploma and certificate programmes offer education and training in specialised areas such as the CAS (30 ECTS) in Planning for Urban Agglomerations $^{36}$ at the ETH Zürich. Overall, there are two main providers, the Network City and Landscape $(\mathrm{NSL})^{37}$ at ETH Zürich for the German-speaking parts of Switzerland and the Communauté d'études pour

\footnotetext{
32 http://www.nsl.ethz.ch/.

${ }^{33} \mathrm{http} / / /$ www.masraumplanung.ethz.ch/education/master/master11/ index_EN.

${ }^{34}$ http://www.hsr.ch/spatialentwicklung.5600.0.html.

35 http://www.unil.ch/ouvdd/page46993.html.

${ }^{36}$ CAS Planen in Agglomerationsräumen, 15 ECTS (FHO), CAS Regionalentwicklung und CAS Gemeinde- und Stadtentwicklung, je 15 ECTS (Hochschule Luzern).

${ }^{37}$ http://www.nsl.ethz.ch.
} 
Table 16

Institutions, programmes and student numbers in spatial planning and related education.

\begin{tabular}{|c|c|c|c|c|c|}
\hline Institution & 1st cycle Bachelor & 2nd cycle Master & $\begin{array}{l}\text { Doctoral education \& } \\
\text { postgraduate/CPD, } \\
\text { 3rd cycle, CPD }\end{array}$ & Language & AESOP \\
\hline $\begin{array}{l}\text { University of Applied Science } \\
\text { of Eastern Switzerland } \\
\text { Rapperswil }\end{array}$ & $\begin{array}{l}\text { BSc in Spatial } \\
\text { Planning ( } 3 \text { yrs) }\end{array}$ & $\begin{array}{l}\text { MSc in Public } \\
\text { Planning ( } 1.5 \text { years) }\end{array}$ & MAS in Spatial Development & German & Yes \\
\hline $\begin{array}{c}\text { The Swiss Federal Institute of } \\
\text { Technology (ETH Zürich) }\end{array}$ & $\begin{array}{l}\text { BSc in Geomatic } \\
\text { Engineering and } \\
\text { Planning ( } 3 \text { yrs })\end{array}$ & $\begin{array}{l}\text { MSc in Spatial } \\
\text { development and } \\
\text { Infrastructure systems } \\
\text { MSc in Geomatic } \\
\text { and Planning }\end{array}$ & $\begin{array}{l}\text { Doctorate } \\
\text { Master in Advanced Studies } \\
\text { (ETH) in spatial Planning } \\
\text { ( } 2 \text { years) } \\
\text { CAS (ETH) in spatial Planning } \\
\text { ( } 6 \text { months FT or PT depending), } \\
\text { Various CPD programmes }\end{array}$ & German, English & Yes \\
\hline University of Geneva & & & $\begin{array}{l}\text { CAS in sustainable urbanism, } \\
2 \text { semesters } \\
\text { MAS in Ecourbanism, Urban } \\
\text { Sustainability and Governance }\end{array}$ & French & \\
\hline $\begin{array}{l}\text { HES-SO University of Applied } \\
\text { Sciences of Western } \\
\text { Switzerland, Lausanne }\end{array}$ & & $\begin{array}{l}\text { HES-SO en Ingénierie } \\
\text { du territoire }\end{array}$ & & French & \\
\hline University of Lausanne & & & $\begin{array}{l}\text { Doctoral programme in "ville, } \\
\text { urbanisme and mobilite", MAS } \\
\text { in Ecourbanism, Urban } \\
\text { Sustainability and governance } \\
\text { DAS, CAS in Environmental } \\
\text { strategy and } \\
\text { economics }\end{array}$ & French & \\
\hline University of Neufchâtel & & & $\begin{array}{l}\text { MAS in Ecourbanism, Urban } \\
\text { Sustainability and Governance }\end{array}$ & French & \\
\hline $\begin{array}{l}\text { Lucerne University of Applied } \\
\text { Science }\end{array}$ & & & $\begin{array}{l}\text { MAS in Community, City and } \\
\text { Regional Development }\end{array}$ & German & \\
\hline
\end{tabular}

l'aménagement du territoire (CEAT) at UAS West Switzerland in Lausanne in the French language region.

\subsubsection{Doctoral studies}

Doctoral degrees in spatial planning related topics can be earned at either the ETH Zürich or the University of Lausanne. Responding to emerging guidance (e.g., Bergen Communique, 2005) for third cycle degrees which recommends providing more structure, research training and improved mentoring and supervision as well as international experience for doctoral students, several novel ideas have been explored in respect to doctoral education for spatial planning. In 2006, planning academics at the ETH Zürich initiated the Doctoral College Research Laboratory 'Space', ${ }^{38}$ a doctoral programme jointly run by a loosely coupled

\footnotetext{
$38 \mathrm{http} / / / \mathrm{w} w \mathrm{w}$. forschungslabor-raum.info.
}

network of a total of six universities from Germany and Austria. Under the auspices of the Research Laboratory these institutions offer joint seminars and methods training for a cohort of around 30 doctoral candidates in planning studying at the six partner institutions. The objective was to provide opportunities for intellectual debate and effective cross-fertilisation of ideas for emerging researchers working on similar topics.

\subsubsection{Professional recognition}

The profession of spatial planners does not have an institutionally protected title in Switzerland. Possible sectors of employment are manifold and include private planning offices and public administration. Planners also work as experts in engineering offices, the banking, insurance and transport sectors. The use of a title after a successfully completed education or obtaining membership in a professional body such as the Association of Regional Planning (Verein für Landesplanung (VLP)), 
the Association of Swiss Spatial Planners (Fachverband Schweizer RaumplanerInnen (FSU)), the Swiss Engineering and Architecture Association (Schweizerischer Ingenieur- und Architektenverein (SIA)), or the Swiss professional registration board (Stiftung der Schweizerischen Register REG) may require different qualifications depending on regulations which differ between cantons.

\subsubsection{Conclusion, evaluation and outlook}

In sum, a range of different degrees offering planning education exist in Switzerland, however 2nd cycle and advanced study degrees dominate the provision. Educational opportunities are limited to institutions in the French and German speaking parts of the country. At all levels, spatial planning education is strongly anchored in practice featuring a project-centred pedagogy. Traditionally, there was a clear differentiation of graduates' competencies and aspiration depending on the institution they attended. The majority of graduates with a bachelor's degree were and still are active in local and regional planning, whether in a private planning office or in public administration at the community or cantonal level. Spatial planners with a master's degree are perceived to have management potential required for positions at cantonal and national level. However, the introduction of a modular degree structure under Bologna has created a more flexible higher education system. Differences between employment prospects for university graduates and graduates from universities of applied sciences are becoming increasingly blurred. Nevertheless, spatial planning research is still dominated by university graduates. In response to market demand for more qualified planners and new skills/knowledge areas, several new Masters in Advanced Studies degrees have been established recently including one in ecourbanism, sustainability and governance at the UAS West Switzerland in Lausanne.

Swiss planning educators are highly active in maintaining a cutting edge approach in planning education provision. At the ETH Zürich, for example, educators have experimented with novel formats of inter-institutional doctoral education and training as in the doctoral college research laboratory space (20062010). They have also organised a series of workshops and seminars with international contributors exploring thematic areas, skills and competencies critical for future spatial planning practice (Scholl, 2012). The following thematic areas were identified as vital for future spatial planning practice: (a) Innovative and practice-oriented planning methods, instruments and processes, (b) integrated spatial and infrastructure development, (c) cross-border planning and spatial development; and (d) urban design. Pedagogically, projects were identified as a core element of an effective interdisciplinary planning education - while new possibilities for time- and location-independent learning (e-learning) need to be more and more adopted. This may be especially important in the Swiss context with its emphasis on advanced studies programmes catering to a market of professionals in the work place.

\section{Educating planners in Europe: evaluation and recommendations}

This study's aim was to take stock and examine the level and character of the educational provision in urban, regional or spatial planning in European countries at the start of the 21 st century. Building on previous studies, the goal was to better understand current trends and developments in the provision. A particular objective was to examine the impact of European integration policies, pan-European higher education reforms (Bologna Declaration, 1999) and general developments in higher education such as globalisation and massification upon education for planning, which has been traditionally nation- and context specific.

In sum, education for planning has evolved considerably from the initial post-professional programmes which were developed to up-skill architects, surveyors and engineers early in the 20th century in response to an emerging demand to provide better designs for town extensions. Curricula and focus of planning education has shifted for the most part beyond mere aesthetical, technical concerns to cover also social, environmental and economic aspects of city planning. Over the past decades, in particular, geographic information systems (GIS) training and to some degree simulation and modelling (transport, urban growth and environmental) have been integrated into many curricula in planning education, especially in schools with a technical focus. Interestingly, knowledge in GIS is listed as a requirement in Poland and Slovakia but is not explicit in the UK's RTPI learning outcomes. Sustainability, planning for resiliency and climate change, food and health as well as European-wide planning approaches are themes that are increasingly integrated in planning curricula.

Yet, concerns over the status of the discipline and quality and adequacy of the provision for planning are not unfounded and ought to be addressed to ensure future development, relevancy and support for the field. 
Independent and free-standing planning education degrees are still not the norm across European nations. The study reveals stark inequalities in the provision across countries corroborating findings from earlier reviews (Commonwealth Secretariat, 2011; Stiftel et al., 2009). The multitude of educational pathways and curricular orientations leads to a complexity and diversity that makes it not only difficult to compare degrees across national boundaries but also to specify a distinct identity of planning. The work of (inter)national associations and networks such as GPEAN, AESOP, APERAU and others in recent years as well as the quality assurance framework requirements stipulated for Bologna signatories has helped to increase awareness of existing diversities. This has improved prospects to enhance the provisions' quality through the exchange and dissemination of best practice in curriculum design and pedagogy. Educators need to urgently address how planning can reconcile national-professional needs with institutional demands to internationalise curricula. Relatively small planning education programmes that often rely on resource intensive pedagogies are increasingly vulnerable in light of rationalisation measures by institutions concerned about maximising research output and profit.

\subsection{Level and character of educational provision}

For the purpose of this study, the level of provision has been assessed, if crudely, by the number of institutions whereas the character of provision addresses programme content, format and pedagogy. The diversity of conceptions of what is understood by planning, let alone planning education, presented a sizable challenge and it became clear that our compilation will neither be entirely accurate nor complete. European or national level data on higher education does generally not offer sufficiently detailed subject classifications and as planning education is often provided within and under the label of overarching subjects such as engineering or architecture (e.g., Finland, see Section 4.3), no comprehensive list of programmes for education in planning can be derived. Most up to date information is typically held by professional associations and networks of providers which have been our primary source. However, as planning is rarely part of the canon of regulated professions in European countries and therefore not subject to statutory control of qualifications and education awards, membership is voluntary and selfselecting. Thus, the existence of programmes providing planning education can easily be overlooked, especially if providers or institutions are not associated with any national or international professional bodies or organisations. The study's list of 218 institutions (see online resource) offering planning education programmes of one sort or another, that allow graduates to practice planning from 36 of 47 Council of Europe member states and Kosovo is therefore a conservative account. It nevertheless represents an increase from the 155 institutions reported by Stiftel et al. in 2009 for Europe of around $1 / 3$ and suggests a steadily rising level of importance and recognition of the field.

As a very rough evaluative measure we deem the provision comparatively excellent for countries with population to institution ratios of up to 5 million: 1 and medium for those with ratios of 5-10 million:1 (Table 2 ). This leaves five nations (aside from very small nations such as Liechtenstein and those where no verifiable information could be obtained) where the provision for planning education appears underdeveloped: Hungary, Romania, Russian Federation, Spain, and Ukraine. The classification is basic at best and requires improvements in future but it offers at least some indication of the opportunities for developing planning capacity in various nations. It can be criticised from many different perspectives. Some programmes offer many more study places than others and ideally the quality of provision needs to be considered for a more balanced judgement. One could also argue that there may be a higher demand for planners in countries with a high level of urbanisation, but in light of emerging notions that planning is a key contributor for sustainable land and resource use such thinking may be misguided. Indeed, planning today covers much more than just the urban realm (e.g., Dalton, 2001; Birch \& Silver, 2009; Blanco et al., 2009a, 2009b).

Education leading to professional planning qualifications is offered in various formats: 1 st (Bachelor or traditional long-continuous) and 2nd cycle (Master) degree, post-professional awards (the latter are sometimes classed as 2nd cycle but also as CPD depending on programme length) and as specialisation within other fields of study. It should be noted that post-Bologna reforms, in many countries, professional associations do not deem a first cycle Bachelor sufficient for professional practice in planning. Interestingly, a Master in planning, regardless if the first degree was in planning or an unrelated subject, does provide a professional qualification. Doctoral degrees in planning are also offered and are becoming increasingly necessary for those wishing to work in academia.

The case studies illustrate clearly that education for planning in Europe assumes different models and 
formats in different countries. Rodriguez-Bachiller (1988, pp. 188-213) identified several educational models each of which can be associated with particular conceptions and professional ideologies of planning and the planner. With minor adjustments the same three models, each matching particular ideologies, can still be observed in the current provision (Table 17).

Model (1) conceives planning as a part of an established profession or field of study. It is the prevalent model for planning education in Spain and to a lesser degree in Portugal where a few comprehensiveintegrated programmes were established along the way. Under this model, planning education is delivered as minor or major specialisation in, for example, architecture, engineering, geography or sociology, with curricula containing on average between $5 \%$ and $15 \%$ content related to planning. Interestingly, in Portugal, civil engineering programmes have a greater market share in respect to planning education (Pereira \& Quadrado, 2010) while in Spain architecture is more prevalent. An alternative, Model (2), provides education for planning via postgraduate, post-professional degrees; it is an expression for the conception of planning as an extension of other disciplines or fields such as geography, politics, or law. This is the dominant (although not the only) format applied in Switzerland. Planning as a distinct professional field and discipline in its own right, perhaps the preferred conception by planning academics, is supported by the integrativecomprehensive Model (3). It has been widely adopted in the UK but matches also the newly developed curricula in Slovakia and Poland.

Considering the developments over the past twothree decades, it seems that planning education has not converged on a single, preferred educational approach but entertains a greater plurality of models today within nations than at the time of Rodriguez-Bachiller's study. This can be seen as positive, flexible and effective response to market conditions to provide professional skills and knowledge for the wide range of roles that planners are to assume (ECTP, 2003). However, it may not necessarily be helpful in providing a unified image of the planning profession and planning as a discipline.

A limited implementation of the integrative-comprehensive model, aside from cultural reasons, can possibly be related to costs. Model (3) entails combining academic and practical, analytical-theoretical with applied, intuitive and creative skills and knowledge, which pedagogically needs to be supported by project/studio, problem-based learning (e.g., Scholl, 2012) and, ideally, work experience. For a small field that at present lacks major government endorsements (unlike the technology sector) it will be difficult to maintain and justify high level education expenses especially with increasing resource scarcity and pressures to reduce teaching cost. It will matter little

Table 17

Educational Ideologies and Models for Planning.

\begin{tabular}{|c|c|c|c|}
\hline & Ideology & Education model(s) & Primary examples \\
\hline 1 & $\begin{array}{l}\text { Architect-planner/engineer-planner (here } \\
\text { planning is associated as belonging to } \\
\text { one discipline representing a particular } \\
\text { specialization within) } \\
\text { Intuitive, technical, applied }\end{array}$ & $\begin{array}{l}\text { Technical } \\
\text { a) Professional programme in architecture } \\
\text { or engineering with a relative limited } \\
\text { proportion of modules focusing on } \\
\text { planning/larger scale issues; longer } \\
\text { programmes are better for this (see Spain); } \\
\text { b) consecutive bachelor and master in } \\
\text { Architecture/ Engineering }\end{array}$ & $\begin{array}{l}\text { Spain, Portugal, Bulgaria, } \\
\text { Croatia, Albania, Czech Republic, } \\
\text { Denmark, Finland, Italy, } \\
\text { Netherlands, Norway, Poland, } \\
\text { Russia, Sweden, Greece }\end{array}$ \\
\hline 2 & $\begin{array}{l}\text { Planning as an extension of various social } \\
\text { sciences whereby the planner is either a } \\
\text { generalist coordinating the practice of } \\
\text { interdisciplinarity or as a specialist having } \\
\text { a particular spatial understanding of politics, } \\
\text { or an applied notion of geography etc. } \\
\text { Analytical, academic, (applied) - planning } \\
\text { as a supplemental qualification }\end{array}$ & $\begin{array}{l}\text { Postgraduate/academic } \\
\text { a) Postprofessional awards (e.g., urban } \\
\text { management /administration) } \\
\text { b) Master catering to students with a social } \\
\text { science/other technical background } \\
\text { c) Planning as Specialisation in bachelor or } \\
\text { master of Politics, geography, law }\end{array}$ & $\begin{array}{l}\text { Switzerland, Germany, Spain, } \\
\text { Norway, UK, Greece }\end{array}$ \\
\hline 3 & $\begin{array}{l}\text { Planning as an independent discipline with a } \\
\text { core of its own; planners as professionals are } \\
\text { experts in this and manage core techniques - } \\
\text { or specialize in various methods of } \\
\text { interdisciplinary analysis, normative policy } \\
\text { development etc. }\end{array}$ & $\begin{array}{l}\text { Integrative-comprehensive } \\
\text { a) Independent autonomous programmes } \\
\text { in planning } \\
\text { b) Consecutive bachelor-Master combinations }\end{array}$ & $\begin{array}{l}\text { UK, Austria, Greece, Germany, } \\
\text { Poland, Slovakia, Netherlands, } \\
\text { France, Italy, UK }\end{array}$ \\
\hline
\end{tabular}


if costs are internalised (i.e., covered by public state subsidy) or externalised through tuition fees. Moderate income prospects and social standing of planning professionals will not justify spending disproportional public or personal funds towards gaining a planning degree.

With the exception of one distance learning programme, planning education so far has not engaged much with novel approaches to programme delivery and online pedagogies. A reason might be that start-up investment in online provision is significant and cannot easily be supported by relatively small planning schools. More, the subject itself may not be suited to online delivery as a significant portion of planning skills development relies on team work, personal interaction and communication rather than individual study. Key pedagogies for planning education as identified by Scholl (2012), i.e., workshops and projects, are not easily delivered remotely. Yet, with access to technology becoming more ubiquitous (skype $\mathbb{C}$, videoconferencing etc.) it may be worthwhile for providers to reexamine the use of technologies in order to prepare graduates for future oriented work routines while also offering more flexible access to education. The exploitation of media and remote working technologies could potentially also address issues of international mobility of home and foreign students.

Planning education programmes are not only diverse in format but also in terms of curriculum content and pedagogy. Unlike in other fields (Frank et al., 2012) there are no international standards or guidelines for planning education however desirable (Harrison, 2003). AESOP has developed a generic core curriculum (Fig. 3) and updated it about a decade ago but it has no binding character. National level guidance for curricula and accreditation of programmes remain the norm but even those do not exist in every state (see Grams and Scholl, 2014). The style of guidelines varies from prescriptive apportioning of study time for certain subjects (e.g., Poland) to a list of learning outcomes. In this latter format it is up to the provider to demonstrate how and through what teaching these learning outcomes are achieved. The recent changes in Poland indicate that the learning outcomes approach may become more common in future. Not having to fight over the apportionment of study hours per subject will likely ease creating common criteria.

The need to regularly adjust programme contents to skill requirements has been highlighted by Keller and Blaser (2005). Updating of curricula content is triggered through either educator-practitioner dialogue (Switzerland), and/or formal professional or governmental guidelines (UK, Slovakia or Poland). Indeed, in Poland and Slovakia planning education programmes have been established following government determined core curricula precisely to address identified skills and knowledge gaps in spatial planning. In the UK, concern about the integration of environmental and sustainability issues in planning education has lately been shifted to recognising and mitigating implications of climate change as per the most recent version of learning outcomes (RTPI, 2011a).

Throughout Europe, the link of educational programmes, their curricula and the profession varies. In some countries professional bodies have direct influence on curricula by setting learning outcomes and participating in the accreditation of programmes, in others there is little dialogue or influence. While there is overall more oversight on programme quality, as in the wake of Bologna (see also Section 3.3.3), quality assurance requirements have been implemented throughout the signatory countries, accreditation alone - especially if it is along state determined guidelines cannot guarantee that degrees provide the right level of skills and knowledge to ensure graduate employability. In some countries professional bodies have asserted their disproval of curricula in rejecting 1 st level degrees as being sufficient for professional practice in planning and related disciplines. Reports that pedagogy and curricula have not kept pace with practice as, for example, in Finland are disconcerting. There surveys of professionals suggest that current provision falls short in offering the requisite skills and knowledge plans feel they need for practice. There is a need by education providers to make curricula relevant to future working conditions (European University Association, 2003) but, a relationship between education providers and professional bodies that is too dependent is also not desirable and could stifle the development of the field (Frank et al., 2012).

\subsection{European developments and emerging trends}

A range of recent European developments have influenced the provision of planning education. For example, the demise of communism, the liberation of Central and Eastern European nations and the expansion of the EU has resulted on one hand in revisions of planning practices and subsequently the education for planners (e.g., Frank \& Mironowicz, 2009), and on the other hand it has triggered a re-orientation of spatial planning research and teaching on European matters (Jammal, 1993). 
As the case studies of Poland and Slovakia illustrate, trajectories for the development and change of planning education are quite different in comparison. This uneven development applies to the entire former Eastern bloc nations. In both, Poland and Slovakia planning is a recognised profession and increasingly independent from architecture or other cognate subjects. At present a more structured institutional framework and partial regulation via the Chamber of Planners (Frank et al., 2012) has been implemented in Poland whereas the links between academia and practice seem to be stronger in Slovakia. Both countries have embraced an integrated-comprehensive model for education in planning but, while in Poland, education in planning has proliferated rapidly with new programmes being set up by a range of faculties from economics to architecture in Slovakia only one institution has implemented the new curriculum in "spatial planning." Even when the different population size of the two countries is taken into account, in Poland there are five times more opportunities to obtain a planning education than in Slovakia. Adaptations and development of planning education and curricula are progressing much slower in some of the other Central and Eastern European countries such as Romania, Czech Republic and Bulgaria where planning education mostly follows model one (e.g., Maier, 1994). In Albania comprehensive-integrated planning education programmes are being offered to date only in specialised private institutions.

European integration, which includes the above mentioned Eastern expansion but also builds on the establishment of a common economic market, political reconciliation and increasingly seeks to enhance the competitiveness of European countries at a variety of levels in the global context does not just effect planning education in Central and Eastern European countries. The process gained significant momentum in the late 1990s (e.g., Faludi, 2010) with the publication of the European Spatial Development Perspective (CSD, 1999) and the success of planning related programmes (e.g., INTERREG) which have stimulated a crossnational policy exchange on unprecedented scale. In conjunction with long standing initiatives such as the ERASMUS mobility and exchange programmes, and the Bologna Declaration (1999), this has led in our view to an emergent "Europeanisation" of (planning) education programmes. While definitions of "Europeanisation" in the literature are contested (Radaelli, 2004), the term is used here liberally to mean a diffusion and institutionalisation of shared ideas, concepts and structure with a focus on Europe amongst European institutions.
In this sense, "Europeanisation" is reflected in new curriculum content whereby a growing number of providers are including European-wide planning topics and instruments in their curricula in order to prepare students to use European instruments effectively and work in a European labour market. A few specialist Master degrees on European spatial planning have also been created. Additionally, "Europeanisation" becomes manifest in programme structure, formats and delivery. The (ongoing) Bologna reforms have and are establishing increasingly similar programme structures (although there is still considerable variance in implementation, nationally) and have facilitated the establishment of quality assurance frameworks. It has also created unexpected opportunities for rethinking planning education and adopting formats that may better fit prevailing ideologies. For example, in Portugal programme restructuring to achieve Bologna compliance has led to a reduction in Model (1) but also in comprehensive-integrated undergraduate programmes (Model (3)) provision. There is only one bachelor in planning left at the private Lusófona University in Lisbon. In Germany and the UK more and diverse specialist and spatial masters in planning were developed (Frank \& Kurth, 2010). This suggests, for good or bad, in the longer term there may be a trend towards Model 2 and the planning as extension of other disciplines approach as is prevalent in the USA. Finally, unique European delivery format are also emerging with integrated student mobility within Europe as a part of the study experience through the intensive programmes, or innovative Erasmus Mundus master and doctoral degrees where students study at different institutions and countries over the course of their degree, not seldom in different languages. These new degrees represent novel opportunities to gain wider understanding of planning cultures, systems and context.

For the third cycle, Bologna has triggered major adjustments to more systematic research training for doctoral studies. There is generally an effort to provide greater support, a cumulative credit system and encourage several months of research or experience at another institution to foster the development of broader knowledge. Academic networks such as AESOP or APERAU actively support the interaction and exchange amongst young/new planning academics and researchers.

At the same time, higher education institutions are engaging increasingly in an economically minded internationalisation seeking to attract non-European students by also switching to greater levels of English 
language provision of programmes. The debate about how European planning issues can be reconciled in a curriculum catering to large numbers of Asian and Middle Eastern students has not been had - except in parts of the sector in the UK (Peel \& Frank, 2008). So far no clear strategy is emerging. Especially unclear are the implications for the link between academia and the profession. In general, a one-world approach to planning education has a greater theoretical-academic focus, emphasising principles but not necessarily local practice, which might not be desirable. A focus on local practice alone will not be valuable to foreign students and longer term may also not serve home students as employers increasingly expect global competencies (e.g., Greif, 2012). This suggests that in future perhaps undergraduate provision will become less viable especially if it focuses on local planning practice with a rise in master level provision (Model 2, Table 17).

The differential status of the planning profession across Europe, the different conceptions and ideologies for planning and the planner create an obstacle to crossnational mobility of planning professionals in the European and international labour markets. Degree portability however is becoming increasingly a concern for graduates in a globalising world. International professional associations have started to address this. At the same time schools are looking increasingly to benchmark themselves against others looking for some kind of international quality label or accreditation. While APERAU is accrediting its member schools, AESOP is currently only offering advice through its socalled expert pool. Albeit highly problematic due to the diversity of national models for accreditation and quality assurance, calls for some form of international level accreditations have been arising occasionally (e.g., Harrison, 2003), but have so far not been implemented (Frank et al., 2012). A new initiative under the leadership of the ECTP-EU (2013a, 2013b) is currently underway to establish a common set of criteria, skills and knowledge in an effort to facilitate cross-national recognition of planning qualifications in Europe.

\subsection{Recommendations}

The review provides considerable food for thought. The field could definitely benefit from collaborative joined-up actions geared to enhance the profile and recognition of planning and make explicit its contributions to society by planning schools and professional societies. Although the future and shape of the European Union as a transnational body of governance and joint market might be unclear, there is little doubt that the internationalisation and Europeanisation of labour markets and higher education will continue. To strengthen the recognition of planning as a field in its own right we propose:

- to conduct regular monitoring of supply and demand for planning education across Europe. As we move to a more open, barrier-free EHEA it will be vital to have cross-national educational databanks and information as basis for higher education policy decisions, to raise awareness of what the field can contribute to solve societal problems, and for marketing to interested students and publishers. The EU platforms for searches of suitable project partners could be a model for a networked database of education provisions where those willing to seek out educational offers can develop their own cross-national education programmes. AESOP, APERAU, TUPOB, and other national planning schools associations may want to collaborate to produce the cornerstones of such an information set.

- to develop and implement a model of European-wide recognition of qualifications and agreed pathways to professional practice which is linked to programme accreditation and educational guidelines; although professional and academic associations such as AESOP and ECTP-CEU have started to cooperate on a scoping study (ECTP-CEU, 2013a, 2013b), further means will have to found to progress this so that within the framework of the European Programmes in 2020 the profession has a more 'European' profile and cross-national qualification recognition. Ultimately this might help to enhance quality and standards of degree programmes.

- to engage in documenting the achievements of planning and planners to urban development, resiliency, sustainability and enhancing quality of living environments.

- to engage in work on profiling different conceptions of planners and planning and monitor professional requirements on a regular basis, to ensure high levels of graduate employability and assure the relevance of degree programmes in higher education.

- to improve the understanding of HE administrators of planning as a professional field; with the identified future focus on HE performativity (Barnett, 2000, 2004) planning should take advantage of its dual orientation as both a discipline and professional field where innovative pedagogic approaches marry academic study and rigorous research training with experiential and reflective practical learning. 
- to examine the impact of new inter-institutional programmes on the profiles of planning graduates, to consider internationalisation impacts on the planning curriculum and to explore new pedagogies (online, conference style, and work-based study) to ensure the field's competitiveness, and to bridge practice and theory development to support reflective practice in students and professionals.

\section{Acknowledgements}

We are grateful for the help from colleagues and friends who assisted with data enquiries and collection. Particular thanks go to Judith Ryser for editing support, Mervi Ilmonen, and Jenni Ståhl, for their assistance in producing the Finnish case study, and Polish colleagues for providing details of Polish planning programmes. An earlier version of the Polish case study has been published by the UN online.

\section{Appendix A. Supplementary data}

Supplementary data associated with this article can be found, in the online version, at http://dx.doi.org/ 10.1016/j.progress.2013.05.001.

\section{References}

Ache, P., \& Jarenko, K. (2010). The adaptation of European planning schools to the Bologna Process. In A. Geppert \& G. Cotella (Eds.), Planning education No. 2. Quality issues in a consolidating European higher education area (pp. 11-30). Leuven: AESOP.

Adelman, C. (2008). The Bologna club: What U.S. higher education can learn from a decade of European reconstruction. Washington, DC: Institute for Higher Education Policy.

AESOP: Association of European Schools of Planning. (n.d.) Various data and information: AESOP Membership Directory, http:// www.aesop-planning.eu/en_GB/members-directory Accessed August 2012; AESOP Charter http://www.aesop-planning.eu/ en_GB/charter.

Afshar, F. (2001). Preparing planners for a globalizing world: The planning school at the University of Guelph. Journal of Planning Education and Research, 20(3), 339-352.

Albers, G. (1997). Zur Entwicklung der Stadtplanung in Europa: Begegnungen, Einflüsse Verflechtungen. Braunschweig: Vieweg.

Allinson, J. (2008). Personal Phone interview, 30 June 2008.

Alterman, R. (1992). A transatlantic view of planning education and professional practice. Journal of Planning Education and Research, 12(1), 39-54.

Alto University. (2011). Student enrolment http://arkkitehtuuri.tkk.fi/ engl/introduction.htm Accessed 13.1.11.

Alto University. (n.d.) Programme description, http://arkkitehtuuri.tkk.fi/engl/introduction.htm Accessed 13.1.11.

Amos, F., Burns, W., Cherry, G. E., Cockburn, C. K., Holliday, J. C., Koenigsberger, O. H., et al. (1973). Education for planning. The development of knowledge and capability for urban governance. Progress in Planning, 1(1), 1-108.
Babalik-Sutcliffe, E. (2012). Personal conversation, 13 July 2012.

Balducci, A., Fedeli, V., \& Pasqui, G. (2011). Strategic planning for contemporary urban regions. City of cities: A project for Milan. Farnham, UK: Ashgate.

Banachowicz, B. (2012). Personal conversation, 3 May 2012.

Barnett, R. (2000). Supercomplexity and the curriculum. Studies in Higher Education, 25(3), 255-265.

Barnett, R. (2004). Learning for an unknown future. Higher Education Research \& Development, 23(3), 247-260.

Batey, P. (2003). Introductory note: The planning education commission's report. Town Planning Review, 74(3), 331-332.

Batey, P. W. J. (1985). Postgraduate planning education in Britain. Its purpose, content and organisation. Town Planning Review, 56(4), 407-420.

Baum, H. (1994). A further case for practitioner faculty. Journal of Planning Education and Research, 14(1), 214-216.

Bergen Communique. (2005). The European higher education area Achieving goals. Communique of the conference of European ministers responsible for higher education http://ec.europa.eu/ education/policies/educ/bologna/bergen.pdf.

Birch, E. L., \& Silver, C. (2009). One hundred years of city planning's enduring and evolving connections. Journal of the American Planning Association, 75(2), 113-122.

Blanco, H., Alberti, M., Olshansky, R., Chang, S., Wheeler, S. M., Randolph, J., et al. (2009a). Shaken, shrinking, hot, impoverished and informal: Emerging research agendas in planning. Progress in Planning, 72, 195-250.

Blanco, H., Alberti, M., Forsyth, A., Krizek, K. J., Rodriguez, D. A., Talen, E., et al. (2009b). Hot, congested, crowded and diverse: Emerging research agendas in planning. Progress in Planning, 71, 153-205.

Bologna Declaration. (1999). http://ec.europa.eu/education/policies/ educ/bologna/bologna.pdf Accessed 2.7.12.

Booth, P. (2003). Planning by consent. The origins and nature of British development control. London: Routledge.

Brković, M. B. (2012). Societies in transition and planning education: The case of the West Balkan countries. In B. Scholl (Ed.), (2012) HESP - Higher education in spatial planning - Positions and reflections (pp. 152-165). Zürich, Switzerland: vdf Hochschulverlag AG, ETH Zürich.

Brown, C., Claydon, J., \& Nadin, V. (2003). The RTPI's education commission: Context and challenges. Town Planning Review, 74(3), 333-345.

Burayidi, M. A. (1993). Dualism and universalism: Competing paradigms in planning education? Journal of Planning Education and Research, 12(3), 223-229.

Bushell, H. (1864). City plans. Work and play, NY: Charles Scribner308-336.

Butler, N. L., \& Kritsonis, W. A. (2006). The impact of Poland's 1990 bill on schools of higher education. International Journal of Scholarly Academic Intellectual Diversity, 9(1), 1-8.

Castells, M. (1998). The education of city planners in the information age. Berkeley Planning Journal, 12, 25-31.

Central Statistical Office of Poland. (2007a). Maty rocznik statystyczny 2007 http://www.stat.gov.pl/cps/rde/xbcr/gus/PUBL_maly_rocznik_statystyczny_2007.pdf.

Central Statistical Office of Poland. (2007b). Demographic yearbook of Poland, Warsaw http://www.stat.gov.pl/gus/ 5840_4992_ENG_HTML.htm.

Central Statistical Office of Poland. (2011). Higher education institutions and their finances 2011, Warsaw http://www.stat.gov.pl/gus/ 5840_657_ENG_HTML.htm. 
Chamber of Town Planners in Poland. (n.d.). List of members. http:// izbaurbanistow.pl/ Accessed 30.5.08.

Chandler, E. W. (1985). The components of design teaching in a planning context. Town Planning Review, 56(4), 468-482.

Checkoway, B. (1998). Professionally related public service as applied scholarship: Guidelines for the evaluation of planning faculty. Journal of Planning Education and Research, 17(4), $358-360$.

Commonwealth Secretariat. (2011). Commonwealth capacity building for planning: Review of planning education across the commonwealth. London/Edinburgh: UCL Development Planning Unit and Commonwealth Association of Planners.

Correia, P. V. D. (2004). Portugal. In A. Fubini (Ed.), Improving planning education in Europe (pp. 434-438). Milano: FrancoAngeli.

CSD: Committee on Spatial Development. (1999). ESDP: European spatial development perspective. Luxembourg: Office for the Official Publications of the European Community.

Cuthbert, A. R. (1994a). An agenda for planning education in the nineties: Part I - Flexible production. Australian Planner, 31(4), 206-211.

Cuthbert, A. R. (1994b). An agenda for planning education in the nineties: Part II - The enduring crisis of planning. Australian Planner, 32(1), 49-55.

Dalton, L. C. (2001). Weaving the fabric of planning as education. Journal of Planning Education and Research, 20(4), 423-436.

Davoudi, S., \& Pendlebury, J. (2010). Evolution of planning as an academic discipline. Town Planning Review 2010, 81(6), 613-644.

Dima, A.-M. (2005). Higher education in Portugal. Country report. Centre for Higher Education Policy Studies, The Foundation for Science and Technology.

Dos Santos, L. (1998). O ensino e a formação profissional dos urbanistas em Portugal. Urbanismo e poder local: Jornadas internacionais, Coimbra 24 a 26 de Novembro de 1988: Comunicações. pp. 497-548.

Dühr, S., Colomb, C., \& Nadin, V. (2010). European spatial planning and territorial cooperation. London: Routledge.

EACEA: Education, Audiovisual \& Culture Executive Agenda. (n.d.). Erasmus Mundus. http://eacea.ec.europa.eu/static/en/mundus/ index.htm Accessed 13.6.08.

ECTP-CEU: European Council of Town Planners; Conseil européen des urbanistes. (2003). Founding charter online http://www.ceuectp.eu/index.php?option=com_content $\&$ view $=$ article $\&$ id $=89 \& I-$ temid=14 Accessed December 2012.

ECTP-CEU. (2013a). ECTP-CEU Study on the recognition of planning qualifications in Europe. Stage I report http://www.ectpceu.eu/index.php?option=com_content $\&$ view $=$ article $\&$ i$\mathrm{d}=229$ \&Itemid=131 Accessed January 2013.

ECTP-CEU. (2013b). Draft stage 2 study on the recognition of planning qualifications in Europe Draft report January 2013..

Egan, J. (2004). Skills for sustainable communities. The Egan review. London: Office of the Deputy Prime Minister.

Ellis, G., Morison, S., \& Purdy, J. (2008). A new concept of interprofessional education in planning programmes: Reflections on healthy urban planning project. Journal for Education in the Built Environment 3(2.).

Ellis, G., Murtagh, B., \& Copeland, L. (2010). Future of the planning academy. London: RTPI.

Etzkowitz, H., \& Leydesdorff, L. (2000). The dynamics of innovation: From National systems and "Mode 2" to a Triple Helix of university - Industry - Government relations. Research Policy, 29, 109-123.
Etzkowitz, H., Webster, A., Gebhardt, Ch. , \& Terra, B. R. C. (2000). The future of the university and the university of the future: Evolution of ivory tower to entrepreneurial paradigm. Research Policy, 29, 313-330.

European Commission. (1983). European spatial/regional planning charter. Torremolinos: EC - CEMAT Strasbourg. http://www.coe.int/ t/dg4/cultureheritage/heritage/cemat/Version Charte/Charte_bil.pdf.

European Commission. (1997). The EU compendium of spatial planning systems and policies. Luxembourg: Office for Official Publications of the EC.

European Commission, Directorate General for Education and Culture. (2010). Lifelong learning programme. The Erasmus programme. 2008/2009. A statistical overview. Brussels: EU.

European University Association [EUA]. (2003). Trends 2003: Progress towards the European higher education area. Brussels: European University Association.

Faludi, A. (2010). Cohesion, coherence, cooperation: European spatial planning coming of age? London: Routledge.

Finnish National Board of Education. (2008). Education in Finland. Helsinki: Finnish National Board of Education.

FISE. (2011). http://www.fise.fi/default/www/suomi/patevyysvaatimukset_ja_patevyyshakemuslomakkeet/kaavan_laatijat/ Accessed 15.01.11.

Fitzgerald T., White J. \& Gunder H. M. (Eds.), Hard labour? Academic work and the changing landscape of higher education. International perspectives on higher education research series (Vol. 7). Bingley, UK: Emerald Books.

Forsyth, A., \& Gross, M. (1998). Transatlantic lessons: Developing planning degree programs in provincial Russia. Journal of Planning Education and Research, 17(3), 259-273.

Frank, A. (2006). CPL bibliography 376: Three decades of thought on planning education. Journal of Planning Literature, 21(1), 15-67.

Frank, A. (2007). Entrepreneurship and enterprise skills: A missing element of planning education? Planning Practice and Research, 22(4), 635-648.

Frank, A. (2010). Making a case for student learning from year long work-based placement in town planning. Learning and Teaching in Higher Education, 4(2), 21-45.

Frank, A. (2012). Planning (education) - From marginal interface to central opportunity space? (Interface) Planning Theory and Practice, 13(3), 467-471.

Frank, A., \& Kurth, D. (2010). Planning education in Germany: Impact of the Bologna Agreement. DisP, 182, 25-35.

Frank, A., \& Mironowicz, I. (2009). Planning education in Poland. Unpublished case study prepared for Global Report on Human Settlements 2009 http://www.unhabitat.org/downloads/docs/ GRHS2009CaseStudyChapter10Poland.pdf.

Frank, A., Kurth, D., \& Mironowicz, I. (2012). Accreditation and quality assurance for professional degree programmes: Comparing approaches in three European countries. Quality in Higher Education, 18(1), 75-95.

Friedmann, J. (1996). The core curriculum in planning revisited. Journal of Planning Education and Research, 15(2), 89-104.

Fubini, A. (Ed.). (2004). Improving planning education in Europe. Milano: FrancoAngeli.

Fulton, O., Santiago, P., Edquist, C., El-Khawas, E., \& Hackl, E. (2007). OECD reviews of tertiary education: Poland. Paris: OECD. www.eng.nauka.gov.pl/_gAllery/31/80/3180/OECD_Tertiary_Reviews_POLAND_2007.pdf Accessed May 2008.

Geppert, A., \& Cotella, G. (Eds.). (2010). Planning education no. 2. Quality issues in a consolidating European higher education area. Leuven: AESOP. 
Geppert, A., \& Verhage, R. (Eds.). (2008). Planning education no. 1. Towards a European recognition of the planning profession. Leuven: AESOP.

Giannakourou, G. (2005). Transforming spatial planning policy in Mediterranean countries: Europeanization and domestic change. European Planning Studies, 13(2), 319-331.

Godfrey, K. B., \& Glasson, J. (1997). The appeal of planning education in the UK: Findings from a 1994 student survey. Planning Practice and Research, 12(2), 161-168.

Gospodini, A., \& Skayannis, P. (2005). Towards and 'integration model' of planning education programmes in a European and international context: The contribution of recent Greek experience. Planning Theory and Practice, 6(3), 355-382.

Grant, M. (1999). Planning as a learned profession. Planning, 1299, 5-6.

Greif, F. (2012). Urban and spatial planning - Higher educational requirements from the perspective of an independent planning office. In B. Scholl (Ed.), (2012) HESP - Higher education in spatial planning - Positions and reflections (pp. 122-127). Zürich, Switzerland: vdf Hochschulverlag AG, ETH Zürich.

Gurran, N., Norman, B., \& Gleeson, B. (2008). Planning Education Discussion Paper. Prepared for the Planning Institute of Australia. http://www.planning.org.au/documents/item/67 Accessed 13.02.12.

Hall, P. (1996). Cities of tomorrow. An intellectual history of urban planning and design in the 20th century. Oxford: Blackwell.

Harrison, P. (2003). Towards the international accreditation of education in planning. Newsletter of the Commonwealth Association of Planners CAP News, 9, 5-7.

Healey, P. (1985). The professionalisation of planning in Britain: Its form and consequence. Town Planning Review, 56(4), 492-507.

Healey, P., \& Samuels, O. (1981). British planning education in the 1970s and 1980s. London: Social Science Research Council.

Hedelin, B. (2005). Potential implications of the EU Water Framework Directive in Sweden. European Journal of Spatial Development 14 .

Higgins, M. (2004). The United Kingdom. In A. Fubini (Ed.), Improving planning education in Europe (pp. 445-453). Milano: FrancoAngeli.

Higgins, M., \& Simpson, F. (1997). Work-based learning within planning education: A good practice guide. London: Discipline Network in Town Planning, University of Westminster Press.

Hirt, S., \& Stanilov, K. (2009). Revisiting urban planning in transitional countries Unpublished regional study prepared for Global Report on Human Settlements 2009. http://www.unhabitat.org/ downloads/docs/GRHS2009RegionalTransitionalCountries.pdf. Accessed 3.7.10.

Hurlimann, A. (2009). Responding to environmental challenges: An initial assessment of higher education curricula needs by Australian planning professionals. Environmental Education Research, 15(6), 643-659.

Institute for Spatial and Landscape Development. (2008). Spatial Planning and Development in Switzerland. Report of international experts to the Swiss Federal Office of Spatial Development (ARE). http://www.irl.ethz.ch/re/publications/PDF_docs/ch_eva_engl.pdf Accessed 30.1.12.

Jääskeläinen, L., \& Syrjänen, O. (2003). Maankäyttö-ja rakennuslaki selityksineen. Helsinki: Rakennustieto.

Jammal, I. M. (1993). Country profiles of international planning education in Europe. Environment and Planning B: Planning and Design, 20, 585-605.

Kangasoja, J., Mälkki, M., Puustinen, S., Hirvonen, J., \& Mäntysalo, R. (2010). Architectural education as basis for planning work - The pros and cons of professional enculturation. Journal for Education in Built Environment, 5(2), 25-38.

Keeling, R. (2006). The Bologna Process and the Lisbon Research Agenda: The European commission's expanding role in higher education discourse. European Journal of Education, 42(2), 203-223.

Keller, D. A., Koch, M., \& Selle, K. (1996). 'Either/or' and 'and': First impressions of a journey into the planning cultures of four countries. Planning Perspectives, 11(1), 41-54.

Keller, P., \& Blaser, C. (2005). Which Education for Which Planning in Switzerland. Paper presented at AESOP Congress in Vienna, July 2005. http://e-collection.ethbib.ethz.ch/eserv/eth:29539/eth29539-01.pdf.

Kunzmann, K. R. (1985). Educating planners in Europe: Trends and requirements: An international perspective. Town Planning Review, 56(4), 442-457.

Kunzmann, K. R. (1991). Planning transatlantic - Planning education in the nineties between San Francisco, Oxford, Brussels, and Weimar. Environment and Planning B, 18(2), 140-145.

Kunzmann, K. R. (2004). Unconditional surrender: The gradual demise of European diversity in planning. PlanerIn, 4, 5-7.

La Greca, P. (2012). From urban design to regional policies: A new role for planners in Italy. In B. Scholl (Ed.), (2012) HESP - Higher education in spatial planning - Positions and reflections (pp. 166173). Zürich, Switzerland: vdf Hochschulverlag AG, ETH Zürich.

Lamiquiz, P. (2004). The national system of planning research in Spain. In A. Fubini (Ed.), Improving planning education in Europe (pp. 321-336). Milano: FrancoAngeli.

Lorens, P. (2012). Building sustainable cities - Challenge for professional education with special attention on Poland. In B. Scholl (Ed.), (2012) HESP - Higher education in spatial planning Positions and reflections (pp. 176-185). Zürich, Switzerland: vdf Hochschulverlag AG, ETH Zürich.

Lourenço, J. M., \& Klein, P. (2001). Formação em Ordenamento do Território e Urbanismo: Uma Reflexão. Engenharia Civil, 10, 67-76.

Lourenço, J. M. (2003). Expansão Urbana. Gestão de Planos Processo. Textos Universitários da Fundação Calouste Gulbenkian.

Lourenço, J. M., Guedes, M. G., Filipe, A. I., Almeida, L., \& Moreira, M. A. (2007). Bolonha: Ensino e Aprendizagem por Projecto. Editora Centro Atlântico.

Maier, K. (1994). Planning and Education in Planning in the Czech Republic. Journal of Planning Education and Research, 13(4), 263-269.

Mangels, K., \& Cotella, G. (2012) Awareness-Raising for European Territorial Cohesion in Planning Education with Reference to Italian and German Examples. Presentation Paper presented at the AESOP Annual Congress, Ankara, Turkey, 11-15 July 2012.

Markowski, T., \& Mironowicz, I. (2008). Perspektywy kształcenia planistów w Polsce [Future of education of planners in Poland]. Urbanista, 4(64), 2008.

Martin, S., Hartley, K., \& Cox, A. (1999). Public procurement directives in the European union: A study of local authority purchasing. Public Administration, 77(2), 387-406.

Matulíková, I., \& Rehorovská, J. (2010). International student's guide to Slovakia (3rd ed.). Bratislava: SAIA.

McLoughlin, B. (1994). Center or periphery? Town planning and spatial-political economy. Environment and Planning A, 26(7), 1111-1122.

Mironowicz, I. (2006). Podstawy programowe ksztalcenia na kierunku gospodarka przestrzenna [Teaching guidelines for planning education]. In Kudłacz, T. (Ed.), Teoria i praktyka w zakresie edukacji kadr dla gospodarki przestrzennej. Theory and practice of planning educationBiuletyn KPZK PAN vol. 224. 
Mironowicz, I. (2007). O zbytecznym kształceniu krawców na ogrodników czyli jak kształcić urbanistów? [On the useless retraining of tailors into gardeners, or how to teach urban planners?]. Urbanista $4(52)$.

Mironowicz, I. (2010). Specyfika kształcenia planistów na uczelniach technicznych [How to teach planners at universities of technology]. In T. Markowski \& T. Kudłacz (Eds.), Poprawa jakości $i$ efektywności planowania $i$ zarzadzania rozwojem $w$ administracji publicznej: Wyzwania wobec ksztatcenia na kierunku gospodarka przestrzenna. Improvement of the quality and effectiveness of planning and development management in public administration: Challenges for planning educationWarszawa: Komitet Przestrzennego Zagospodarowania Kraju PAN.

Morgan, K. (2009). Feeding the city: The challenge of urban food planning. International Planning Studies, 14(4), 429-436.

MSc in Geographical Information Management and Application. (n.d.) Programme description. http://www.msc-gima.nl/.

Mundus Urbano. (2007). Programme description http://www.mundus-urbano.eu/programme/ Accessed 13.6.08.

Myers, D., \& Banerjee, T. (2005). Toward greater heights for planning. Journal of the American Planning Association, 71(2), 121-129.

Nadin, V., \& Stead, D. (2008). European spatial planning systems, social models and learning. DisP, 172, 35-48.

Needham, B. (2004). The Netherlands. In A. Fubini (Ed.), Improving planning Education in Europe (pp. 414-420). Milano: FrancoAngeli.

Newman, P., \& Thornley, A. (1996). Urban planning in Europe: International competition, national systems, and planning projects. London: Routledge.

Ninot Pie, R. (2005). Urban teaching in schools of architecture in Spain. Urban 10, Magazine of the department of Urban and Regional Planning, Madrid: Madrid Polytechnic University.

Ozawa, C. P., \& Seltzer, E. P. (1999). Taking our bearings. Mapping a relationship among planning practice, theory and education. Journal of Planning Education and Research, 18, 257-266.

Parliament of the Czechoslovak Republic. (1990). Law Act 172/1990 Zb. on Higher Education Establishments http://www.zbierka.sk/ zz/predpisy/default.aspx?PredpisID $=13885 \&$ FileName $=97 z 030 \&$ Rocnik=1997.

Parliament of the Kingdom of Spain. (2007a). Royal Decree 1393/2007.

Parliament of the Kingdom of Spain. (2007b). Royal Decree ECI $3856 / 2007$.

Parliament of the Kingdom of Spain. (2010). Royal Decree 861/2010, EDU/2075/2010.

Parliament of the Republic of Poland. (1990). Act on Higher Education (Dz.U $1990 \mathrm{nr} 65$ poz. 385) http://isap.sejm.gov.pl/DetailsServlet?id=WDU19900650385 Accessed August 2012.

Parliament of the Republic of Poland. (2005). Act on Higher Education (Dz.U. 2005 nr 164 poz. 1365) http://isap.sejm.gov.pl/DetailsServlet?id=WDU20051641365 Accessed August 2012.

Parliament of the Republic of Poland. (2010). Act on Change of the Act on Higher Education (Dz.U. 2010 nr 75 poz. 471) http:// isap.sejm.gov.pl/DetailsServlet?id=WDU20100750471+2010\% 2405\%2420\&min=1 Accessed August 2012.

Parliament of the Republic of Poland. (2011). Act on Change of the Act on Higher Education (Dz.U. 2011 nr 84 poz. 455) http:// isap.sejm.gov.pl/DetailsServlet?id=WDU20110840455+2011\% 2410\%2401\&min=1 Accessed August 2012.

Parliament of the Slovak Republic. (2002). Law Act 131/2002 Z.z. on Higher Education Establishments http://web.tuke.sk/lf/legislativa/ 131_2002.pdf.
Pawłowski, K. K. (1973). Narodziny miasta nowoczesnego. Sztuka drugiej połowy XIX w. Materiały sesji Stowarzyszenia Historyków Sztuki.

Peel, D. (2011). Signature pedagogies and the built environment. Journal of Education in the Built Environment, 6(2), 1-7 http:// www.cebe.heacademy.ac.uk/jebe/pdf/DeborahPeel6(2).pdf Accessed 10.8.12.

Peel, D., \& Frank, A. (2008). The internationalisation of planning education: Issues, perceptions and priorities for action. Town Planning Review, 79(1), 757-776.

Pereira, R., \& Quadrado, J. C. (2010). Diversity aspects of Portuguese engineering education under the strategic management planning. IGIP-SEFI Annual Conference.

Perloff, H. (1957). Education for planning: City, state and regional. Baltimore: John Hopkins University Press.

Pezzoli, K., \& Howe, D. (2001). Planning pedagogy and globalization: A content analysis of syllabi. Journal of Planning Education and Research, 20(3), 365-375.

Planning Degree descriptions in Portugal. (various years). https:// fenix.ist.utl.pt/cursos/met, https://webserv.dec.uc.pt/weboncampus/2modulecursos.do?idcurso=39, http://www.civil.uminho.pt/ meu_uk.htm, http://www.fa.utl.pt/index.php?option=com_content\&task=view\&id=505\&Itemid=27, http://www.fe.up.pt/si_uk/ cursos_geral.FormView?P_CUR_SIGLA=MIEC, http:// www.gri.uac.pt/en, http://www.ua.pt/guiaonline/PageCourse.asp$\mathrm{x}$ ?id=103\&b=1\&lg=en, Universidad dos Azores (2010, 2012). Programme description. http://www.gri.uac.pt/en (October 2010, and August 2012).

Polish Ministry of Education. (2012). 2010/10 statistics http:// www.nauka.gov.pl/szkolnictwo-wyzsze/dane-statystyczne-oszkolnictwie-wyzszym/v Accessed 31.7.12.

Radaelli, C. M. (2004). Europeanisation - Solution or problem? European Integration Online Paper (EioP),8(16) http://eiop.or.at/eiop/texte/2004-016a.htm.

Rodriquez-Bachiller, A. (1988). Town planning education: An international survey. Aldershot: Avebury.

Rodwin, L., \& Sanyal, B. (Eds.). (2000). The profession of city planning: Changes, images and challenges 1950-2000. New Brunswick, NJ: Centre for Urban Policy Research.

Royal Town Planning Institute (RTPI). (2003). Education Commission Report http://www.rtpi.org.uk/resources/publications/educationcommission/report.pdf Accessed May 2008.

Royal Town Planning Institute (RTPI). (2004). Policy Statement on Initial Planning Education http://www.rtpi.org.uk/download/237/ Policy-Statement-on-Initial-Planning-Education.pdf Accessed December 2010.

Royal Town Planning Institute (RTPI). (2011a). Revised Learning Outcomes for RTPI Accredited Courses http://www.rtpi.org.uk/ item/4514\&ap=1 Accessed 30.11.11.

Royal Town Planning Institute (RTPI). (2011b). List of 2011/12 RTPI Accredited Courses http://www.rtpi.org.uk/item/178/23/5/3 Accessed 15.11.11.

Ryser, J., \& Franchini, T. (Eds.). (2008). International manual of planning practice. The Hague: International Society of City and Regional Planners.

Sandercock, L. (1997). The planner tamed. Australian Planner, 34(4), 90-95.

Scholl, B. (2002). Anforderungen an die Raumplanung und Konsequenzen für die Ausbildung. DisP, 148, 42-57.

Scholl, B. (Ed.). (2012). (2012) HESP - Higher education in spatial planning - Positions and reflections. Zürich, Switzerland: vdf Hochschulverlag AG, ETH Zürich. 
Schuster, G. (1950). Report of the committee on the qualifications of planners (Cmd8059). London: HMSO.

Schwarz, S., \& Westerheijden, D. F. (Eds.). (2004). Accreditation and evaluation in the european higher education area. Dortrecht: Kluwer.

Shaw, T., Pendlebury, J., \& Mawson, J. (2003). The supply and demand for qualified planners. London: RTPI.

Sigalas, E. (2010). Cross-border mobility and European identity: The effectiveness of intergroup contact during the ERASMUS year abroad. European Union Politics, 11(2), 241-265.

Sikorová, T. (2007). Slovak University of technology in Bratislava 70 Years. Bratislava: Vydavatel'stvo STU.

Skayannis, P. (2011). Personal conversation.

SPRING. (n.d.). International Joint MSc in Spatial Planning for Regions in Growing Economies - SPRING. Programme description. http://www.raumplanung.uni-dortmund.de/geo/typo3/ index.php?id=39 Accessed August 2012.

Stiftel, B., Demerutis, J., Frank, A. I., Harper, T., Inkoom, D. K. B., Lee, L., et al. (2009). Chapter 10: Planning education. In UN Habitat (Ed.), Planning sustainable cities. UN Habitat Global Report on Human Settlements. London: Earthscan.

Trow, M. (2000). From mass higher education to universal access: The American advantage. Minerva, 37(4), 1-26.

Trow, M. (2005). Reflections on the Transition from Elite to mass to Universal Access: Forms and Phases of Higher Education in Modern Societies since WWII. Berkeley: eScholarship Publication of the Institute of Governmental Studies, University of California. http://escholarship.org/uc/item/96p3s213 Accessed 10.12.12.

UN Habitat. (2009). Planning sustainable cities. London: Earthscan.

University College London. (n.d.). A Brief History of the Bartlett, http://www.bartlett.ucl.ac.uk/general/admissions/history.htm Accessed December 2010.

University of Valencia, Centre for Urban Development and Environmental Managment (CUDEM), EU-POLIS sistemi urbani europei e mediterranei, University of Dortmund, University of Graz, NORDREGIO, et al. (2006). ESPON Project 2.3.2 - Governance of Territorial and Urban Policies from EU to Local Level. Valencia: Draft Final Report.

Vaytens, A. G. (2012). The problems of planning education in Russia and St. Petersburg: Heritage, at present and perspectives. In B. Scholl (Ed.), (2012) HESP - Higher education in spatial planning - Positions and reflections (pp. 1186-1191). Zürich, Switzerland: vdf Hochschulverlag AG, ETH Zürich.

Virtanen, P. (2004). Finland. In A. Fubini (Ed.), Improving planning education in Europe (pp. 398-402). Milano: FrancoAngeli.

Watson, V. (2007). Revisiting the role of urban planning: Concept paper for the 2009 global report on human settlements. Cape Town: University of Cape Town.

Weltgruber, B., \& Csekel, L. (2009/10). Bologna 1999-2010: Achievements, challenges and Perspectives. Ministry of Science and Research (Austria) and Ministry of Education and Culture (Hungary). Berlin: Raabe. http://www.duz.de/docs/downloads/ duz_spec_Bologna.pdf Accessed 15.11.2011.

Westerheijden, D. F., Beerkens, E., Cremonini, L., Huisman, J., Kehm, B., Kovac, A., et al. (2010). The first decade of working on the European Higher Education Area - The Bolonga Process Independent Assessment (Vol. 1). Kassel: CHEPS, International Centre for Higher Education research/ECOTEC. www.utwente.nl/cheps/ publications Accessed 10.12.12.

Wildavsky, A. (1973). If planning is everything, maybe its nothing. Policy Sciences, 4, 127-153.
Williams, R. H. (1989). Internationalizing planning education, 1992 and the European ERASMUS program. Journal of Planning Education and Research, 10(1), 75-78.

\section{Glossary}

AESOP: Association of European Schools of Planning (a network of institutions providing planning education); www.aesop-planning. eu

APC: Assessment of professional competence

APERAU: Association pour la Promotion de l'Enseignement et de la Recherche en Aménagement et Urbanisme (a network of institutions offering planning education in Francophone countries); www.aperau.org/organismes.html

$B S c$., BA., Bc.: Bachelor of Science, Bachelor of Arts; Bachelor; first cycle (undergraduate) degree title; as planning education is offered through science and arts faculties both degree titles coexist as in $B A$ in Planning and Urban Design; or BSc in City Planning. Some countries just use Bachelor in [subject] i.e., urban planning without the distinction between sciences or arts.

CAS: Certificate of Advanced Studies (Swiss title of a CPD degree)

CoE: Council of Europe; an international body with 47 member countries. The aim of the $\mathrm{CoE}$ is to create a common democratic and legal area throughout the continent; www.coe.int

$\mathrm{CIH}$ : Chartered Institute of Housing, professional body for those working in the housing sector in the UK; www.cih.co.uk

$C A P$ : Commonwealth Association of Planners; www.commonwealth-planners.org

$C P D$ : Continued Professional Development

CSD: Committee on Spatial Development of the European Commission

CSERP: Committee for Spatial Economy and Regional Planning of the Polish Academy of Science

DAS: Diploma in Advanced Studies (Swiss title of a CPD degree)

Dipl-Ing: Diplom Ingenieur (pre-Bologna degree title awarded in technical disciplines following completion of a 4 or 5 year undergraduate, first degree programme)

D.Sc: Doctor of Science, 3rd cycle degree title; see also $\mathrm{PhD}$

EACEA: The Education, Audiovisual and Cultural Executive Agency (of the EC) manages certain cultural and educational programmes of the EU; eacea.ec.europa.eu/index_en.php

$E C$ : European Commission, a governance body, which represents the interest of the European Union with its 27 member countries (as of 2012); ec.europa.eu

ECTP, ECTP-CEU: European Council of Town Planners - Conseil Européen des Urbanistes: umbrella organisation for spatial planning institutes in Europe; www.ectp-ceu.eu

ECTS: European Credit Transfer and Accumulation System; a currency to allow students to transfer credits earned at an institution other than their home institution and have it count towards their degree.

EEC: European Economic Community; international organisation created in 1957 and superseded by the European Community and European Union (EU)

EHEA: European Higher Education Area: a region of countries within which comparable, compatible and coherent systems of higher education exist. Its creation was one objective of the Bologna process.

ERASMUS: EU programme supporting mobility and institutional cooperation in $\mathrm{HE}$ 
ERASMUS Mundus: EU supported world-wide cooperation and mobility programme in the field of higher education (2009-2013)

ESDP: European Spatial Development Perspective - European Commission policy document on the development of the Territory of the EU

ETH: Eidgenössische Technische Hochschule; Swiss Federal Institute of Technology

$E U$ : European Union, an economic and political alliance of 27 member countries governed by the European Commission (EC) and its parliament; europa.eu/

EUA: European University Association; www.eua.be/Home.aspx

EURA: European Urban Research Association; www.eura.org

FISE: Professional body overseeing the qualification of professionals in the Finnish Building, HVAC and Real Estate Sector; www.fise.fi/default/www/suomi/in_english/

FSU: Schweizerischer Ingenieur- und Architektenverein; Swiss Engineering and Architecture Association

GIS: Geographic Information Systems

GPEAN: Global Planning Education Association Network, an umbrella organisation representing nine planning schools associations; www.gpean.net/g

HE, HEIs: Higher Education, Higher Education Institution(s)

IFHP: International Federation for Housing and Planning; www.ifhp. org

ILT: The Chartered Institute for Logistics and Transport - world-wide organisation with a UK arm which serves as professional body for those working in Transport \& Logistics; www.cilt.org.uk

INTERREG: Initiative aimed at stimulating cooperation and share solutions between regions in the EU; various phases since 1989

IP: Intensive Programme, one element of the ERASMUS scheme supporting short-term mobility and collaborative project work in multinational teams; www.britishcouncil.org/erasmus_ip_leaflet_english_final.pdf

ISCED: International Standard Classification of Education from 1997 defines 7 and the updated version (2011) defines 9 levels of educational attainment from 0 (early childhood) to level 8 (doctoral); epp.eurostat.ec.europa.eu/statistics_explained/index.php/ Glossary:ISCED

ISOCARP: International Society of City and Regional Planners; nongovernmental international association of professional planners; www.isocarp.org

LLP: Lifelong Learning Programme - EU suite of educational development programmes supporting learning from childhood to old age including ERASMUS, TEMPUS, ERASMUS Mundus, GRUNDTVIG, etc.; eacea.ec.europa.eu/llp/index_en.php

Module: learning unit, typically worth between 2 and 20 ECTS; outside UK, also known as 'course'

MSc., MA.: Master of Science, Master of Arts; second cycle degree title; as planning education is offered through science and arts faculties both degree titles coexist as in MA in Urban design; or MSc in Planning. In some countries only Master in Urban Planning (or similar) is used without distinguishing science or arts focus.

MAS: Master in Advanced Studies (Swiss degree title for a Postprofessional degree)

NB: National Board - statutory body of professionals in Portugal

$P h D$ : Abbreviation for Doctor of Philosophy; used as synonym for various 3rd cycle doctoral level degree titles; see also D.Sc.

Planning course: See planning programme

Planning (degree) programme: A curriculum with a set of modules or learning units providing a coherent body of knowledge and skills leading to a degree such as Bachelor or Master. In the UK, a degree programme is typically called a course.

Programme Accreditation: Approval by designated body (government, university committee or professional body) of the quality and standards of a degree programme

QAA: Quality Assurance Agency for Higher Education-independent body that reviews performance of universities and colleges of higher education in the UK and internationally; http://www.qaa.ac.uk

SIA: Stiftung der Schweizerischen Register REG; Swiss professional registration board

RICS: Royal Institution of Chartered Surveyors - professional body for land, property and construction professionals; http://www.rics. org

RTPI: Royal Town Planning Institute - professional body of planners in the UK; http://www.rtpi.org.uk

TUPOB: Türkiye Ulusal Planlama Okullari Birliği, Planning Schools Association of Turkey; http://www.spo.org.tr/tupob

UAS: University of Applied Sciences

$U N$ : United Nations; www.un.org

UNESCO: United Nations Educational Scientific and Cultural Organisation; www.unesco.org

$U K$ : United Kingdom

$V L P$ : Verein für Landesplanung; Association of Regional Planning WWII: World War II

Andrea I. Frank is a Senior Lecturer at the School of Planning and Geography, Cardiff University. Until 2012, she was Deputy Director (Planning, Housing \& Transport) of the Higher Education Academy Subject Centre for Education in the Built Environment with a UK-wide remit to enhance teaching as well as students' learning experiences and disseminate good pedagogical practice through workshops and conferences. Her research interests range from pedagogical issues such as work-based learning, creativity techniques and teaching entrepreneurial skills to cross-national studies of planning systems. She serves on the editorial board for the Journal of Education in the Built Environment.

Izabela Mironowicz is Associate Professor and Director of studies in Spatial Planning in the Department of Spatial Planning (Faculty of Architecture) at Wrocław University of Technology, where she also runs international courses in planning. She is President of the Society of Polish Town Planners in Wrocław and a member of the Polish Task Force for Planning Education and Career Development, which has a remit to facilitate the cooperation of Polish planning schools. Her research focuses on urban development and urban transformations. She is a practicing urban planner and consultant, and a member of the Commission on Architecture and Town Planning in Wrocław, an advisory body to the mayor and local authorities. 
Julia Lourenço is a Professor at the University of Minho in Braga, Portugal. Educated originally as Civil Engineer she has worked more than 10 years at the Regional Development Agency for the North of Portugal. Following a postgraduate course at the Social Studies Institute in The Hague, she obtained her PhD from the Instituto Superior Técnico in Lisbon. Her research interests focus on territorial planning, spatial plan assessment, sustainable urban mobility, tourism planning, and climate change and energy issues in Portugal and abroad.

Teresa Franchini is currently Professor in urban and regional planning at the CEU San Pablo University in Madrid, Spain. She has a broad international background with degrees in Architecture and City and Regional Planning from Argentina, University College London and a PhD from Madrid Polytechnic University. As a researcher, she regularly collaborates with the Spanish National Council of Scientific Research. Between 2002 and 2005 she was a VicePresident of the International Society of City and Regional Planners (ISOCARP) and she still serves on ISOCARP's Scientific Committee.

Peter Ache is Professor of Planning at Radboud University, Nijmegen. From 2006 to 2011, he was Professor of European Metropolitan Planning at the Centre for Urban and Regional Studies (YTK), Aalto University, School of Technology (Aalto TKK), where he became familiar with planning education in Finland. During his Presidency of AESOP, the Association of European Schools of Planning, he oversaw a survey of planning schools on implementing Bologna reforms. Peter also set up the AESOP expert pool, a new facility supporting members of the association in questions of quality development and assurance.

Maroš Finka is Professor at the Institute of Management at the Slovak University of Technology in Bratislava and is also the Director of the Central European Research and Training Centre in Spatial Planning. He has participated and led numerous research projects in the field of European spatial planning, urban development and regeneration, environmental planning and social environmental assessment and is considered to be one of the leading academics in CEE countries in spatial planning. He teaches spatial and strategic planning, urbanism, European spatial planning and landscape management at his home university and abroad.

Bernd Scholl is Professor for Spatial Planning and Development and Director of the Institute of Spatial and Landscape Development at the Swiss Federal Institute of Technology (ETH Zürich). He is also Director of the Network City and Landscape (NSL), which aims to lay the foundations for a design of our environment that meets human needs, is sustainable, and has high aesthetic and cultural qualities. His teaching and research focus consists of land and spatial management, local and regional development, space and infrastructure development, transnational tasks as well as development of innovative planning processes and methods in spatial planning.

Anita Grams is a research assistant and PhD student at the Institute for Spatial and Landscape Development at the ETH Zürich. She is responsible for the development of problem-related self-study through interdisciplinary projects in the MAS Program in Spatial Planning at ETH. Her research focus is on sustainable land use at the interface between architecture and spatial planning. 